\title{
Standby Lovers: A Typology and Theoretical Investigation of Back Burner Relational Maintenance
}

\author{
Dana Borzea \\ West Virginia University, daborzea@mix.wvu.edu
}

Follow this and additional works at: https://researchrepository.wvu.edu/etd

Part of the Interpersonal and Small Group Communication Commons

\section{Recommended Citation \\ Borzea, Dana, "Standby Lovers: A Typology and Theoretical Investigation of Back Burner Relational Maintenance" (2021). Graduate Theses, Dissertations, and Problem Reports. 8046. \\ https://researchrepository.wvu.edu/etd/8046 \\ This Dissertation is protected by copyright and/or related rights. It has been brought to you by the The Research Repository @ WVU with permission from the rights-holder(s). You are free to use this Dissertation in any way that is permitted by the copyright and related rights legislation that applies to your use. For other uses you must obtain permission from the rights-holder(s) directly, unless additional rights are indicated by a Creative Commons license in the record and/ or on the work itself. This Dissertation has been accepted for inclusion in WVU Graduate Theses, Dissertations, and Problem Reports collection by an authorized administrator of The Research Repository @ WVU. \\ For more information, please contact researchrepository@mail.wvu.edu.}




\begin{abstract}
Standby Lovers: A Typology and Theoretical Investigation of
Back Burner Relational Maintenance
\end{abstract}

\title{
Dana Borzea
}

\author{
Dissertation submitted \\ to the Eberly College of Arts and Sciences \\ at West Virginia University \\ in partial fulfilment of the requirements for the degree of \\ Doctor of Philosophy in \\ Communication Studies
}

\author{
Matthew M. Martin, Ph.D., Chair \\ Alan K. Goodboy, Ph.D. \\ Megan R. Dillow, Ph.D. \\ Jessica Troilo, Ph.D. \\ Department of Communication Studies
}

Morgantown, West Virginia

2021

Keywords: Relational maintenance, back burners, attachment, uncertainty, self-expansion, relational characteristics

Copyright 2021 Dana Borzea 


\begin{abstract}
Standby Lovers: A Typology and Theoretical Investigation of Back Burner Relational Maintenance
\end{abstract}

\title{
Dana Borzea
}

The purpose of this dissertation was to investigate the connections between relational maintenance behaviors, theoretical factors, and relational characteristics in back burner relationships. A back burner relationship involves at least one individual who is romantically or sexually interested in a target, but they are not currently involved with the target. Given that back burners maintain communication with each other with the possibility of becoming romantically or sexually involved in the future, Study 1 was concerned with inductively identifying the relational maintenance behaviors used in back burner relationships. Following prior typology methods, participants $(N=86)$ in Study 1 were currently involved in at least one back burner relationship and responded to an open-ended question. The findings revealed that individuals use 10 back burner maintenance behaviors (i.e., Flirting \& Humor, Minimize Intimacy, Openness, Positivity \& Support, Regular Contact, Relationship Talk, Shared Activities, Social Networks, Special Occasions \& Gifts, and Strategic Deceit). Study 2 questioned the behavioral predictability of theoretical factors (i.e., attachment style, relationship uncertainty, and selfexpansion) and hypothesized that the use of maintenance behaviors would be positively associated with relational characteristics (i.e., commitment, liking, control mutuality, and relationship satisfaction). Participants $(N=187)$ were currently involved in at least one back burner relationship and completed an online questionnaire. The results indicated that individuals' preoccupied attachment, secure attachment, behavioral uncertainty, future uncertainty, and experienced self-expansion each uniquely predicted the use of various back burner maintenance behaviors. The hypothesis was partially supported. Six maintenance behaviors (i.e., Flirting \& Humor, Openness, Positivity \& Support, Regular Contact, Shared Activities, and Special Occasions \& Gifts) were positively associated with commitment, liking, control mutuality, and relationships. The results also revealed several unique associations for the Relationship Talk, Social Networks, Minimize Intimacy, and Strategic Deceit back burner maintenance behaviors. 


\section{ACKNOWLEDGEMENTS}

To be honest, I started writing these acknowledgements four years ago when I started my first dissertation. I was already pretty grateful for the people in my life who had got me to that point. Little did I know then that these people would be the ones to get me through the darkest years of my life. Some people played encouraging minor roles, while others were center stage for it all. Yet, each one deserves recognition because I would not have been able to finally finish these acknowledgements without them.

\section{To My Committee...}

Dr. Martin, you took on an almost impossible challenge and made it happen. Thank you for your unwavering support and guidance. You always believed in me, even more so when I did not believe in myself. You are not only my advisor, but you are the person who saved me by giving me another chance with my last two years in Morgantown. I hope to someday bump into you again at Goodwill on a half off Sunday. I promised to try and keep this direct, sincere, and kind - just like you.

Dr. Goodboy, you know every single piece of instrumental support that you have given me over the past seven years. You also know how extremely grateful I am for your help through it all since the "It's a distraction!!" day one. Thank you for never, ever giving up on me sir. F\&F Forever.

Dr. Dillow, you pushed me to work harder than I ever thought imaginably possible. I was lucky to learn and study IP communication from one of the most badass IP scholars. However, you also taught me how to be a strong woman from both observing your actions and listening to your advice. I sincerely appreciate you and the roles you have played throughout the years. I am looking forward to the next time we get to go all out at Muriale's! 
Dr. Troilo, thank you for completing my all-star committee. You always provided unique and complementary perspectives, but you also stuck it out with me over the course of this entire journey. For that, I'll be forever grateful!

\section{To My Broncos...}

All of this started when this daughter of immigrants and first-generation college student traveled west to Kalamazoo and had no idea what she was doing as a freshman at WMU. Chad and Autumn, thank you for changing my major from pre-med to communication studies. Since Chad is responsible for setting up my interview for WVU's doc program way back when, I am now a different type of doctor. Stephanie, I am thankful for your role as a professor during my first semester at WMU, as well as your grad school guidance. Dr. Apker, my very first advisor! You equally guided and supported me through my MA professional project process. Your support continued when we talked doc school over my last breakfast in Kalamazoo and still does today. Shoutout to my O.G. grad school gang, including the lovely Deirdre, Sam, Andrew, Jacqui, Brett, Bethany, Nate, and unofficial cohort member Riley.

Mike, my much younger older brother. Thank you for unconditionally being there for me for over a decade. I'm so glad that we get to do our 30s together too. Renee, my cartel ride or die and my first call in a crisis. The two of you were at my MA defense and I was lucky enough to celebrate my Ph.D. defense with my long-time besties as well.

\section{To My Mountaineers...}

After five years and two degrees at WMU, I traveled south into the mountains headed towards WVU. However, Dr. Myers is the man who made that journey happen. Dr. Myers, you were one of my top 3 hardest breakups (and that is saying something). There is no doubt in my mind that finishing this would have never happened if it was not for you. You picked me up out 
of a dark place and threw me into the doc office to get my third (and luckily final) dissertation started. I can't thank you enough for your persistent efforts. Over 7 years ago, you changed the trajectory of a lost 22-year-old girl's life when we first met and you interviewed me at that hotel lobby in Minneapolis.

Joy, I'll forever cherish our office chats and hallway strolls. Thank you for all of your formal and informal help. I'll always think of you when I look at your WVU train! Terri, thank you for always saving the day whenever I locked myself out of the office! Rest in Peace Renee Kisner. You were so kind and adored by all who met you. Nikki Loy, thank you for the laughs, lunch pizza, and for being the best meeting buddy! Shoutout to some of my other favorite former WVU professors as well, including Dr. Rittenour and Dr. Weber!

Although I appreciate all of my WVU students, several of you have forever impacted me as a professor. I'm looking at you Emily, Matt, Hassan, Steph, Osama, Hailey, Shaina, Jacob, Rachel, Autumn, Ben, Austin, and Joey. I am also thankful for two of my former students turned amazing friends. Anna, you were my savior my last few years in Morgantown. I'll always cherish our many roadtrips, 2 am chats, speed racing to everything, and the hilarious memories we have created. Lindsey, my Midwest girl who understands me in ways in which no one else does. Thank you for always calling me out, while also always showing me love.

If anyone has been in doc school, they know that the people around you are a major part of your survival. I have had the support of some wonderful MA students over the years, but a special shoutout to my gems Molly, Emma, and Sarah O. I am thankful for my predecessors turned forever conference buddies Sean, Kerry, Katie, Zac, and Hannah. Given that I was a 7year doc student, I crossed paths with a handful of awesome doc students. However, I am extra thankful that I was able to bust into 113 Armstrong to see Stephen K., Sarah P., Catie/Kathy, 
Kevin, James, Mckay, Stephen J, and Laura. Kylie, one of my favorite ladies that I got to meet because of WVU. I am happy that I helped convince you to stay. Who else would have been my spontaneous “dinner" buddy, karaoke partner, and all around most kindhearted friend?

I don’t even know where to begin with my Molly, Mary, and Jordan *starts slowly chanting $3 C 1 D^{*}$ Molly, I am beyond grateful that you were my first friend at WVU. The wild card, one with a crass joke handy, and always down for something sweet after a meal. Thank you for being the first person I called after every milestone from setting my defense date to submitting the actual document. Mary, my spirit animal and forever hype woman. Thank you for always being the positive perspective we all need. Jordan, my teaching guru, unofficial mentor, and shoulder to cry (or spill coffee) on. I made sure not to eat any hot dogs before my defense just in case. Thank you for being a compassionate, McDonald's loving, and hilarious friend. Collectively, you three baby girls have gotten me/still get me through so much (there is a theory out there about closeness developed from traumatic experiences, right?). I love each of you and I am grateful that WVU gave me three lifelong friends. Hey Alexa, play Enya...

\section{To My Family...}

Candice \& Cooper, you two are not my blood, but you are my family. You two are responsible for making Morgantown feel like home, from family dinners to spending holidays together. I'll forever cherish watching Cooper grow up from the shy 2-year-old who woke up to this loud lady in his house to being the kind, hilarious, and weird-like-us kid he is today. Although I have not had the pleasure of physically meeting him yet, Trent seems pretty cool when he is not crying. Candice, we do not have sisters, but we will always have each other (especially when we are running late and/or forgot something).

My big fat Romanian family, I cannot list all of you because of space, but also because I 
feel like I might accidently leave someone out since there are so many wonderful people who I am lucky enough to call my family. Regardless of distance or stress from doc school, nothing brought a smile to my face like traveling home and getting to spend time with everyone at holiday parties. Vă iubesc pe toți!

Mel \& Kev, the trusty parents in my life! Mel, thank you for sacrificing yourself and raising me into the woman who I am today. Are we not both glad that I did not take your original advice about doc school? Although you have done a lot to me, bringing Kev into all of it was one of your best yet! Kev, I really lucked out with the step-dad lotto. Thank you for your fatherly guidance and endless good laughs. Love you both!

Shoutout to my Bunica Maria and Bunicu George. You two escaped the communist regime in Romania, fled to Italy, and then came to America with nothing but four kids, a few suitcases, and ambition that no one could ever touch. Thank you for all of your sacrifices, but even more your unconditional love and support. You two also gave me the best gift ever...She may be the last mention here, but everyone knows Blanks is my \#1 ride or die. The most consistent presence in my life. Good or bad she was there through it all (she is even sitting next to me right now).

\section{To The Past \& Future...}

As I bring this to an end, I need to lastly mention a vivid memory that I kept close to me throughout this process. Several years ago, I was struggling with Jordan at 2 am in 115 Armstrong. He wanted to show me something encouraging that Sara LaBelle wrote in her dissertation acknowledgements and a particular part stuck out to me: "When everything gets overwhelming and you feel like quitting, take a BIG breath and think about this: if your biggest worry right now is that you won't do well in a $\mathrm{PhD}$ program, you are lucky as hell." I cannot 
explain how badly I needed to hear those words that night. Jordan and I always talked about our anxieties and fears related to the potential of not finishing our dissertations. Years after that night, I went back and read Jordan's acknowledgements and something he wrote stuck out to me as well: "If there are times you think you want to quit, remember that you are not alone."

Now it is my turn to try and keep the hope alive. If you are a doc student reading this and likely experiencing your own struggles, just know that I finally finished after three advisors, three half-written dissertations, two prospectus defenses (one failed, one successful), and failing my instructional comps before passing all three. I questioned many, many times why I went to doc school and why I thought that I was even close to capable of doing it. I am not physically able to count how many times I was on the verge of giving up. Yet, despite all of these questions, I never once questioned why I went to WVU. I will never find another place like WVU. I will never work with people like I did at WVU. If you have been lucky enough to grace the halls of Armstrong, you know exactly what I mean. Morgantown and the people I met there will forever have a special place in my heart. 
Table of Contents

$\underline{\text { Page }}$

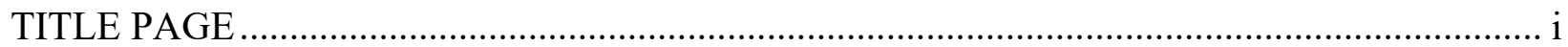

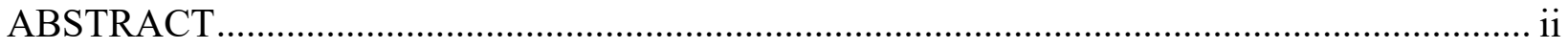

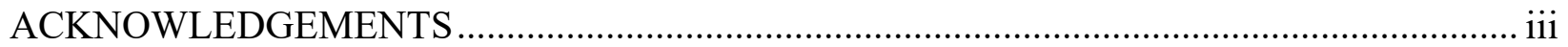

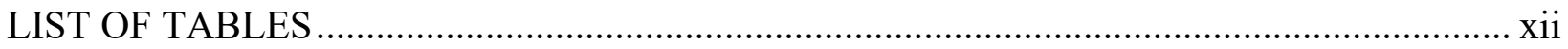

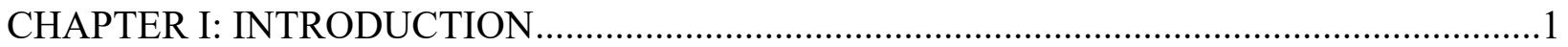

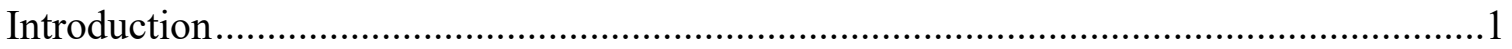

Relational Maintenance Behaviors ..........................................................................

Relational Maintenance Typologies ............................................................4

Theoretical Approaches to Relational Maintenance ................................................ 17

Attachment Theory Theoretical Approach ........................................................... 17

Uncertainty Theory Theoretical Approach ......................................................19

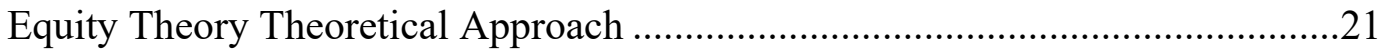

Self-expansion Theory Theoretical Approach ...................................................22

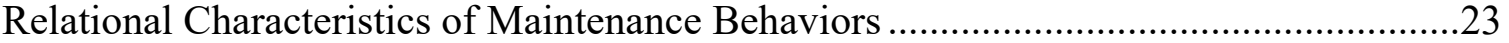

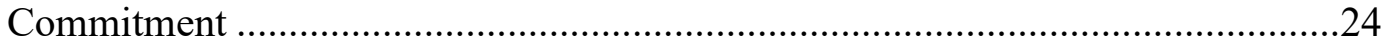

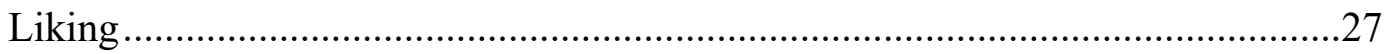

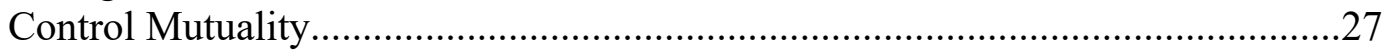

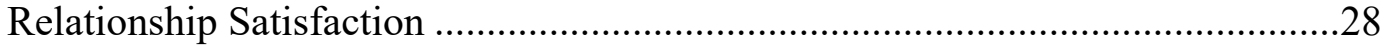

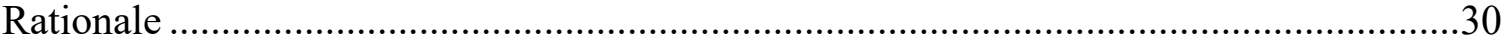

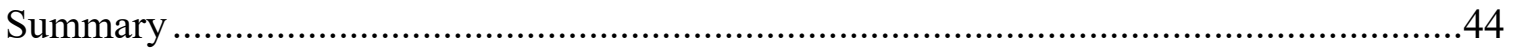

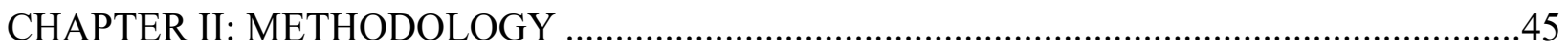

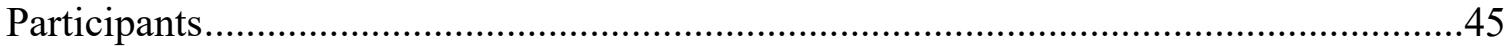

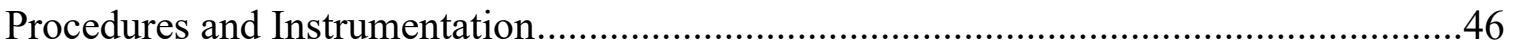

The Back Burner Maintenance Behaviors Typology.......................................51

The Attachment Style Measure...................................................................52

The Relationship Uncertainty Scale ........................................................5

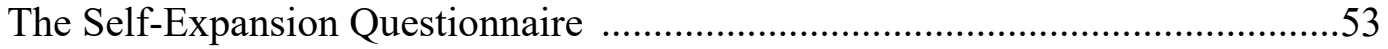

The Global Commitment Measure …................................................................54

The Liking Measure ...................................................................................54

The Control Mutuality Measure ............................................................5

The Relationship Assessment Scale..........................................................55

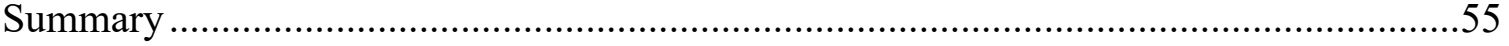

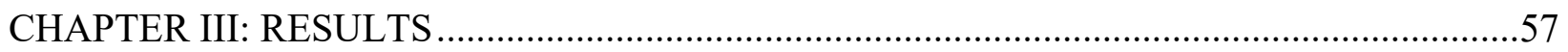

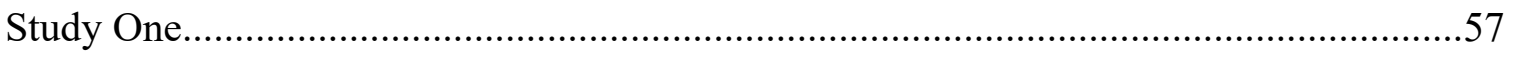

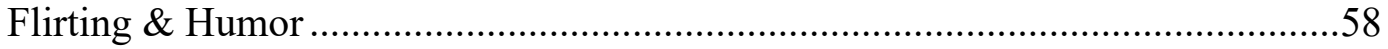

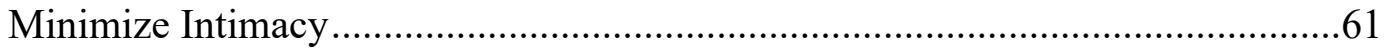

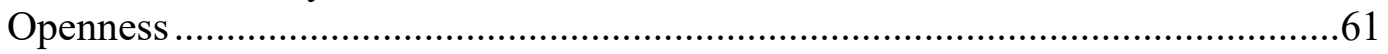




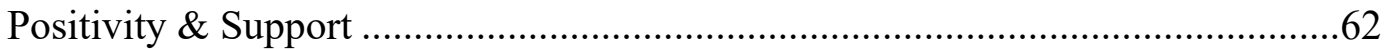

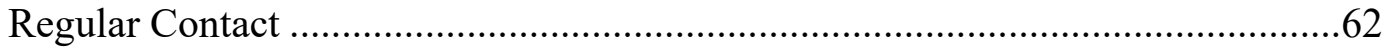

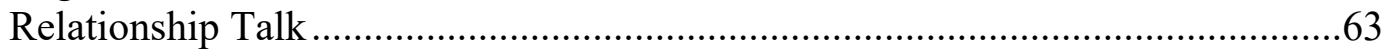

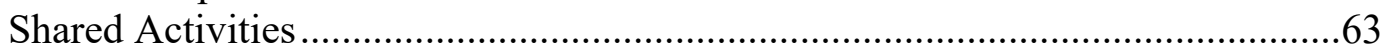

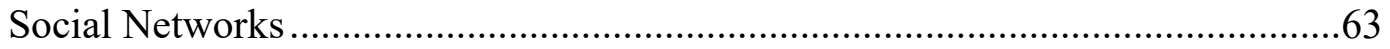

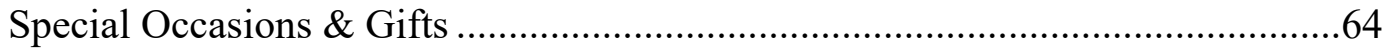

Strategic Deceit ......................................................................................64

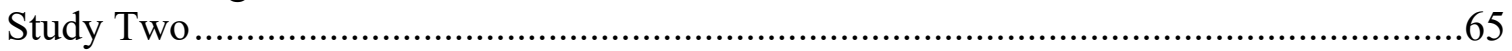

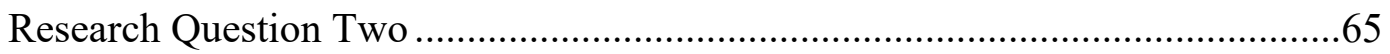

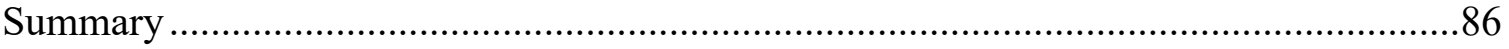

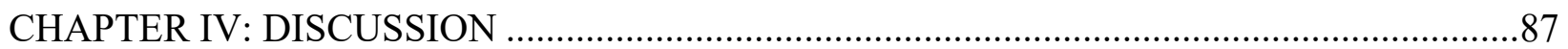

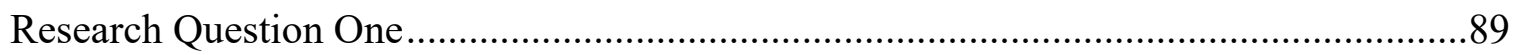

Back Burner Maintenance Behaviors Typology ................................................89

Research Question Two …………….......................................................................

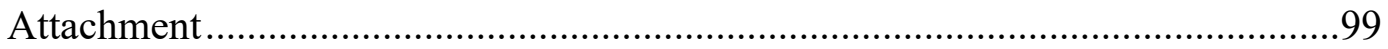

Relationship Uncertainty ..........................................................................102

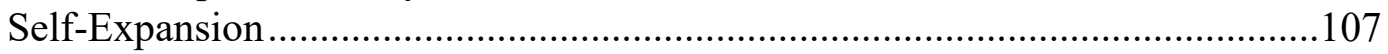

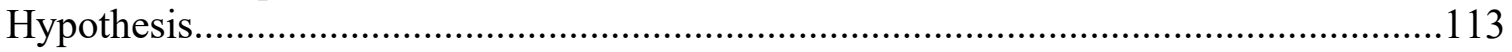

Limitations and Future Directions …………………….......................................121

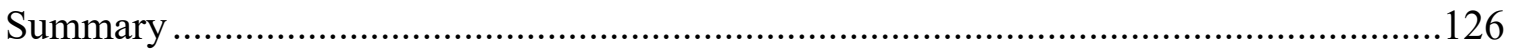

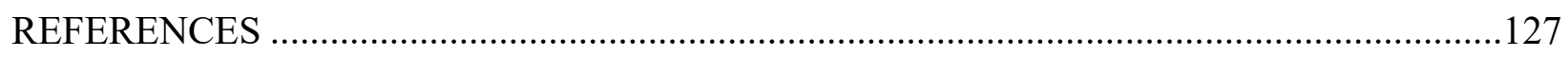

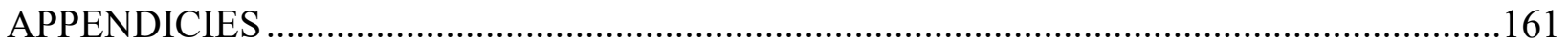

Appendix A: Study 1 Printed Bulletin Board "Mach Form" Recruitment Script.............161

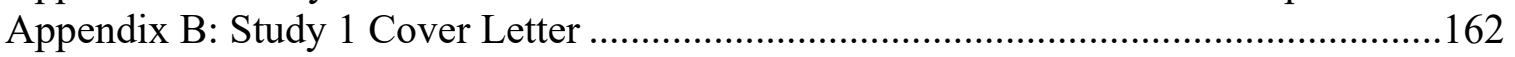

Appendix C: Study 1 Questionnaire ………………………………………………....164

Appendix D: Study 2 Printed Bulletin Board "Mach Form" Recruitment Script.............168

Appendix E: Study 2 Email Recruitment Script ............................................................169

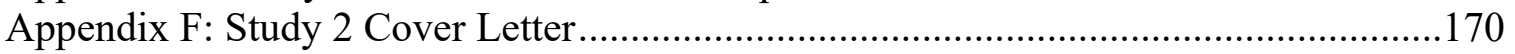

Appendix G: Study 2 Questionnaire ………………………………………………...173

Appendix H: Back Burner Maintenance Behaviors Typology .........................................181

Appendix I: Attachment Style Measure....................................................................182

Appendix J: Relationship Uncertainty Scale ...............................................................183

Appendix K: Self-Expansion Questionnaire ...............................................................184

Appendix L: Global Commitment Measure ……………............................................185

Appendix M: Liking Measure.....................................................................................186

Appendix N: Control Mutuality Measure ………………...........................................187

Appendix O: Relationship Assessment Scale ...........................................................188

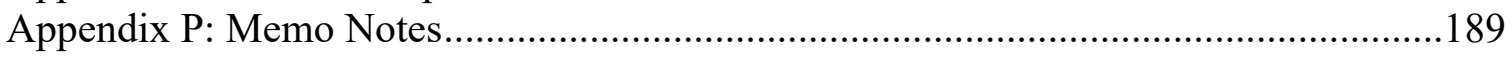

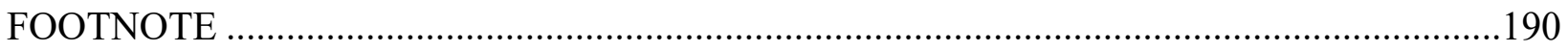




\section{LIST OF TABLES}

$\underline{\text { Page }}$

Table 1. Relational Maintenance Behaviors ....................................................................... 7

Table 2. Taxonomy of Relational Maintenance Behaviors ....................................................9

Table 3. Relational-Maintenance Communication Scale........................................................ 15

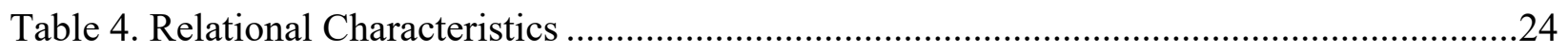

Table 5. Platonic Opposite-Sex Friendship Maintenance Behaviors.........................................34

Table 6. Relational Maintenance Behaviors in Cross-Sex Friendships ......................................36

Table 7. Means and Standard Deviations for the Back Burner Maintenance Behaviors...............59

Table 8. Correlation Matrix of Back Burner Maintenance Behaviors ......................................66

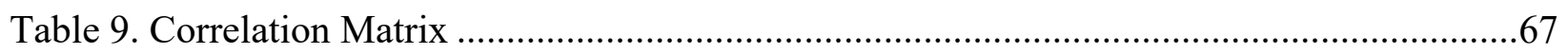

Table 10. OLS Regression Analysis: Flirting \& Humor..........................................................69

Table 11. OLS Regression Analysis: Minimize Intimacy ................................................ 71

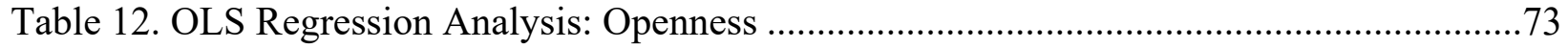

Table 13. OLS Regression Analysis: Positivity \& Support.....................................................74

Table 14. OLS Regression Analysis: Regular Contact ........................................................ 76

Table 15. OLS Regression Analysis: Relationship Talk ..................................................78

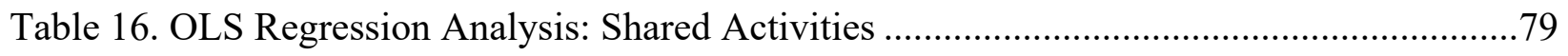

Table 17. OLS Regression Analysis: Social Networks ..................................................... 81

Table 18. OLS Regression Analysis: Special Occasion \& Gifts ...........................................83

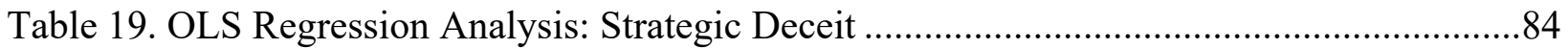




\section{Chapter I}

\section{Introduction}

For over two decades, relational maintenance scholars have been asking "Do people actually engage in communication behavior for the purpose of maintaining their relationships?", and, if so, "What are the communication behaviors people use for maintenance?" (Ragsdale \& Brandau-Brown, 2004, p. 122). Although researchers have predominantly focused their efforts on traditional interpersonal relationships such as romantic relationships and friendships (Canary \& Yum, 2016), variations of these two relationship types also have been investigated. For instance, several common types of romantic relationships have been examined, such as dating, seriously dating, engaged, or marital relationships (Canary \& Stafford, 1992; Dainton, 2003; McEwan \& Horn, 2016; Ragsdale, 1996; Ragsdale \& Brandau-Brown, 2004, 2005; Stafford \& Canary, 1991; Weigel \& Ballard-Reisch, 1999a, 1999b, 1999c, 1999d, 2001, 2008). Additional variations of romantic relationships have been considered, including on-again/off-again relationships (Dailey et al., 2010), long distance relationships (Billedo et al., 2015; Dainton \& Aylor, 2001; Dainton \& Aylor, 2002b; Pistole et al., 2010), and military deployment relationships (Maguire et al., 2013; Merolla, 2010; Theiss \& Knobloch, 2014). Different types of friendships have been investigated as well, including casual, close, or best friends (Oswald et al., 2004); active, dormant, or commemorative friends (LaBelle \& Myers, 2016); long-distance and geographically close friends (Johnson, 2001); and platonic cross-sex friends (Messman et al., 2000). Collectively, these studies have demonstrated the importance of considering variations of interpersonal relational contexts when examining the behaviors, theoretical approaches, and relational characteristics associated with maintaining these relationships.

Interpersonal scholars also have demonstrated the prevalence of alternative relationship 
types that combine the characteristics of romantic relationships and friendships. For example, maintenance researchers have explored friends-with-benefits relationships that consist of individuals who are both platonic friends and casual sexual partners (Goodboy \& Myers, 2008; Wentland \& Reissing, 2014), or booty call relationships involve when sexual activity between two people who know each other is initiated when one individual contacts the other individual for the sole purpose of engaging in sexual activity (Wentland \& Reissing, 2014). A new type of alternative interpersonal relationship is the back burner relationship, which involves two partners who are not currently romantically or sexually involved, but maintain communication with each other in the hopes of eventually becoming romantically or sexually involved (Dibble \& Drouin, 2014; Dibble et al., 2015). The back burner relationship is a unique interpersonal context to be explored by communication scholars, given that the existence of a back burner relationship is centered around the continued communication between both individuals.

The goal of this dissertation, then, was to investigate the connections between relational maintenance behaviors, theoretical approaches, and relational characteristics in back burner relationships. This chapter consists of four parts. The first part reviews the research conducted on relational maintenance behaviors, including an inventory of relational maintenance behavior typologies. The second part compares the theoretical approaches used to explain and predict individuals' use of relational maintenance behaviors. The third part reports the findings regarding the relational characteristics historically associated with relational maintenance. The fourth part offers the rationale for this dissertation, including the two research questions and one hypothesis. 


\section{Relational Maintenance Behaviors}

Although the research conducted on relational maintenance has focused primarily on romantic relationships, scholars also have examined the relational maintenance behaviors utilized in other interpersonal relationships such as friendships (Bippus \& Rollin, 2003; Bryant \& Marmo, 2009; Forsythe \& Ledbetter, 2015; Johnson, 2001; LaBelle \& Myers, 2016; Ledbetter, 2009; 2010; Ledbetter \& Kuznekoff, 2012; McEwan, 2013; McEwan \& Guerrero, 2012; McEwan et al., 2018; Oswald \& Clark, 2006; Oswald et al., 2004) and family, including the family as whole (Morr et al., 2007), in addition to specific relationships such as parent-child (Burke et al., 2016; Chang, 2015; Ledbetter \& Beck, 2014; Myers \& Glover, 2007; Rodriguez, 2014), siblings (Goodboy et al., 2009; Dorrance Hall \& McNallie, 2016; McNallie \& Dorrance Hall, 2015; Mikkelson et al., 2011; Myers et al., 2008; Myers et al., 2011; Myers \& Goodboy, 2010; Myers et al., 2013; Myers \& Members of COM 200, 2001; Myers \& Odenweller, 2015; Myers \& Weber, 2004), and grandparent-grandchild (Mansson, 2014, 2016; Mansson et al., 2010).

Within these interpersonal relationships, researchers also have examined the use of maintenance behaviors influenced by participant sex (Aylor \& Dainton, 2004; Canary \& Stafford, 1992; Dainton \& Aylor, 2001; Dainton \& Stafford, 1993; Dainton et al., 1994; Ragsdale, 1996; Simon \& Baxter, 1993; Stafford, 2011; Stafford \& Canary, 1991; Stafford et al., 2000; Weigel \& Ballard-Reisch, 1999b, 2008), gender (Aylor \& Dainton, 2004; Baker \& McNulty, 2011; Ragsdale et al., 2010; Stafford et al., 2000), and personality and communication traits such as alexithymia, Machiavellianism, concern for appropriateness, self-monitoring, tolerance for ambiguity, relational maximization, trait communication apprehension, and the Big Five personality traits (Brandau-Brown et al., 2010; Hesse et al., 2015; Mikkelson et al., 2016; 
Pauley et al., 2014; Ragsdale \& Brandau-Brown, 2005; Seidman, 2018; Toale \& McCroskey, 2001).

The next section reviews the extant literature on relational maintenance behaviors. Specifically, the section discusses the development of several maintenance behavior typologies that have emerged over the past 25 years, which includes positive and negative behaviors as well as strategic and routine behaviors.

\section{Relational Maintenance Typologies}

Relational maintenance scholars have given considerable attention to the maintenance behaviors used in romantic relationships (Ogolsky \& Bowers, 2012). In fact, multiple maintenance typologies focusing on romantic relationships have emerged over the past two decades. Stafford and Canary (1991) conducted one of the foundational studies of relational maintenance by utilizing an equity theory theoretical framework to examine the strategic behaviors individuals use to maintain their romantic relationships. Strategic relational maintenance behaviors are enacted at a higher level of consciousness to achieve a particular relational goal (Canary \& Stafford, 1994; Stafford \& Canary, 1991). The 956 participants $(n=$ 465 married, $n=491$ dating) in their study provided open-ended responses to the question "What do you do to maintain a satisfactory relationship?” (p. 227). From these participants, 309 responses were identified and grouped into 19 categories before being subjected to factor analysis. This factor analysis resulted in the emergence of a five-factor typology that Stafford and Canary (1991) named the Relational Maintenance Strategies Measure (RMSM). These five factors were labeled assurances, openness, positivity, sharing tasks, and social networks. Assurances are messages that imply a future for the relationship, openness refers to the promotion of direct and honest discussions, positivity involves being cheerful and encouraging, 
sharing tasks refers to helping each other accomplish daily responsibilities and goals, and social networks refers to the inclusion of other relationships external to the primary relationship, such as friends or family members (Canary \& Stafford, 1992; Stafford \& Canary, 1991).

Dainton and Stafford (1993) then extended Stafford and Canary's (1991) findings by focusing on romantic partners' routine use of relational maintenance behaviors. Unlike strategic behaviors, routine relational maintenance behaviors are used less consciously while still attempting to achieve a particular relational goal (Canary \& Stafford, 1994; Dainton \& Stafford, 1993). Their investigation aimed to accomplish four goals, which were to (a) extend the existing literature on routine maintenance behaviors, (b) compare the maintenance behaviors enacted in married versus dating relationships, (c) identify differences in the behaviors enacted by men and women, and (d) compare partners' use of relational maintenance behaviors within couples. The recruited participants consisted of 243 romantic couples (129 married, 114 dating) who were instructed to provide demographic information and asked to respond to two open-ended questions. The first open-ended question, first used by Stafford and Canary (1991), asked participants to "Please offer examples of behaviors (positive and/or negative) that you have used to maintain your relationship" (p. 260). The second open-ended question functioned as a probe to focus on the routine nature of the behaviors, telling participants that "much of maintaining a relationship can involve mundane or routine aspects of day-to-day life. These are things you might not have thought of above because they might seem too trivial. Please try to describe the routine things you do to maintain your relationship" (p. 260). Their identification of behaviors was guided by prior maintenance research (Dindia \& Baxter, 1987; Stafford \& Canary, 1991). From these responses, the first goal was attained and 12 behaviors emerged. These behaviors are positivity, openness, assurances, social networks, sharing tasks, joint activities, talk, mediated 
communication, avoidance, antisocial, affection, and focus on self. A description of each behavior is listed in Table 1.

The second goal of this study was to compare the use of maintenance behaviors in dating versus married relationships. Although the results generally obtained little differences between contexts, dating individuals used the mediated communication behavior more frequently and married individuals used the sharing tasks behavior more frequently. Addressing the third goal, several differences in the use of maintenance behaviors emerged between men and women. In general, the results indicated that women used the positivity, openness, talk, and antisocial behaviors more frequently than men. Sex differences emerged between married and dating individuals as well, in that married women used the avoidance, sharing tasks, and focus on self maintenance behaviors more frequently, whereas dating women used the mediated communication maintenance behaviors more frequently. Additionally, married men used the sharing tasks behaviors more frequently, whereas dating men used the joint activities and mediated communication behaviors more frequently. The fourth goal was to compare the maintenance behaviors enacted within couples; the results demonstrated that partners were more similar than dissimilar in their use of maintenance behaviors. Moreover, married couples reported greater similarities in their maintenance behaviors than did dating couples.

At around the same time, Canary and colleagues (1993) extended relational maintenance behaviors by asking 579 undergraduate students to write a course paper describing both the positive and negative behaviors they used to maintain three current relationships, with the requirement that each relationship must have lasted a minimum of three months. Of the sample of 579 students, 214 students reported on friends (i.e., friends, close friends, acquaintances), 127 students reported on romantic relationships (i.e., dating seriously dating, engaged married), 185 
Table 1

Relational Maintenance Behaviors (Dainton \& Stafford, 1993)

Behaviors Definitions

Positivity

Openness

Assurances

Social Networks

Sharing Tasks

Joint Activities

Talk

Mediated Communication

Avoidance

Antisocial

Affection

Focus on Self
Trying to make interactions pleasant

Sharing, listening to, and discussing each other's thoughts and feelings

Communicating commitment and reassurances to a partner about the future state of the relationship

Relying on friends and family as support resources

Performing tasks that benefit each other

Spending joint time together

Engaging in regular small talk

Communicating through channels other than face-to-face

Circumventing discussions with a partner or certain issues

Engaging in socially unfavorable behaviors

Displaying intimacy towards a partner

Working on self-directed improvements 
students reported on family members, 12 students reported on co-workers, and 41 students reported on another relationship (e.g., roommates). In the paper, students were instructed to answer the question, "What are the communication behaviors that I use to maintain my various relationships?” (p. 7). For each identified behavior, students were instructed to label it and provide specific examples describing it. Canary et al. then sampled 100 of the papers and coded these 300 behaviors using Stafford and Canary's (1991) relational maintenance typology, adding categories when a behavior represented something other than the five relational maintenance behaviors. After three rounds of coding, 10 behaviors were identified, which were positivity, openness, assurances, social networks, sharing tasks, joint activities, cards/letters/calls, avoidance, anti-social, and humor. These behaviors are listed and defined in Table 2. Because the studies conducted to this point only considered maintenance behaviors enacted within heterosexual romantic relationships, Haas and Stafford $(1998,2005)$ set out to identify the maintenance behaviors utilized in same-sex relationships. Haas and Stafford (1998) initially recruited 32 participants involved in a gay or lesbian romantic relationship who responded to a series of open-ended questions.

Participants were first asked to "Please offer examples of behaviors (positive and/or negative) that you have used to maintain your relationship" followed by "Much of maintaining a relationship can involve mundane or routine aspects of day-to-day life. There are things you might not have thought of above [first question] because they might seem too trivial. Please try to describe the routine things you do to maintain your relationship" (p. 848). Participants then were instructed to respond again to the same two open-ended questions, but were told to report on their partner's use of maintenance behaviors with them. They then responded to two final questions referencing gay and lesbian relationships: "In American society, gays and lesbians face 
Table 2

Taxonomy of Relational Maintenance Behaviors (Canary et al., 1993)

Behaviors Definitions

Positivity Trying to interact in a pleasant way by showing affection, being nice, and doing favors for each other

Openness

Engaging in direct communication and listening behaviors (e.g., self-disclosure, advice giving, showing empathy)

Assurances $\quad$ Reassuring each other the value of the relationship by providing comfort, support, and overt expressions

Social Networks

Using friends, family, and non-relational others as support

Sharing Tasks

Engaging in chores and assisting with responsibilities

Joint Activities

Spending time with one's partner at routine events and occasional trips

Cards, Letters, and Calls Using different forms of mediated communication and technology, such as cards and letters, phone calls, or a combination of the three.

Avoidance Circumventing certain issues or one's partner through topic avoidance, person avoidance, alternate associations, and negotiated autonomy

Antisocial Behavior Being unfriendly or unkind, either indirectly or directly

Humor

Engaging in positive or negative sarcastic humor or jokes 
a certain degree of social discrimination. Are there behaviors that you and your partner engage in to reinforce your relationship in order to overcome social discrimination? Please list and explain" and "Are there any other ways that you and your partner maintain your relationship that you feel are unique to gay or lesbian relationships" (p. 848).

As a result, 14 relational maintenance behaviors emerged. Although 12 of the behaviors had previously been identified by Dainton and Stafford (1993), Haas and Stafford (1998) identified two new maintenance behaviors: gay/lesbian supportive environments (i.e., living and interacting in environments supportive of gay/lesbian relationships) and same as heterosexual couples (i.e., modeling values and behaviors similar to heterosexual couples in order to illustrate a lack of difference). Haas and Stafford (2005) further found that of these 14 behaviors, samesex relational partners most frequently used the sharing tasks, meta-relational communication (i.e., a subcategory of openness), joint activities, reactive prosocial behaviors (i.e., a subcategory of positivity), and overt expressions (i.e., a subcategory of assurances) relational maintenance behaviors in their romantic relationships.

In an attempt to identify both the strategic and routine behaviors that romantic partners use to maintain their relationships, Stafford et al. (2000) developed the revised seven-factor RMSM. Two studies were conducted to explore the roles that gender and sex played in predicting partners' enacted relational maintenance behaviors. They recruited 520 married individuals who completed a 58-item measure of maintenance behaviors [i.e., the 27-item measure of maintenance behaviors developed by Canary and Stafford (1992), along with the 31 items previously identified by Dainton and Stafford (1993)]. Participants were directed to "Indicate the extent to which each of the following statements accurately reflects the way that you maintain your relationship. Do not indicate agreement with things that you think you should 
do, or with things you did at one time but no longer do. That is, think about the everyday things you actually do in your relationship right now. Remember that much of what you do to maintain your relationship can involve mundane or routine aspects of day-to-day life" (Stafford et al., 2000, p. 311). Seven behaviors emerged from their factor analysis. Although five of these maintenance behaviors (i.e., assurances, openness, sharing tasks, positivity, and social networks) were identified previously by Stafford and Canary (1991, two additional behaviors emerged. The two new behaviors were conflict management (i.e., understanding and cooperating with a partner) and advice giving (i.e., sharing directions and opinions about problems).

In 2011, Stafford identified several conceptual and measurement issues with the fivefactor RMSM (Canary \& Stafford, 1992; Stafford \& Canary, 1991) and the revised seven-factor RMSM (Stafford et al., 2000), arguing that several of the items were not measuring behaviors, but were instead measuring individuals' perceptions of relational characteristics. She also noted that several of the five behaviors did not contain enough items to fully measure the behavior, suggesting it was necessary to include more items to capture the use of each behavior. The use of equity theory as a guiding theoretical frame also was brought into question due to then inconsistent support for its predictive connection to maintenance behaviors, as well as the fact that several RMSM items deviated from the equity framework. Thus, in an attempt to develop a new measure of romantic partners' use of relational maintenance behaviors, Stafford (2011) conducted a series of four studies in her quest to create a new measure of relational maintenance in romantic relationships that she named the Relational Maintenance Behavior Measure (RMBM).

In Study 1, Stafford began with a 44-item measure that contained items created by both Canary and Stafford (1992) and Stafford et al. (2000). Additional items then were included to 
address issues of double- and triple-barreled questions, items referring to attitudes rather than behaviors, and items that needed to be put in more simple terms. Items also were added that referenced help from outside others and friends. This revision resulted in a total of 80 items, which added 32 modified items and four new items to the original 44-item measure. Stafford recruited 152 married participants to complete to the 80 -item measure. In addition to responding to the items, participants also were instructed to make a note on any words or phrasing that was unclear. Participants identified several items whose wording either was ambiguous or problematic.

In Study 2, Stafford made modifications to the 80-item measure based on participants' comments and recruited 486 married participants to complete this modified measure. Participants were instructed to indicate the extent to which their spouse engaged in each behavior within the past two weeks. Stafford utilized structural equation modeling (SEM) to examine the five-factor RMSM (Stafford \& Canary, 1991), the revised seven-factor RMSM (Stafford et al., 2000), and the new RMBM to determine if first two models would still contain predictive value in comparison to the RMBM that addressed the ambiguous issues with the first two typologies. After eliminating several items, the results indicated that the final 55-items of the RMBM emerged as the best fit. The RMBM contains seven maintenance behaviors including positivity (i.e., acting generally cheerful and optimistic), assurances (i.e., appreciating a partner and talking about the future with him/her), understanding (i.e., feeling understood and not judged by a partner), relationship talk (i.e., discussing feelings and perceptions about the relationship), selfdisclosure (i.e., talking about feelings, thoughts, and fears with a partner), networks (i.e., relying on family members and friends for support and involving them in activities), and tasks (i.e., helping a partner with responsibilities and tasks). The major changes to this new maintenance 
measure were (a) the addition of the understanding behavior and (b) the replacement of the openness behavior by two distinct behaviors, self-disclosure and relationship talk.

The purpose of Study 3 and Study 4 was to provide additional evidence for the viability of the RMBM and compare it to the five-factor RMSM in terms of predicting individuals' reports of liking, love, satisfaction, and commitment. She recruited 411 married couples to complete both maintenance measures, along with measures of liking, love, satisfaction, and commitment. The results of Study 3 provided additional items to further stabilize the networks behavior in the RMBM. The results of Study 4 indicated that the RMBM accounted for more variance in regard to predicting liking, loving, satisfaction, and commitment than did the fivefactor RMSM.

Moving forward, Ledbetter, and his colleagues (Ledbetter, 2013; Ledbetter et al., 2013; Ledbetter et al., 2010) suggested that self-expansion theory would function as a better theoretical explanation of romantic partners' relationship maintenance than equity theory. Equity theory and self-expansion theory have been distinguished as fundamentally distinct in their approaches to understanding romantic relationships, in that equity theory takes a social-exchange perspective and self-expansion theory takes a communally-oriented perspective (Ledbetter et al., 2013). From equity theory's social-exchange perspective, partners judge their relationships based on perceptions of equal contributions, whereas self-expansion theory's communal perspective focuses on the greater good of relationships rather than individual benefits. Although equity has provided some significant insight into how individuals use relational maintenance behaviors, Ledbetter (Ledbetter, 2013; Ledbetter et al., 2013, Ledbetter et al., 2010) argued that selfexpansion theory provided a stronger and more consistent theoretical framework for understanding the process of relational maintenance. Thus, Ledbetter attempted to support his 
claims by using the self-expansion theoretical framework to develop the Relational-Maintenance Communication Scale (RMCS).

To do so, Ledbetter (2013) conducted two studies. In Study 1, he recruited 474 participants who completed the RMCS to validate the measure. After conducting a factor analysis, Ledbetter identified 11 relational maintenance behaviors (see Table 3). These behaviors then were categorized into three dimensions that reflect the ways in which individuals can expand the self through their involvement in close relationships, which are (a) resources (i.e., shared possession, time together, and shared media), (b) perspectives (i.e., verbal affection, informal talk, deep talk, shared tasks, conflict management, and humor), and (c) identities (i.e., physical affection and social networks). In Study 2, Ledbetter recruited 246 participants (123 dyads) who were romantically involved with each other. Along with providing support for the validity of the RMCS, the results also revealed a positive association between individuals' inclusion of the other in the self (IOS; Aron \& Aron, 1986; Aron et al., 1991; Aron et al., Aron, 1998) and their use of all of the maintenance behaviors except for social networks and physical affection. IOS has been deemed the way in which people self-expand in close relationships (Aron et al., 1991).

Between 1991 and 2005 (and then again in 2011 and 2013), relational maintenance research efforts have focused largely on partners' prosocial behaviors, overlooking the notion that relational maintenance involves a variety of both positive and negative behaviors (Ayres, 1983; Canary et al., 1993; Dindia \& Baxter, 1987). To address this oversight, Dainton and Gross (2008) investigated the negative relational maintenance behaviors utilized in romantic relationships--defining negative relational maintenance as the antisocial behaviors in which partners engage for the "sake of the relationship" (p. 183)--by creating a typology of negative 
Table 3

Relational-Maintenance Communication Scale (Ledbetter, 2013)

Behaviors Definitions

Shared Possessions

Sharing financial resources, including both low-cost items (e.g., food) and high-cost items (e.g., cars)

Time Together

Participating together in various activities ranging from sharing common hobbies together to simply just spending time hanging out with each other

Shared Media

Watching, playing, or browsing various media outlets (e.g., TV, movies, video games, Internet) together

Verbal Affection

Communicating messages of love and attention that individuals communicate uniquely to their partners

Deep Talk

Engaging in more serious and in-depth communicative exchanges between partners about personal or problematic issues

Shared Tasks

Helping, and relying on, one another to accomplish goals, responsibilities, and decisions

Conflict Management

Handling conflict episodes constructively (e.g., talking about disagreements, apologizing) instead of engaging in deconstructive conflict (e.g., yelling, displacing blame)

Humor

Telling jokes, stories, and engaging in behaviors that attempt to make the other laugh

Physical Affection

Hugging, kissing, cuddling, and holding hands

Shared Networks

Spending joint time together with friends and family members, as well as the way in which partners communicate the nature of their romantic relationship to their shared social networks 
relational maintenance behaviors. The development of this typology emerged from two samples. The first sample consisted of 188 undergraduate and graduate communication students who responded to an open-ended question regarding their use of negative behaviors to maintain either a current or past romantic relationship. Participants were provided with the following statement and open-ended question: "In order to maintain our relationships the way we like them we engage in maintenance behaviors. Some of these behaviors are positive: for example, we assure our partner that we love them; we are open and self-disclose our feelings; and we compliment our partner. However, we occasionally engage in negative behaviors within our relationships, and we do these negative things for the sake of the relationship. Please describe any negative behaviors that you have used for the sake of the relationship" (p. 182).

The open-ended responses from these 188 participants resulted in the identification of 455 negative maintenance behaviors. The 455 behaviors were reduced to 30 items guided by the findings obtained in previous studies (Ayres, 1983; Dainton \& Stafford, 1993; Dindia \& Baxter, 1987; Metts, 1989). The second data collection consisted of 151 participants who were currently involved in a romantic relationship, with more than half of the participants $(n=102)$ reporting being married. The participants responded to the 30 items, which then were factor analyzed. From this factor analysis, six negative maintenance behaviors emerged, which included allowing control (i.e., letting a partner exert power over determining decisions and activities), avoidance (i.e., circumventing partner communication in general or in regards to specific topics), destructive conflict (i.e., purposefully initiating arguments in attempt to control the partner), jealousy induction (i.e., intentionally attempting to increase jealous feelings in a partner), infidelity (i.e., flirting or taking part in extradyadic sexual activity), and spying (i.e., monitoring a partner's communication and interactions with others). 
The next section reviews the theories used by researchers to predict and explain individuals' relational maintenance behaviors. The theoretical frameworks discussed are attachment theory, relational uncertainty, equity theory, and self-expansion theory.

\section{Theoretical Approaches to Relational Maintenance}

A number of theoretical approaches has been used to explain the relational maintenance behaviors used in romantic relationships, friendships, and family relationships. Maintenance scholars have focused primarily on attachment, uncertainty, and equity theory theoretical approaches (Canary \& Zelley, 2000; Dainton, 2011). Each theoretical approach has advanced the study of relational maintenance by providing theoretically-driven explanations for the motivations, behaviors, and outcomes associated with the process of maintaining romantic relationships (Canary \& Zelley, 2000; Dainton, 2011), although questions have been raised regarding the utility of the equity theory approach (Canary, 2011; Ragsdale, 1996; Ragsdale \& Brandau-Brown, 2007a, 2007b). As a result, self-expansion theory has been offered as an alternative explanation to equity theory (Ledbetter, 2013; Ledbetter et al., 2010). This section synthesizes the romantic relational maintenance research conducted to date from the attachment, uncertainty, equity, and self-expansion theoretical approaches.

\section{Attachment Theory Theoretical Approach}

The attachment theory theoretical approach recognizes the significance of early infantcaregiver bonds (Bowlby, 1969) and posits that initial interactions with a primary caregiver shape an individual's attachment style (Hazan \& Shaver, 1987), which then influences the way in which they tend to behaviorally and cognitively act with close others (Ainsworth, 1989; Bowlby, 1969). Bartholomew and Horowitz (1991) posited that four adult attachment styles exist: secure (i.e., positive views of self and others), preoccupied (i.e., negative views of self and positive 
views of others), dismissive (i.e., positive views of self and negative views of others), and fearful-avoidant (i.e., negative views of self and others).

Attachment theory has been used to explain romantic partners' use of prosocial maintenance behaviors (Dainton, 2007; Guerrero \& Bachman, 2006; Pistole et al., 2010; Simon \& Baxter, 1993; Yum \& Li, 2007), negative maintenance behaviors (Goodboy et al., 2017; Goodboy \& Bolkan, 2011), and relational repair maintenance strategies (Ragsdale et al., 2010). For instance, partners with a secure attachment style maintain their romantic relationships by using the assurances behavior, being open, and offering romantic affection (Guerrero \& Bachman, 2006; Simon \& Baxter, 1993). Dainton (2011) applied attachment theory to predicting married partners' reciprocity of maintenance behavior usage (i.e., similarities between individuals' self-reported use of maintenance behaviors and perceptions of their partners' use of maintenance behaviors). She found that individuals' use of the secure attachment style was associated positively with their marital partners' reciprocity of the positivity maintenance behavior, whereas individuals' use of the preoccupied and fearful-avoidant attachment styles was both associated negatively with their marital partners' reciprocity of the positivity maintenance behavior (Dainton, 2011). Individuals with a dismissive attachment style was associated negatively with their marital partners' reciprocity of the conflict management, openness, and sharing tasks maintenance behaviors (Dainton, 2011).

In long-distance relationships, preoccupied partners are more likely to use the assurances and advice maintenance behaviors than fearful-avoidant partners (Pistole et al., 2010), which further supports the claim that the use of the assurances behavior is relationally beneficial, even when the maintenance behavior is not enacted frequently (Canary et al., 2002). Across cultures, individuals with a secure attachment style are more likely to engage in prosocial maintenance 
behaviors regardless of their respective culture (Yum \& Li, 2007). Although individuals with a secure attachment style are less likely to engage in negative maintenance behaviors, individuals with either a dismissive or a fearful-avoidant attachment style are more likely to use the avoidance, jealousy induction, and infidelity negative maintenance behaviors (Goodboy \& Bolkan, 2011).

These theoretically driven predictions may explain the relational impact of individuals' own use of maintenance behaviors, as well the impact of their perceptions of a partner's use of maintenance behaviors (Dainton, 2007; Simon \& Baxter, 1993; Simpson, 1990). For example, individuals who are romantically involved with a dismissive, fearful-avoidant, or preoccupied partner have reported maintaining the relationship by allowing the partner more control over relational decisions (Goodboy et al., 2017). When involved with a dismissive partner in particular, individuals are more likely to use the jealousy induction and spying relational maintenance behaviors (Goodboy et al., 2017).

\section{Uncertainty Theory Theoretical Approach}

Past studies have demonstrated that experiences of relational uncertainty seem to facilitate distinct maintenance experiences (Guerrero \& Chavez, 2005; Weger \& Emmett, 2009). According to Knobloch and Solomon (1999), relational uncertainty is defined as "the degree of confidence people have in their perceptions of involvement within close relationships" (p. 264), including distinct dimensions of self uncertainty (i.e., ambiguities regarding one's own relational goals, attitudes, and behaviors), partner uncertainty (i.e., ambiguities regarding a partner's relational goals, attitudes, and behaviors), and relationship uncertainty (i.e., ambiguities regarding the current and future state of the dyad). Relational uncertainty has emerged as a significant explanation for romantic partners' use of prosocial maintenance behaviors (Dainton, 
2003) and negative maintenance behaviors (Dainton et al., 2017).

Several studies have focused specifically on the different types of relationship uncertainty, including behavioral uncertainty (i.e., ambiguities regarding the acceptable actions in what partners can engage within the relationship), definitional uncertainty (i.e., ambiguities regarding the way in which individuals describe their relationships to people external to the relationship), future uncertainty (i.e., ambiguities about the status of the relationship in the long term), and mutuality uncertainty (i.e., ambiguities regarding the degree of similarity between partners' shared perceptions and feelings). Greater behavioral, definitional future, and mutuality uncertainty is negatively associated with partners' use of the advice, assurances, conflict management, social networks, openness, positivity, and sharing tasks relational maintenance behaviors (Dainton, 2003). Mutuality uncertainty also has been linked negatively with partners perceived reciprocal use of all seven prosocial maintenance behaviors in marriage (Dainton, 2011). Dainton (2003) also found that individuals' use of the seven prosocial maintenance behaviors was associated negatively with their perceptions of future uncertainty and mutuality uncertainty.

Stewart et al. (2014) utilized the relationship uncertainty construct to explain relational partners' use of Facebook relational maintenance behaviors. Individuals who perceived greater definitional uncertainty were more likely to use the monitoring, openness, and assurances maintenance behaviors on Facebook. Moreover, individuals who perceived greater mutuality uncertainty were more likely to use the monitoring behavior, and individuals who perceived greater future uncertainty were more likely to use the openness and assurances maintenance behaviors (Stewart et al., 2014). Furthering the focus on relationship uncertainty, KennedyLightsey (2018) discovered that individuals' perceptions of their partners' enacted maintenance 
behaviors were related negatively with individuals' reports of relationship uncertainty and cognitive jealousy. Taking relationship-specific characteristics into consideration, romantic partners who experienced relational uncertainty in conjunction with greater geographic distance and lesser amounts of trust are less likely to engage in the assurances and openness maintenance behaviors (Dainton \& Aylor, 2001). Military couples who have experienced relational uncertainty report a decrease in their use of the assurances, conflict management, and openness maintenance behaviors during the post-deployment transition (Theiss \& Knobloch, 2014). Uncertainty also has functioned as a positive predictor of romantic partners' use of the spying, destructive conflict, avoidance, jealousy induction, infidelity, and allowing control negative maintenance behaviors (Dainton et al., 2017; Knobloch \& Carpenter-Theune, 2004; Knobloch \& Theiss, 2011; Pytlak et al., 2015). In sum, researchers have articulated that the presence and experience of relational uncertainty significantly influences individuals' relational maintenance behaviors across the trajectory of a relationship (Dainton \& Aylor, 2001).

\section{Equity Theory Theoretical Approach}

From an equity theory theoretical approach, partners have viewed maintenance behaviors as the primary mechanism through which they are able to maximize the amount of rewards in the relationship (Canary \& Stafford, 1992). As one of the initial assumptions behind why individuals maintain their relationships, Canary and Stafford (1994) articulated that "people are more motivated to maintain equitable relationships than inequitable relationships" (p. 7). Whereas equitable relationships involve partners who perceive costs and rewards to be distributed equally, individuals in underbenefitted relationships perceive less reward in comparison to their amount of input and individuals in overbenefitted relationships perceive more reward in comparison to their amount of input (Hatfield et al., 1979). Both types of inequitable 
relationships (i.e., underbenefitted and overbenefitted) have been viewed as distressing which, in turn, lowers partners' use of prosocial maintenance behaviors (Canary \& Stafford, 1992, 1994; Dainton, 2003; Stafford \& Canary, 2006). For instance, individuals in inequitable romantic relationships are less likely to use the positivity, sharing tasks, and conflict management maintenance behaviors, whereas individuals in equitable relationships are more likely to use the assurances maintenance behavior (Canary \& Stafford, 1992; Dainton, 2003; Stafford \& Canary, 2006). However, Dainton (2003) did obtain a positive association between individuals' use of the openness maintenance behavior and their involvement in an inequitable relationship, arguing that individuals may be more concerned with using partner-oriented behaviors when maintaining equitable relationships.

When husbands and wives were compared, underbenefitted husbands engaged in prosocial maintenance behaviors less frequently than overbenefitted husbands and equitable husbands (Stafford \& Canary, 2006). However, Dainton (2011) found that spouses' perceptions of being overbenefitted was not associated significantly with their use of relational maintenance behaviors, although she also found that underbenefitted spouses engaged in less frequent reciprocal use of the seven maintenance behaviors. Yum and Canary (2009) considered culture in their investigation of individuals' use of relational maintenance behaviors using the equity theoretical approach. Equity, however, did not play a significant role in predicting the use of maintenance behaviors for Chinese, Czechoslovakian, or South Korean romantic couples, suggesting that equity is a culturally-based influential factor.

\section{Self-Expansion Theory Theoretical Approach}

As aforementioned, Ledbetter and his colleagues (Ledbetter, 2013; Ledbetter et al., 2010; Ledbetter et al., 2013) suggested that self-expansion theory would function better as a theoretical 
explanation of romantic partners' relationship maintenance than equity theory. Self-expansion refers to the novel or exciting life experiences that add content to an individual's self-concept (Aron \& Aron, 1986; Aron et al., 1997) and posits that individuals most commonly self-expand through their involvement in close romantic relationships (Aron \& Aron, 1986). Specifically, individuals self-expand by acquiring resources, perspectives, and identities from close relational partners through the process of IOS (Aron \& Aron, 1986; Aron et al., 1991; Aron et al., 1997). IOS has been described as a largely communicative process, as communication is required to experience, negotiate, and integrate partners' resources, perspectives, and identities (Agnew et al., 1998; Aron et al., 2013; Aron et al., 1997). Indeed, empirical evidence has demonstrated that a positive link exists between individuals' perceptions of their current IOS and their use of the five original relational maintenance behaviors (i.e., assurances, openness, positivity, sharing tasks, and social networks; Ledbetter et al., 2013). However, Ledbetter (2013) suggested that the frequency of individuals' enacted maintenance behaviors is influenced collectively by both relational partners' perceptions of IOS.

In sum, interpersonal relational maintenance scholars have demonstrated the importance of conducting theoretically-driven research to further predict and explain individuals' use of relational maintenance behaviors. Attachment theory, uncertainty theory, equity theory, and selfexpansion theory theoretical approaches have furthered researchers' understanding of the relational maintenance process within romantic relationships. The next section focuses on the influence of relational maintenance behaviors on relational characteristics.

\section{Relational Characteristics of Maintenance Behaviors}

To date, relational partners' use of relational maintenance behaviors has demonstrated consistently its positive effect on close relationships. Typically, relational maintenance 
researchers investigate relational partners' use of maintenance behaviors in tandem with relational characteristics as indicators of relational quality (Canary \& Stafford, 1994; Dindia \& Canary, 1993). The most commonly studied relational characteristics related to maintenance behaviors are commitment, liking, control mutuality, and relationship satisfaction, although scholars also have investigated additional relational characteristics such as trust (Dainton \& Aylor, 2001; Mansson, 2014; Myers \& Glover, 2007; Myers \& Weber, 2004), respect (Dainton \& Gross, 2008; Goodboy et al., 2010), loving (Dainton et al., 1994; Stafford, 2011; Weigel \& Ballard-Reisch, 1999a, 1999b, 1999c, 1999d), and communication satisfaction (Forsythe \& Ledbetter, 2015; Mansson et al., 2010; Myers \& Odenweller, 2015). This section synthesizes the romantic relational maintenance research conducted to date on commitment, liking, control mutuality, and relationship satisfaction in conjunction with the development of the relational maintenance behavior typologies (see Table 4).

\section{Commitment}

Commitment refers to individuals' long-term goals and dependency within a relationship (Rusbult, 1980). Consequently, romantic partners engage in maintenance behaviors as a way to communicate their level of commitment to one another (Rusbult, 1983). It is not surprising, then, that researchers have obtained positive associations between commitment and individuals' use of prosocial relational maintenance behaviors in romantic relationships (Canary et al., 2002; Canary \& Stafford, 1992; Dainton \& Aylor, 2002a; Ogolsky, 2009; Ogolsky \& Bowers, 2012; Stafford, 2011; Stafford \& Canary, 1991; Stafford et al., 2000; Weigel \& Ballard-Reisch, 1999a, 1999b, 1999c, 1999d, 2008). Interestingly, it should be noted that Weigel and Ballard-Reisch (1999c) reported that the length of marriage did not influence the association between both wives' and husbands' commitment and their use of relational maintenance behaviors with each other. 
Table 4

Relational Characteristics

\begin{tabular}{lcccc}
\hline & Commitment & Liking & $\begin{array}{c}\text { Control } \\
\text { Mutuality }\end{array}$ & $\begin{array}{c}\text { Relational } \\
\text { Satisfaction }\end{array}$ \\
\hline Stafford \& Canary (1991) & $\mathrm{X}$ & $\mathrm{X}$ & $\mathrm{X}$ & $\mathrm{X}$ \\
Canary \& Stafford (1992) & $\mathrm{X}$ & $\mathrm{X}$ & $\mathrm{X}$ & \\
Canary et al. (1993) & & $\mathrm{X}$ & $\mathrm{X}$ \\
Dainton \& Stafford (1993) & $\mathrm{X}$ & $\mathrm{X}$ & $\mathrm{X}$ \\
Dainton et al. (2000) & & $\mathrm{X}$ & $\mathrm{X}$ \\
Dainton \& Gross (2008) & & & $\mathrm{X}$ \\
Stafford (2011) & & & \\
Ledbetter (2013) & & & & \\
\hline
\end{tabular}


Regardless of the online or offline nature of the relationship, highly committed individuals engage in maintenance behaviors with their romantic partner at a higher rate (Rabby, 2007).

Further investigations of commitment have claimed that perceptions of partners' enacted maintenance behaviors is a greater predictor of commitment than one's own enacted maintenance behaviors, as partners' behaviors can reaffirm their commitment to the relationship which, in turn, fosters their own commitment (Canary \& Stafford, 1994; Etcheverry \& Le, 2005; Stafford \& Canary, 1991). This claim also has been supported in the marital relationship context, suggesting that a partner's use of maintenance behavior is crucial--and potentially even more important than one's own maintenance--to fostering commitment in marriage (Ramirez, 2008). Indeed, Weigel and Ballard-Reisch (2008) acknowledged that marital partners' engagement in relational maintenance behaviors is interdependent by demonstrating that individuals' perceptions of commitment influence their own use of relational maintenance behaviors, as well as their partner's use of relational maintenance behaviors. For instance, husbands' and wives' use of the assurances maintenance behavior was associated positively with their own perceptions of commitment (Weigel \& Ballard-Reisch, 1999b, 1999c), but wives' enactment of the assurances, openness, and positivity maintenance behaviors affected both spouses' perceptions of commitment (Weigel \& Ballard-Reisch, 1999d).

The type of marriage also influences partners' commitment, as the connection between the use of relational maintenance behaviors and commitment is strongest for the Independent couple type, followed by the Traditional couple type and the Separate couple type (Weigel \& Ballard-Reisch, 1999a). Commitment also has been connected to the use of negative maintenance behaviors in that less committed partners report engaging in all six negative maintenance behaviors to maintain their romantic relationships (Dainton \& Gross, 2008; 
Goodboy et al., 2010).

\section{Liking}

Liking refers to the enjoyment individuals associate with their relationship partner (Stafford \& Canary, 1991). Liking has been positively associated with all seven prosocial maintenance behaviors (Canary \& Stafford, 1992; Canary et al., 2002; Dainton et al., 1994; Stafford, 2011; Stafford \& Canary, 1991; Stafford et al., 2000). Although romantic partners have reported using the openness behavior used less frequently when they did not like their partner (Stafford \& Canary, 1991), Dainton et al. (1994) found that wives used the openness behavior less frequently when they did like their husbands. Moreover, individuals' perceptions of a partners' enacted maintenance behaviors positively predicts liking (Canary \& Stafford, 1992; Dainton et al., 1994). Less liking also has been associated with greater use of all six negative maintenance behaviors (Dainton \& Gross, 2008).

\section{Control Mutuality}

Control mutuality refers to partners' agreement regarding decision making within the relationship (Stafford \& Canary, 1991). To date, control mutuality has been linked positively with individuals' use of all seven positive relational maintenance behaviors (Canary et al., 2002; Canary \& Stafford, 1992; Stafford \& Canary, 1991; Stafford et al., 2000). Dainton and Gross (2008) also obtained negative associations between control mutuality and all six negative maintenance behaviors, with Goodboy et al. (2010) indicating further that control mutuality predicts partners' use of the spying and destructive conflict negative relational maintenance behaviors. 


\section{Relationship Satisfaction}

Relationship satisfaction refers to the extent to which one's romantic partner contributes to the relationship and meets or exceeds his or her expectations of the relationship (Stafford \& Canary, 1991). Given that individuals' ability to effectively maintain relationships is crucial to the stability, continuation, and satisfaction of relationships (Paul et al., 1998), it is not surprising that more satisfied romantic partners tend to engage in more prosocial maintenance behavior usage (Stafford \& Canary, 1991; Stafford et al., 2000; Weigel \& Ballard-Reisch, 1999a, 1999b, 1999c, 1999d). Specifically, the use of the assurances, positivity, understanding, social networks, and sharing tasks maintenance behaviors predicts greater relationship satisfaction, whereas the use of the openness behavior predicts lower relationship satisfaction (Dainton et al., 1994; Stafford, 2011; Stafford \& Canary, 1991; Stafford et al., 2000). Stafford (2011) also reported a negative association between satisfaction and the relationship talk maintenance behavior. Dainton et al. (1994) identified that partners' use of the five prosocial maintenance behaviors predicted positively wives' relationship satisfaction, whereas partners' use of only the positivity and assurances behaviors positively predicted husbands' relationship satisfaction. The results of additional studies have suggested that husbands' use of the social network relational maintenance behavior was associated positively with their own perceptions of satisfaction (Weigel \& BallardReisch, 1999b, 1999c), whereas wives' use of the sharing tasks relational maintenance behavior was associated positively with their own perceptions of satisfaction (Weigel \& Ballard-Reisch, 1999c, 1999d).

Perceptions of a partner's maintenance behaviors also has been linked positively with individuals' reports of relationship satisfaction in that perceptions of a partner's use of maintenance behaviors is a stronger predictor of satisfaction than the discrepancies between the 
expectations and actual use of a partner's maintenance behaviors (Dainton, 2000). Indeed, husbands' and wives' perceptions of their own satisfaction, as well as perceptions of their spouses' satisfaction, play an important role in influencing both partners enacted maintenance behaviors (Dainton et al., 1994; Weigel \& Ballard-Reisch, 2008). The positive connections between maintenance behaviors and marital satisfaction holds true over time (Weigel \& BallardReisch, 2001). However, it is important to note that husbands' perceptions of both partners' enacted relational maintenance and relational characteristics do not seem to influence husbands' own use of relational maintenance behaviors, especially in comparison to the positive associations observed between wives' use of maintenance behaviors and perceptions of their relationship satisfaction, commitment, and love (Weigel \& Ballard-Reisch, 1999d).

The type of marriage also plays an influential role in the relationship between use of relational maintenance behaviors and relationship satisfaction is strongest for the Independent couple type, followed by the Traditional couple type and the Separate couple type (Weigel \& Ballard-Reisch, 1999a). When maintaining romantic relationships through Facebook, individuals' relationship satisfaction is associated positively with their use of the assurances maintenance behavior (Stewart et al., 2014). Less satisfied partners, on the other hand, are more likely to engage in negative maintenance behaviors and both face-to-face and online spying (Dainton \& Berkoski, 2013; Dainton \& Gross, 2008; Goodboy et al., 2010; Tokunaga, 2016).

In sum, over the past two decades, relational maintenance researchers have investigated the connections between maintenance behavior usage and a host of relational characteristics. Taken together, individuals' perceptions of relational characteristics, as well as perceptions of their own and their partners' use of maintenance behaviors, are distinctively connected to the ways in which they maintain their romantic relationships. 


\section{Rationale}

The primary purpose of this dissertation was to investigate the theoretical approaches and relational characteristics associated with the relational maintenance behaviors individuals use to maintaining their back burner relationships. Recall that back burner relationships involve an individual who is romantically or sexually interested in--but not currently involved with--a target and they maintain communication with each other in the hopes of becoming romantically or sexually involved in the future (Dibble \& Drouin, 2014; Dibble et al., 2015).

The back burner relationship is characterized by four features. First, it should be noted that the target of the admirer (i.e., the back burner) is not necessarily cognizant that the admirer desires such a relationship (Dibble et al., 2015). As such, these relationships have been investigated only from the perspective of the "admirer," or the person who desires a future romantic or sexual relationship with the target (Dibble et al., 2015); historically, the research to date has only examined heterosexual back burner relationships. Borzea and Dillow (2017) examined the dispositional characteristics that predict admirers' involvement in a back burner relationship. These dispositional characteristics were the Big Five personality traits (i.e., agreeableness, conscientiousness, extraversion, neuroticism, and openness to new experiences), narcissism, and Machiavellianism. Although no significant relationships emerged between admirers' total number of current back burner relationships and admirers' dispositional characteristics, it was found that admirers' total number of current back burner relationships was positively related to admirers' socio-sexual orientation and level of sensation-seeking (Borzea \& Dillow, 2017).

Second, communication is fundamental to the development and maintenance of back burner relationships, whether these relationships occur face-to-face or through mediated 
technologies, such as text messaging and Facebook (Dibble \& Drouin, 2014; Dibble et al., 2015). The content of individuals' communication with the back burner can vary from highly sexual to entirely platonic (Dibble et al., 2015). Although the frequency of communication with a back burner also varies, more than half of the individuals in two separate studies reported that they communicate with their back burner weekly (Borzea \& Dillow, 2017; Dibble et al., 2015). In addition, Dibble and Drouin (2014) suggested that the availability of more discreet communication channels (e.g., text messaging) makes it easier for individuals' in committed romantic relationships to also maintain back burner relationships.

Third, both single and dating individuals can be involved in back burner relationships. While maintaining at least one back burner relationship, over $40 \%$ of individuals in two separate studies reported also being involved in committed romantic relationships (Borzea \& Dillow, 2017; Dibble et al., 2015), although the extent to which the individuals' current relational partners are aware of the back burner varies. That is, some partners are fully aware of their significant others' communication with a back burner, whereas other partners have no knowledge about the back burner (Dibble et al., 2015). Because individuals can be involved in a committed romantic relationship and simultaneously maintain a back burner relationship, Dibble and Drouin (2014) used the Investment Model as a guiding theoretical framework to investigate back burner relationships. They found that individuals who reported having a greater quality of alternatives reported a higher number of back burner relationships, although their investment in and commitment to their current romantic relationships were not significantly associated with this number. Furthermore, no significant differences emerged between single individuals' and coupled individuals' reported number of back burner relationships. Fourth, a back burner can be more than just a back burner to the individual. That is, a back burner can be a former romantic or 
sexual partner, as long as they are not currently romantically or sexually involved (Dibble et al., 2015). In addition, the type of relationship individuals have with their back burner can range from strangers to acquaintances to casual friends, with the majority of individuals describing their back burners as either a casual or a close friend (Dibble et al., 2015).

Given that two-thirds of individuals' label their back burner as a friend (i.e., close, casual, or best friend; Dibble et al., 2015), it is necessary to examine the research conducted thus far on the maintenance of cross-sex friendships. O’Meara (1989) noted that cross-sex friendships contain four challenges (i.e., emotional bond, sexual challenges, public presentation, and equity challenges) that influence the maintenance of this particular relationship type. Emotional bond challenges refer to confusion regarding appropriate levels of closeness and feelings of jealousy toward a friend's significant others, sexual challenges involve the negotiation of boundaries and sexual tension between friends, public presentation challenges refer to the way in which the friendship is explained to other individuals, and equity challenges are concerned with the assumption that the male friend possesses control over the female friend. These challenges, along with the varying perceptions of romantic intent that may exist on the part of either participant, guide the way in which cross-sex friends behave and maintain their relationships (Guerrero \& Chavez, 2005; Weger \& Emmett, 2009). As a result, scholars have examined individuals' use of relational maintenance behaviors across different types of cross-sex friendships, including platonic friends (Messman et al., 2000) and friends with some degree of romantic interest (Guerrero \& Chavez, 2005; Weger \& Emmett, 2009).

In 2000, Messman and her colleagues conducted a two-phase study on individuals' motives for maintaining the platonic nature of cross-sex friendships and the behaviors used to maintain these platonic friendships. The term platonic was defined for participants as 
“non-sexual involvement” (p. 73). In Phase 1, 25 undergraduate student participants were asked to "think of an opposite sex friend and to list their reasons for keeping the relationship platonic" (p. 73). The participants identified a total amount of 81 motives. Several weeks later, the same 25 participants were asked to "write the behaviors you use to keep your opposite-sex friendships as friendships” (p. 73). Participants' responses were compared to Canary et al.’s (1993) 33-item taxonomy of maintenance behaviors. Along with seven new items that were not repetitive of Canary et al.'s taxonomy, there were a total of 40 relational maintenance behavior items. These 81 motives and 40 maintenance behaviors were factor analyzed after a new sample of 348 undergraduate student participants indicated the extent to which they agreed with the motives and the extent to which they felt their behaviors were reflected in the maintenance items. The responses from Phase 1 resulted in eight relational maintenance behaviors used in cross-sex friendships (see Table 5) and six distinct motives for maintaining the platonic nature of cross-sex friendships: not attracted (i.e., a lack of romantic interest in the friend), network disapproval (i.e., a lack of support or approval of the romantic involvement from close outside others), time out (i.e., a desire to not be romantically involved with anyone at the present time), safeguard relationship (i.e., a desire to preserve the positive characteristics and benefits of the existing friendship), third party (i.e., interference in the relationship from an outside other), and risk aversion (i.e., a fear of being hurt or disappointed).

Phase 2 of the study included 224 undergraduate student participants who completed a two-part questionnaire. One part of the questionnaire had participants report on an opposite-sex friend and one part focused on a (current or recent) romantic partner in order to investigate the relationship between individuals' motives for maintaining a platonic cross-sex friendship and their use of relational maintenance behaviors. Although the results indicated that individuals in 
Table 5

Platonic Opposite-Sex Friendship Maintenance Behaviors (Messman et al., 2000)

Behaviors Definitions

Support

No Flirting

Share Activity

Openness

Avoidance

Positivity
Giving/seeking advice and comfort

Avoiding playful and flirtatious behaviors

Engaging in routine and special activities together

Discussing the quality of the friendship and directly sharing feelings

Avoiding the friend and acting negatively in order to evade the friend from wanting to get closer

Trying to have enjoyable and cooperative interactions 
equitable cross-sex friendships engaged in positive relational maintenance behaviors more frequently than individuals in inequitable cross-sex friendships, their motives for doing so were a stronger predictor than equity for maintaining their platonic friendships. The Safeguard Relationship motive was a positive predictor of individuals' use of the Support, Share Activity, Openness, and Positivity maintenance behaviors; it also was a negative predictor of the Avoidance maintenance behavior. The Not Attracted motive was a positive predictor of the No Flirting maintenance behavior. The Risk Aversion and Network Disapproval motives were both positive predictors of individuals' use of the Avoidance relational maintenance behavior.

While Messman et al. (2000) focused on platonic cross-sex friendships, Guerrero and Chavez (2005) used a sample of 440 undergraduate student participants to investigate the use of relational maintenance behaviors across four types of cross-sex friendships: desires romance (i.e., one friend wants to be romantically involved but is unsure that the other friend feels the same way), rejects romance (i.e., one friend does not want to be romantically involved, but thinks the other friend desires romance), mutual romance (i.e., both friends want to become romantically involved with each other), and strictly platonic (i.e., neither friend wants the friendship to evolve into romance). Ten positive and negative relational maintenance behaviors emerged from the results as well (see Table 6). In addition to identifying these relational maintenance behaviors, their results indicated that significant relationships exist between romantic intent and use of maintenance behaviors. Specifically, individuals in the mutual romance type used all relational maintenance behaviors--except for the talk about outside romance behavior--more frequently than the other three types. Individuals in the desires romance type used the routine contact and activity, talk about outside romance, and flirtation behaviors more frequently than those individuals in the rejects romance type, but they also used the 
Table 6

Relational Maintenance Behaviors in Cross-Sex Friendships (Guerrero \& Chavez, 2005)

Behaviors Definitions

Routine Contact and Activity Communicating and interacting frequently, such as going out to places together

Emotional Support and Positivity Acting cheerful and engaging in active listening and comforting behaviors

Relationship Talk Discussing the status of the relationship

Instrumental Support Providing problem-solving and task-oriented support and advice

Social Networking Engaging in activities and spending time with common friends

Antisocial Behavior Complaining and communicating frustrations about the relationship

Humor and Gossip Engaging in jokes and "insiders", as well as gossiping about others outside of the relationship

Talk About Outside Romance Discussing romantic and/or sexual encounters outside of the relationship

Flirtation

Acting in a flirtatious manner

Avoidance of Negativity

Evading communication that may cause conflict or displeasing feelings 
relationship talk maintenance behavior less frequently. Moreover, the results found that individuals in the desire romance type experienced greater levels of relational uncertainty than individuals in the rejects romance, strictly platonic, or mutual romance type.

Weger and Emmett (2009) argued that the maintenance process is more complex in cross-sex friendships due to presence of relational uncertainty. Using a sample of 197 cross-sex friendships (394 individuals), each participant completed a questionnaire responding to questions regarding their romantic desire, relationship uncertainty, relationship length, and use of Guerrero and Chavez's (2005) relational maintenance behaviors. They found that individuals with romantic desires used the routine relationship activity and flirtation behaviors more frequently than those individuals who did not desire romance in the friendship, but they also used the talk about outside romance maintenance behavior less frequently than those who did not desire romance. Moreover, the more romance desired by a friend, the more likely individuals were to report experiencing mutuality uncertainty and definitional uncertainty. As a result, individuals with greater relational uncertainty used relational maintenance behaviors less frequently.

To date, Dibble and colleagues' (2018) research is the only study that has investigated the extent that individuals enact relational maintenance behaviors in their back burner relationships, but they focused only on the use of the positivity, openness, and assurances maintenance behaviors. Although men reported using the assurances behavior more frequently than women, no significant differences emerged between men's and women's use of either the openness or the positivity behaviors. While the study was the first to examine the relational maintenance, behaviors used in back burner relationships, the behaviors used to measure maintenance in the study were intended for the maintenance of romantic relationship (Dibble et al., 2018). This examination is important to note because Ragsdale and Brandau-Brown (2004) urged that 
"there is a considerable amount of evidence to suggest that simply using a relational maintenance instrument already in existence is unwise" (p. 132).

It can be argued, then, that individuals in back burner relationships will likely follow behavioral patterns similar to individuals in cross-sex friendships containing some degree of romantic intent, whether the intent is mutual or one-sided, because back burner relationships share several characteristics with different types of alternative relationships that combine aspects of romantic relationships and friendship (Dibble et al., 2018). For example, a back burner relationship is similar to a friends-with-benefits relationship due to the lack of romantic commitment, but a back burner relationship lacks the sexual activity involved in a friends-withbenefits relationship. A back burner relationship can possess the closeness between platonic cross-sex friends, but differs due to the possible presence of partners' romantic or sexual future intent. Individuals' frequent use of computer-mediated channels to communicate daily and maintain relationships is another notable similarity between friendships and back burner relationships (Dibble \& Drouin, 2014; Dibble et al., 2018; Makki et al., 2018). To date, there is not a typology representative of the relational maintenance behaviors used exclusively in back burner relationships. Given that Ragsdale and Brandau-Brown (2004) identified the lack of assessing context-specific maintenance behaviors as a major empirical shortcoming in relational maintenance behavior research, it is necessary to identify the distinct behaviors that individuals use to maintain back burner relationships. Therefore, the following research question is posited:

RQ1: What relational maintenance behaviors do individuals report using to maintain their back burner relationships?

Beyond investigating the type of relational maintenance behaviors enacted in back burner relationships, this dissertation was also interested in examining the theoretical approaches often 
used to study romantic relational maintenance behaviors as predictors of individuals' use of maintenance behaviors in back burner relationships. As aforementioned in this chapter, the four theoretical approaches commonly utilized by relational maintenance researchers are attachment theory, equity theory, uncertainty theory, and, most recently, self-expansion theory.

Using a sample of 179 married individuals, Dainton (2011) used attachment theory, equity theory, and uncertainty theory to predict partners' use of the seven prosocial relational maintenance behaviors in marital relationships. Of the three theoretical approaches, individuals' attachment styles and levels of inequity emerged as the most consistent predictors of their enacted maintenance behaviors. That is, individuals with a dismissive attachment style used less of the advice, assurances, social networks, openness, and sharing tasks maintenance behaviors, corroborating prior research findings (Dainton, 2007; Guerrero \& Bachman, 2006), whereas the secure attachment style emerged as a positive predictor of the sharing tasks maintenance behavior. Individuals involved in overbenefitted relationships used the sharing tasks and positivity maintenance behaviors less frequently than those in under benefitted or equitable relationships, whereas individuals involved in underbenefitted relationships used the conflict management maintenance behavior less frequently than individuals in overbenefitted or equitable relationships. Involvement in equitable relationships did not emerge as a significant predictor of relational maintenance in marriages. Taken together, Dainton (2011) argued that more adverse theoretical variables, such as the dismissive attachment style and inequitable relationships, function as stronger predictors of romantic partners' use of relational maintenance behaviors more so than prosocial theoretical variables, such as the secure attachment style and equitable relationships.

When maintaining platonic friendships, on the other hand, individuals in equitable 
friendships reported using the support, no flirting, and positivity relational maintenance behaviors more frequently than individuals in inequitable friendships (Messman et al., 2000). Perceptions of equity in platonic cross-sex friendships may reflect friends' reciprocated desires to maintain the platonic nature of the relationship. Given that perceptions of equity have predicted the use of maintenance behaviors within romantic dating relationships (Dainton, 2003), platonic cross-sex friendships (Messman et al., 2000), and friends with benefits relationships (Goodboy \& Myers, 2008), it is likely that equity also plays a significant role in predicting the relational maintenance behaviors used in back burner relationships as well.

Moreover, Dainton (2011) reported that relationship uncertainty did not emerge as a strong predictor of individuals' enacted maintenance behaviors, despite the fact that prior research findings have supported uncertainty as a predictive theoretical approach (Dainton, 2003; Dainton \& Aylor, 2001; Guerrero \& Bachman, 2006). Only mutuality uncertainty emerged as a significant negative predictor of individuals' use of the assurances and positivity relational maintenance behaviors. However, it must be noted that Dainton's (2011) study consisted of individuals in marital relationships and she argued that the effect of uncertainty is likely stronger during the earlier stages of romantic relationships. Indeed, uncertainty has emerged as a strong predictor of the maintenance behaviors enacted in dating relationships (Dainton, 2003; Guerrero \& Bachman, 2006), long-distance and geographically close relationships (Dainton \& Aylor, 2001), on-again/off-again relationships (Dailey et al., 2010), and cross-sex friendships that contain varying levels of romantic intent (Guerrero \& Chavez, 2005; Weger \& Emmett, 2009).

Definitional uncertainty has received a large amount of attention from researchers who investigate the cross-sex friendship context (Dainton et al., 2003). As individuals begin to desire romance from a friendship, their perceptions of definitional uncertainty and 
mutuality uncertainty about the relationship increases (Weger \& Emmett, 2009). When individuals are unsure about behavioral norms, the status of the relationship, or whether their romantic feelings are reciprocated, they are less likely to engage in prosocial maintenance behaviors because they are not confident that such efforts are worth the time and investment (Weger \& Emmett, 2009). Additionally, Guerrero and Chavez (2005) demonstrated that individuals in the desires romance cross-sex friendship type reported the highest levels of uncertainty regarding the status of the friendship in comparison to the mutual romance, strictly platonic, and rejects romance type. As a result, when individuals feel uncertain about their crosssex friendships, they are less likely to engage in the relationship talk, talk about outside romance, routine contact and activity, social networks, humor/gossip, and instrumental support relational maintenance behaviors. Taken together, individuals in the desires romance situations might put in the time and effort to positively maintain their cross-sex friendships as a way to portray themselves as a desirable potential romantic partner (Weger \& Emmett, 2009). Given the contextual similarities between the desires romance type in cross-sex friendships and back burner relationships, along with the fact that individuals involved in back burner relationships often report experiencing uncertainty (Dibble et al., 2018), it is likely that relational uncertainty influences the ways in which individuals maintain their back burner relationships.

Overall, Dainton's (2011) results provided practical support for using multiple theoretical approaches--instead of just one theoretical approach--to predict individuals' use of relational maintenance behaviors in marriages. Extending Dainton's (2011) study to the study of back burner relationships, this dissertation was interested in adding the self-expansion theory approach to the comparisons of theoretical explanations for individuals' enacted maintenance behaviors in back burner relationships. Given the aforementioned findings connecting self-expansion and use 
of relational maintenance behaviors (Ledbetter, 2013), it is likely that the self-expansion theoretical approach also may function as a predictor of maintenance behaviors used in back burner relationships. Therefore, the second research question is posited:

RQ2: To what extent does a combination of attachment style, uncertainty, and self-expansion predict individuals' use of maintenance behaviors in their back burner relationships?

A secondary purpose of this dissertation was to examine how individuals' use of relational maintenance behaviors are linked to the relational characteristics they associate with their back burner relationships. In a meta-analytic study of relational maintenance behaviors, Ogolsky and Bowers (2012) reviewed the primary relational characteristics historically associated with the relational maintenance behaviors, and found that romantic partners' use of all five relational maintenance behaviors (i.e., positivity, openness, assurances, social networks, and sharing tasks) were positively associated with their self-reports of commitment, liking, control mutuality, and relationship satisfaction.

In the friendship context, individuals' use of maintenance behaviors has shown to predict commitment at the dyadic level (Oswald \& Clark, 2006; Oswald et al., 2004). In online relational maintenance between friends, commitment is associated negatively with the use of the responseseeking (i.e., posting impersonal, mass messages with the hopes of gaining support or attention from others) Facebook maintenance behavior, but associated positively with the use of the social contact (i.e., posting personalized messages for friends) and relational assurances (i.e., posting messages that communicate relationship growth and commitment) Facebook maintenance behaviors (McEwan et al., 2014). Ledbetter (2010) determined that although the positivity and social networks behaviors predicted control mutuality in face-to-face encounters, neither 
maintenance behavior emerged as a significant predictor of control mutuality in online interactions. Individuals also tend to like their friends more when both friends use Facebook as a way to maintain and communicate about the friendship (McEwan, 2013). In regards to relationship satisfaction, individuals' use of maintenance behaviors predicted satisfaction from both friends (Oswald \& Clark, 2006; Oswald et al., 2004). That is, individuals are typically more satisfied when they and their friends engage in maintenance behaviors, whether it is face-to-face or through mediated means such as Facebook (McEwan et al., 2018). McEwan and colleagues also found that both the social contact and relational assurances maintenance behaviors are positively associated with satisfaction, whereas the response-seeking behavior is negatively associated with satisfaction (McEwan et al., 2018).

According to Dibble et al. (2018), committed individuals use positive maintenance behaviors less frequently in their back burner relationships than single individuals. Although they examined individuals' use of maintenance behaviors in back burner relationships, Dibble et al. did not investigate whether a connection exists between individuals' use of relational maintenance behaviors and their perceptions of additional relational characteristics. Based on Ogolsky and Bower's (2012) findings and the aforementioned findings of the relationships between relational maintenance behaviors and relational characteristics in both romantic relationships and friendships, it is likely that a positive relationship exists between individuals' use of relational maintenance behaviors and their perceptions of commitment towards, liking for, control mutuality, and relationship satisfaction with their back burner. Therefore, the following hypothesis is posited: 
H1: Individuals' use of relational maintenance behaviors will be positively related with commitment, liking, control mutuality, and relationship satisfaction in their back burner relationships.

\section{Summary}

The primary purpose of this chapter was to identify and describe the relational maintenance behaviors used by individuals in back burner relationships. This dissertation investigated the extent to which various theoretical approaches (i.e., attachment, uncertainty, equity, and self-expansion) are associated with individuals' use of relational maintenance behaviors in back burner relationships. This dissertation also determined the associations between individuals' enacted maintenance behaviors and the four relational characteristics of commitment, liking, control mutuality, and relationship satisfaction. 


\section{Chapter II}

\section{Methodology}

\section{Participants}

Two studies were conducted and all participants were recruited from West Virginia University. To participate in either study, individuals were required to be at least 18 years old and currently involved in at least one back burner relationship. A back burner relationship involves two partners who are not currently romantically or sexually involved with each other, but who maintain communication with each other in the hopes of eventually becoming romantically or sexually involved (Dibble \& Drouin, 2014; Dibble et al., 2015).

Study 1 had 86 participants (54 females, 32 males) who were currently involved in a back burner relationship. Ages ranged from 18 to 24 years of age $(M=20.07, S D=1.48)$. Participants were White/Caucasian $(n=64)$, Black/African-American $(n=11)$, Asian/Asian-American $(n=$ 4), Middle Eastern $(n=4)$, Hispanic $(n=1)$, or other $(n=2)$. Although a majority of participants identified their sexual orientation as heterosexual $(n=81)$, other participants identified as bisexual $(n=4)$ or other $(n=1)$. Participants reported on 86 back burners (35 females, 51 males). Back burners' ages ranged from 18 to $30(M=20.58, S D=2.06)$. Participants' back burners were White/Caucasian $(n=65)$, Black/African-American $(n=9)$, Asian/Asian-American $(n=2)$, Middle Eastern $(n=4)$, Hispanic $(n=4)$, or other $(n=2)$. Although a majority of participants identified their back burners' sexual orientation as heterosexual $(n=82)$, other participants identified them as bisexual $(n=3)$ or other $(n=1)$.

Study 2 had 187 participants ( 72 females, 40 males, 1 preferred not to answer, 74 missing) who were currently involved in a back burner relationship ${ }^{1}$. Ages ranged from 18 to 40 years of age $(M=20.05, S D=2.69)$. Participants were White/Caucasian $(n=86)$, 
Black/African-American ( $n=9)$, Asian/Asian-American ( $n=5)$, Middle Eastern $(n=5)$, Hispanic $(n=5)$, Native American $(n=1)$, other $(n=2)$, or missing $(n=74)$. Although a majority of participants identified their sexual orientation as heterosexual $(n=100)$, other participants identified as gay $(n=3)$, lesbian $(n=1)$, bisexual $(n=4)$, other $(n=2)$, preferred not to answer $(n=3)$, or missing $(n=74)$. Participants reported on 187 back burners (39 females, 71 males, 3 preferred not to answer, 74 missing). Back burners' ages ranged from 18 to 98 ( $M=$ 21.02, $S D=7.67)$. Participants' back burners were White/Caucasian $(n=95)$, Black/AfricanAmerican $(n=10)$, Asian/Asian-American $(n=2)$, Middle Eastern $(n=2)$, Hispanic $(n=3)$, other $(n=1)$, or missing $(n=74)$. Although a majority of participants identified their back burners' sexual orientation as heterosexual $(n=98)$, other participants identified them as gay ( $n$ $=4)$, bisexual $(n=4)$, other $(n=3)$, preferred not to answer $(n=3)$, or missing $(n=75)$.

\section{Procedures and Instrumentation}

Approval to conduct this study was obtained from West Virginia University's Institutional Review Board (IRB). Participants were recruited for both Study 1 and Study 2 using convenience sampling. Convenience sampling allows researchers to collect data from easily accessible individuals who meet the participant criteria (Henry, 1990). Participants were recruited from undergraduate students enrolled in Communication Studies courses at West Virginia University.

For Study 1, an announcement was posted on the physical and virtual research study board for the Department of Communication Studies (see Appendix A). The announcement contained information about the study, participant criteria, and the link to the Qualtrics online questionnaire. The first page of the online questionnaire was the cover letter (see Appendix B), which participants were instructed to read prior to continuing on to complete the questionnaire. 
The Study 1 questionnaire (see Appendix C) consisted of two parts. The first part asked participants to identify one current back burner based on the description provided. With the identified back burner in mind, participants reported on the current nature of their relationship by identifying the person as an acquaintance $(n=12)$, casual friend $(n=34)$, close friend $(n=25)$, best friend $(n=11)$, or other $(n=4)$. Participants also reported if their back burner was a former romantic partner $(n=10)$, former sexual partner $(n=15)$, both a former romantic and sexual partner $(n=26)$, or neither a former romantic nor sexual partner $(n=35)$. Participants reported their interest in this back burner as sexual $(n=18)$, romantic $(n=9)$, both sexual and romantic $(n$ $=48)$, neither sexual nor romantic $(n=10)$, or missing $(n=1)$. Although 65 participants reported that their back burner was aware of their interest in them, 20 participants reported that their back burner was not aware of their interest in them and 1 missing. Aside from the back burner they reported on in this study, 53 participants indicated that they did not have another back burner, 25 participants had 1-3 additional back burners, and 8 participants indicated that they had 4-6 additional back burners. There was a total of 47 participants who indicated that they were also currently involved in a committed romantic relationship outside of the back burner relationship. These participants were then asked to indicate whether the romantic partner knows the full extent of the back burner communication $(n=7)$, somewhat knows that the participant has kept in touch with the back burner, but not to the full extent $(n=14)$, or has no idea about the back burner communication $(n=26)$.

Participants also reported on the frequency through which they used different channels to communicate with their back burner. Participants communicated with their back burner via faceto-face less than once a year $(n=7)$, about once a year $(n=6)$, once every six months $(n=7)$, once every 2-3 months $(n=21)$, once a month $(n=18)$, once a week $(n=9)$, more than once a 
week $(n=8)$, or daily $(n=10)$. Participants communicated with their back burner via email less than once a year $(n=71)$, about once a year $(n=3)$, once every six months $(n=2)$, once every 23 months $(n=3)$, once a month $(n=2)$, once a week $(n=2)$, more than once a week $(n=1)$, daily $(n=1)$, or missing $(n=1)$. Participants communicated with their back burner via text messaging less than once a year $(n=7)$, about once a year $(n=1)$, once every six months $(n=6)$, once every 2-3 months $(n=14)$, once a month $(n=14)$, once a week $(n=13)$, more than once a week $(n=18)$, or daily $(n=13)$. Participants communicated with their back burner via social networking sites less than once a year $(n=4)$, about once a year $(n=2)$, once every six months $(n=5)$, once every 2-3 months $(n=7)$, once a month $(n=17)$, once a week $(n=15)$, more than once a week $(n=16)$, or daily $(n=20)$.

The second part of the Study 1 questionnaire asked participants to identify the behaviors they use to maintain their back burner relationship. Sampling from the directions utilized in past studies that have investigated the relational maintenance behaviors used in romantic relationships (Dainton \& Gross, 2008; Dainton \& Stafford, 1993; Stafford \& Canary, 1991), participants were given the following open-ended prompt:

To maintain our relationships the way we like them, we engage in maintenance behaviors. Some of these behaviors are positive: for example, we are open and selfdisclose our feelings. However, we occasionally engage in negative behaviors within our relationships, and we do these negative things for the sake of the relationship. For example, we might avoid interacting with the other person when we do not want to deal with an issue. Much of maintaining a relationship can involve mundane or routine aspects of day-to-day life. These are things you might not have thought of above because they might seem too trivial. Please offer up to five examples of behaviors (positive, negative, or a combination of both) that you have used to maintain your back burner relationship with this person.

Participants were instructed to not put their name or any other personally identifying markers on the questionnaire to ensure their confidentiality. At the end of the questionnaire, participants were directed to a separate questionnaire that was not attached to their responses to provide 
information in order to receive extra credit. The researcher contacted the instructors of the communication studies courses in order to provide proof of their students' participation to receive any extra credit points offered by the instructor.

For Study 2, an announcement was posted on the physical and virtual research study board for the Department of Communication Studies (see Appendix D). Following the recruitment email script (see Appendix E), an announcement for the study was also emailed to students enrolled in undergraduate communication studies courses. The announcements contained information about the study, participant criteria, and the link to the Qualtrics online questionnaire. The first page of the online questionnaire was the cover letter (see Appendix F), which participants were instructed to read prior to continuing on to complete the questionnaire.

The Study 2 questionnaire (see Appendix G) consisted of two parts. The first part of the Study 2 questionnaire replicated the first part of the Study 1 questionnaire, which asked participants to identify one current back burner based on the description provided. With the identified back burner in mind, participants reported on the current nature of their relationship by identifying the person as an acquaintance $(n=26)$, casual friend $(n=74)$, close friend $(n=60)$, best friend $(n=19)$, or other $(n=8)$. Participants also reported if their back burner was a former romantic partner $(n=16)$, former sexual partner $(n=24)$, both a former romantic and sexual partner $(n=38)$, neither a former romantic nor sexual partner $(n=35)$, or missing $(n=74)$. Participants reported their interest in this back burner as sexual $(n=26)$, romantic $(n=19)$, both sexual and romantic $(n=54)$, neither sexual nor romantic $(n=13)$, or missing $(n=75)$. Although 87 participants reported that their back burner was aware of their interest in them, 26 participants reported that their back burner was not aware of their interest in them and 74 missing. Aside from the back burner they reported on in this study, 71 participants indicated that they did not 
have another back burner, 34 participants had 1-3 additional back burners, 7 participants indicated that they had 4-9 additional back burners, and 75 missing.

There was a total of 104 participants who indicated that they were also currently involved in a committed romantic relationship outside of the back burner relationship. These participants were then asked to indicate whether the romantic partner knows the full extent of the back burner communication $(n=30)$, somewhat knows that the participant has kept in touch with the back burner, but not to the full extent ( $n=34)$, or has no idea about the back burner communication ( $n$ $=40)$.

Participants also reported on the frequency through which they used different channels to communicate with their back burners. Participants communicated with their back burner via face-to-face less than once a year $(n=10)$, about once a year $(n=13)$, once every six months $(n$ $=27)$, once every 2-3 months $(n=42)$, once a month $(n=25)$, once a week $(n=36)$, more than once a week $(n=21)$, or daily $(n=13)$. Participants communicated with their back burner via email less than once a year $(n=154)$, about once a year $(n=8)$, once every six months $(n=5)$, once every 2-3 months ( $n=4)$, once a month $(n=6)$, once a week $(n=6)$, daily $(n=3)$, or missing $(n=1)$. Participants communicated with their back burner via text messaging less than once a year $(n=15)$, about once a year $(n=7)$, once every six months $(n=13)$, once every 2-3 months $(n=19)$, once a month $(n=28)$, once a week $(n=26)$, more than once a week $(n=33)$, or daily $(n=46)$. Participants communicated with their back burner via social networking sites less than once a year $(n=11)$, about once a year $(n=6)$, once every six months $(n=2)$, once every 2-3 months ( $n=18)$, once a month $(n=25)$, once a week $(n=29)$, more than once a week $(n=38)$, or daily $(n=58)$.

The second part of the Study 2 questionnaire contained eight different instruments, 
followed by a series of demographic questions. The items in all the instruments were modified to reflect the back burner relationship. This included the Back Burner Maintenance Behaviors Typology created from the results of Study 1, the Attachment Style Measure (Guerrero, 1996; Guerrero et al., 2009), the Relationship Uncertainty Scale (Knobloch \& Solomon, 1999), the Self-Expansion Questionnaire (Lewandowski \& Aron, 2002), the Global Commitment Measure (Stafford \& Canary, 1991), the Liking Scale (Stafford \& Canary, 1991), the Control Mutuality Scale (Stafford \& Canary, 1991), and the Relationship Assessment Scale (RAS; Hendrick, 1988). Scale reliability was tested with the SPSS OMEGA macro program (Hayes \& Coutts, 2020). The composite reliability for each scale was assessed using the closed-form method HA Omega $(\omega)$ estimate with $95 \%$ bootstrap confidence intervals from 5,000 bootstrap samples (Hancock \& An, 2020). Participants were instructed to not put their name or any other personally identifying markers on the questionnaire to ensure their confidentiality. At the end of the questionnaire, participants were directed to a separate questionnaire that was not attached to their responses to provide information in order to receive extra credit. The researcher contacted the instructors of the communication studies course in order to provide proof of their students' participation to receive any extra credit points offered by their instructor.

\section{The Back Burner Maintenance Behaviors Typology}

The Back Burner Maintenance Behaviors Typology (see Appendix H) contains 10 items intended to measure how frequently individuals used 10 different relational maintenance behaviors in their back burner relationships (i.e., flirting $\&$ humor, minimize intimacy, openness, positivity \& support, regular contact, relationship talk, shared activities, social networks, special occasions \& gifts, and strategic deceit). Responses were solicited using a 5-point Likert scale ranging from 1 (never) to 5 (always). 


\section{The Attachment Style Measure}

The Attachment Style Measure (Guerrero, 1996; Guerrero et al., 2009) is 25-item, fourfactor instrument intended to identify individuals' adult attachment style (see Appendix I). The four factors are secure attachment (seven items), preoccupied attachment (seven items), fearfulavoidant attachment (five items), and dismissive attachment (six items). Responses were solicited using a 7-point Likert scale ranging from 1 (strongly disagree) to 7 (strongly agree). Previously reported Cronbach's alpha reliability coefficients for the four factors were $.73, .86$, and .87 for secure attachment; .77 and .84 for preoccupied attachment; $.82, .85$, and .91 for fearful-avoidant attachment; and .71 and .82 for dismissive attachment (Goodboy et al., 2017; Guerrero et al., 2009; La Valley \& Guerrero, 2012). In this study, the composite reliabilities were: preoccupied attachment $(M=4.23, S D=1.22, \omega=.850,95 \%$ CI $[.798, .885])$; fearfulavoidant attachment $(M=4.22, S D=1.42, \omega=.883,95 \% \mathrm{CI}[.844, .913])$; and dismissive attachment $(M=4.23, S D=1.20, \omega=.852,95 \%$ CI $[.796, .889])$. The initial reliability test for secure attachment revealed a reliable omega value using the McDonald estimate $(\omega=.703)$. However, an error message emerged when using the HA estimate, indicating that there was an error calculating the composite reliability because of low inter-item correlation values (Hancock \& An, 2020; Hayes \& Coutts, 2020). As a result, the three recoded items were removed from the secure attachment measure (i.e., "I sometimes worry that I do not really fit in with other people", "I sometimes worry that I do not measure up to other people", and "I worry that others will reject me"). The composite reliability was retested for the modified 4-item secure attachment scale ( $M$ $=4.78, S D=1.16, \omega=.820,95 \%$ CI $[.744, .872])$. 


\section{The Relationship Uncertainty Scale}

The Relationship Uncertainty Scale (Knobloch \& Solomon, 1999) is a 16-item, fourfactor instrument intended to measure the degree to which individuals are confident in their perceptions about a current relationship (see Appendix J). The four factors are behavioral norms uncertainty (four items), mutuality uncertainty (four items), definitional uncertainty (four items), and future uncertainty (four items). Responses were solicited using a 7-point Likert-type scale ranging from 1 (completely or almost completely uncertain) to 7 (completely or almost completely certain). Previously reported Cronbach's alpha reliability coefficients for each factor were $.73, .80$, and .85 for behavioral uncertainty; $.87, .89$, and .91 for mutuality uncertainty; .85 , .86 , and .90 for definitional uncertainty; and .84, .88, and .90 future uncertainty (Dainton, 2003; Dainton et al., 2017; Knobloch \& Solomon, 1999). In this study, the composite reliability was tested for definitional uncertainty $(M=3.66, S D=1.14, \omega=.843,95 \%$ CI $[.792, .884])$; mutuality uncertainty $(M=3.65, S D=1.17, \omega=.855,95 \%$ CI $[.804, .893])$; future uncertainty $(M=3.34, S D=1.13, \omega=.834,95 \%$ CI $[.776, .878]) ;$ and behavioral uncertainty $(M=4.09, S D$ $=1.16, \omega=.885,95 \%$ CI $[.842, .916])$.

\section{The Self-Expansion Questionnaire}

The Self-Expansion Questionnaire (Lewandowski \& Aron, 2002) is a 14-item, unidimensional instrument intended to measure individuals' experienced relational selfexpansion, or the degree to which the current romantic relationship has facilitated increases in participants' knowledge, resources, perspectives, and novel or exciting experiences (see Appendix K). Responses were solicited using a 7-point Likert-type scale from 1 (strongly disagree) to 7 (strongly agree). Previously reported Cronbach's alpha reliability coefficients have ranged from .86 to .90 (Lewandowski \& Ackerman, 2006; VanderDrift et al., 2011). In this 
study, the composite reliability was tested for self-expansion $(M=4.38, S D=1.12, \omega=.940$, $95 \%$ CI $[.917, .955])$.

\section{The Global Commitment Measure}

The Global Commitment Measure (Stafford \& Canary, 1991) is a six-item, unidimensional instrument intended to measure the degree to which individuals feel strongly about remaining in their current relationship. Responses were solicited using a 7-point Likert scale ranging from 1 (strongly disagree) to 7 (strongly agree). Previously reported Cronbach's alpha reliability coefficients for this measure were $.83, .86$, and .88 (Canary \& Stafford, 1992; Rittenour et al., 2007; Stafford \& Canary, 1991). In this study, the composite reliability was tested for commitment $(M=4.32, S D=1.22, \omega=.812,95 \%$ CI $[.752, .856])$.

\section{The Liking Measure}

The Liking Measure (Stafford \& Canary, 1991) is a five-item, unidimensional instrument intended to measure the degree to which individuals admire and enjoy spending time with a relational partner (see Appendix M). Responses were solicited using a 7-point Likert scale ranging from 1 (strongly disagree) to 7 (strongly agree). Previously reported Cronbach's alpha reliability coefficients for this measure were $.81, .85$, and .86 (Canary et al., 2002; Goodboy \& Myers, 2008; Stafford \& Canary, 1991). In this study, the composite reliability was tested for liking $(M=4.38, S D=1.27, \omega=.868,95 \% \mathrm{CI}[.819, .902])$.

\section{The Control Mutuality Measure}

The Control Mutuality Measure (Stafford \& Canary, 1991) is a five-item, unidimensional instrument intended to measure the degree to which individuals perceive that both partners contribute equally to making decisions (see Appendix N). Responses were solicited using a 7point Likert scale ranging from 1 (strongly disagree) to 7 (strongly agree). Previously reported 
Cronbach's alpha reliability coefficients for the measure were $.82, .85$, and .87 (Canary \& Stafford, 1992; Canary et al., 2002; Stafford \& Canary, 1991). In this study, the composite reliability was tested for control mutuality $(M=4.66, S D=1.23, \omega=.882,95 \%$ CI $[.839, .913])$.

\section{The Relationship Assessment Scale}

The Relationship Assessment Scale (Hendrick, 1988) is a seven-item, unidimensional instrument intended to measure the degree to which individuals are globally happy and content with their relationship and their relational partner (see Appendix O). Responses were solicited using a 7-point Likert scale ranging from 1 (strongly disagree) to 7 (strongly agree). Previously reported Cronbach's alpha reliability coefficients for the measure were $.86, .88$, and .92 (Hendrick, 1988; McEwan \& Horn, 2016; Sacher \& Fine, 1996). In this study, the composite reliability was tested for relationship satisfaction $(M=4.35, S D=1.07, \omega=.760,95 \%$ CI [.660, $.825])$.

\section{Summary}

The purpose of Chapter II was to report on the participants, methods, and measures of data collection used to address the research questions and hypothesis proposed in Chapter I. All participants were at least 18 years of age or older and currently involved in a back burner relationship. All participants were solicited from Communication Studies courses at West Virginia University using convenience sampling. Participants in Study 1 responded to an openended question regarding the different types of behaviors they use to maintain their back burner relationships. Participants in Study 2 completed a series of instruments that measured individuals' use of back burner relational maintenance behaviors, attachment style, relationship uncertainty, self-expansion, commitment, liking, control mutuality, and relationship satisfaction. Participants in both studies also provide demographic and descriptive information about 
themselves and their back burner relationships. 


\section{Chapter III}

\section{Results}

\section{Study One}

The first research question was interested in identifying the context-specific relational maintenance behaviors used by individuals to maintain back burner relationships. Participants' responses to the open-ended question regarding their maintenance behaviors were analyzed using two coding cycles (Saldaña, 2016). First cycle coding was the initial process of coding the participants' responses. The In Vivo Coding method was used, allowing the researcher to sort the data based on the actual words written by the participants, also known as "literal coding, verbatim coding, inductive coding, indigenous coding, natural coding, and emic coding” (Saldaña, 2016, p. 105). The researcher created an In Vivo code for each behavior identified by the participants and each code was written on a notecard. Participants reported 456 relational maintenance behaviors. After a closer review, 12 behaviors were removed because they did not qualify as maintenance behaviors [e.g., "I am a different person now" (282) and "sometimes college is busy" (366)]. This reduced the final number to 444 examples of back burner relational maintenance behaviors to be considered for analysis. As a result of first cycle coding, 10 categories emerged from the data: flirtation \& humor $(n=33)$, minimize intimacy $(n=54)$, openness $(n=39)$, positivity \& support $(n=82)$, regular contact $(n=109)$, relationship talk $(n=$ $26)$, shared activities $(n=49)$, social networks $(n=17)$, special occasions \& gifts $(n=14)$, and strategic deceit $(n=21)$.

Second cycle coding was a way to reanalyze and organize the codes from the first cycle into representative categories. The Axial Coding method was used as a way to identify categories and the specific properties and dimensions of each category (Saldaña, 2016). Thus, the 
researcher then organized the codes from the first cycle into categorizes that represented the relational maintenance behaviors used by individuals in back burner relationships. Axial coding was complete when the researcher achieved saturation (i.e., the researcher can no longer identify any new information during coding). This resulted in a total of 94 unique examples of relational maintenance behaviors within each of the 10 categories: Flirtation \& Humor $(n=9)$, Minimize Intimacy $(n=10)$, Openness $(n=7)$, Positivity \& Support $(n=19)$, Regular Contact $(n=6)$, Relationship Talk $(n=7)$, Shared Activities $(n=13)$, Social Networks $(n=4)$, Special Occasions $\&$ Gifts $(n=6)$, and Strategic Deceit $(n=13)$. See Table 7 for the Back Burner Maintenance Behaviors Typology and the means and standard deviations for each behavior. The researcher actively engaged in memo writing during both coding cycles for reanalysis of the coding and categorizations (Saldaña, 2016). Refer to Appendix P for memo notes. The next section contains descriptive paragraphs for each back burner relational maintenance behavior that emerged from the results of Study 1.

\section{Flirting \& Humor}

The first category refers to playful and fun engagement, including interest-showing verbal and nonverbal flirtatious behaviors that indicate interest in the other person, along with sharing jokes and making each other laugh. Participants reported that they "Naturally flirt" (70) with back burners by engaging in "playful nudging and touching" (163), "showing affection" (201), and "complimenting them on their looks" (184). Social media is also specifically used for both flirting [e.g., "Sending them a selfie every now and then before I go out" (104) and "Post cute pictures that I know he will swipe up and start a conversation with me" (54)] and humor [e.g., "Send them funny tweets" (363) and "Sharing funny videos or memories of going out" (114)]. 
Table 7

Means and Standard Deviations for the Back Burner Maintenance Behaviors

\begin{tabular}{|c|c|c|c|}
\hline Behaviors & Items & $M$ & $S D$ \\
\hline Flirting \& Humor & $\begin{array}{l}\text { We flirt and share funny anecdotes with } \\
\text { each other (e.g., inside jokes, memes, or } \\
\text { funny memories). }\end{array}$ & 3.33 & 1.16 \\
\hline Minimize Intimacy & $\begin{array}{l}\text { We avoid potentially-intimate situations } \\
\text { (e.g., we monitor how much time we spend } \\
\text { alone together) or conversations (e.g., we } \\
\text { avoid conversations about our feelings for } \\
\text { each other and the future of the relationship). }\end{array}$ & 2.97 & 1.15 \\
\hline Openness & $\begin{array}{l}\text { We openly discuss details of our lives with } \\
\text { each other (e.g., personal information, } \\
\text { emotions, experiences, goals). }\end{array}$ & 3.51 & 1.15 \\
\hline Positivity \& Support & $\begin{array}{l}\text { We are there for each other to offer } \\
\text { encouraging emotional support (e.g., listening } \\
\text { to their current struggles) and behavioral } \\
\text { support (e.g., offering help with homework). }\end{array}$ & 3.58 & 1.19 \\
\hline Regular Contact & $\begin{array}{l}\text { We regularly talk via some form of } \\
\text { communication (e.g., Snapchat, texting, } \\
\text { Facetime, phone calls, direct messages). }\end{array}$ & 3.64 & 1.12 \\
\hline Relationship Talk & $\begin{array}{l}\text { We make it clear to each other what we want } \\
\text { and do not want out of this back burner } \\
\text { relationship, both currently and in the future. }\end{array}$ & 2.95 & 1.19 \\
\hline Shared Activities & $\begin{array}{l}\text { We spend time doing different activities } \\
\text { together (e.g., getting food, going out, } \\
\text { watching movies, or traveling). }\end{array}$ & 2.78 & 1.20 \\
\hline Social Networks & $\begin{array}{l}\text { We spend time in the same social circles } \\
\text { (e.g., hanging out with mutual friends, } \\
\text { visiting family members, or following } \\
\text { friends and family on social media). }\end{array}$ & 3.11 & 1.31 \\
\hline Special Occasions \& Gifts & We make sure to somehow recognize & 3.47 & 1.21 \\
\hline
\end{tabular}


special occasions together (e.g., send a text on their birthday, visit during holidays, or exchange gifts).

Strategic Deceit

We purposefully avoid and withhold information from each other (e.g., making up excuses to avoid seeing them; concealing your other sexual partners) and people outside of the back burner relationship (e.g., downplaying the relationship to friends).

Note. Participants responded to each item on a scale from 1 (never) to 5 (always). 


\section{Minimize Intimacy}

The second category refers to behaviors that can be used in terms of either denying emotional and physical closeness with the back burner or avoiding intimate interactions with others outside of the back burner relationship. Participants identified verbal tactics to minimize intimacy [e.g., "Do not talk like we are dating" (312), "Don’t say baby or pet names" (313), and "We remember that the communication we have is only platonic rather than romantic or sexual" (46)], as well as nonverbal/physical tactics [e.g., "Do not go to dinner or something" (264), "Shed away from intimate situations" (408), "Keep conversation to a minimum when I see him out in public" (374), and "Never go out of my way" (122)]. Additional examples reflected restrictions to the back burner relationship: "Have pseudo dates where we go out to dinner and it is essentially a date, but we don't call it one" (35), "Won't do anything else (but go out on the weekends) because he may think we are becoming more" (263), and "Hang out in group settings never one on one" (431). Participants with external romantic/sexual partners indicated that the back burner "Has a girlfriend so I don't cross the line" (254) and "He has a girlfriend and wants to respect her but at the same time he needs to have respect for our friendship" (367).

\section{Openness}

The third category refers to the degree of self-disclosure and honesty within a back burner relationship. Participants said that they engaged in "Self-disclosure" (1) in a few ways. Examples ranged from surface-level disclosures, such as "sharing likes/dislikes" (181), "Talk about things going on with school and life to my back burner because I am close with him" (78), and "share hopes/goals" (359), to more deep disclosures, such as "opening up about the past" (41), "tell each other absolutely everything" (386), and "only talk to this person about my feelings" (135). However, engaging in openness is not always easy, as a participant indicated 
that they "I tell her like it is whether she wants to hear it or not" (117).

\section{Positivity \& Support}

The fourth category refers to kind and encouraging messages, as well as both emotional and instrumental supportive behaviors. For many participants, they described how they "Stay patient” (450), “Send encouraging words" (319), "Be calm” (179), “Be nice” (160), “Easygoing” (443), "He understands" (79), "Never place judgement" (217), and "not speaking and letting them vent" (167). Similarly, participants also reported that they want the other to feel as if someone cares [e.g., "Make sure she feels cared for" (430)]. Examples of emotional support were "Listen to when they had a bad day" (260), "Calling when needed for emotional support" (353), and "Always provide one another with an ear to listen and a shoulder to lean on" (127). Examples of instrumental support were "helped him make his decision on his athletic career" (310), "picking them up" (76) if they need a ride, "help each other with occasional errands/favors" (208), and "always help them with homework when needed" (194).

\section{Regular Contact}

The fifth category refers to the engagement of frequent and casual communication between back burners. These behaviors are often described as checking in, like one participant said they like to "check up on them just to see how they are doing" (33). Participants checked in weekly, if not daily, with their back burner [e.g., "Message once a week using social media or text messages" (38) and "Some form of communication every day" (90)]. Contact with back burners is kept through "Snapchatting" (9), "Texting” (92), "Calling them on the phone" (247), "Facetime" (146), and "Direct messages" (187). 


\section{Relationship Talk}

The sixth category refers to distinct discussions regarding the current and future nature of the back burner relationship. Participants engaged in specific conversations about different issues related to maintaining back burner relationships: "Discussed where we both stand in the relationship" (317), "Being honest with him when we occasionally have open conversation about what we want in a relationship" (196), "Discussed out feelings for each other openly" (318), and "We've talked about how it's important to remember to keep potential options open just in case" (320). In addition, participants indicated that they "set up relationship rules" (207) with back burners. Several participants engaged in relationship talk about external relationships [e.g., "Aware and fully okay with being with other people romantically and sexually" (230) and "If things get serious (with other people) tell the other person" (403)].

\section{Shared Activities}

The seventh category refers to participation in a variety of activities. Participants engaged in numerous activities with their back burners, such as "watch movies" (412), "travel” (143), and "usually go to a concert in the summer together" (270). Some of the examples, however, might not initially appear to be significant. Instead, the focus seems to be more on casual [e.g., "We go see each other a lot around campus" (237)] and enjoyable [e.g., "tell each other when we're going out" (85)] things to do with back burners.

\section{Social Networks}

The eighth category refers to the inclusion of each other within external relationships, such as friends and family. For the most part, participants' reports focused on hanging out with the people from a shared network: "We both are friends and hang out with the same people" (161), "Group outings" (119), and "Looking at family/mutual friends' social media and asking 
them how they are doing" (136). Connections are commonly maintained with back burner's friends [e.g., "Lot of mutual friends which helps for our paths to cross more often" (371), "Went to a friend event of hers" (376), and "Still hang around his friends" (349)] and family [e.g., "Talk to each other's siblings" (228), "Her family loves to invite me over" (305), and "Asking about each other's families" (159)].

\section{Special Occasions \& Gifts}

The ninth category refers to the special nature of interactions and gifts shared between back burners. Participants referred to the behavior "Wishing each other a happy birthday" (55). Examples primarily focused on the holiday or annual aspect of both interacting with each other [e.g., "I usually invite her to my family's Christmas party every year" (88) and "See her at family barbecues in the summer" (178)] and sharing gifts [e.g., "Get small gifts for each other" (130)] during these special occasions.

\section{Strategic Deceit}

The tenth category refers to purposeful actions that are disingenuous and intended to deceive. Participants commonly mentioned withholding information, which included directly lying to the back burner [(e.g., "Give excuses when I'm with other people” (266)], withholding information in its entirety [e.g., "Avoid talking about any other sexual relationships" (149); "He has no idea about my future intentions with him" (261)], or sharing partial truths [e.g., "Not always telling the whole truth of certain situations like 'other' friends" (399); "Leading them on to an extent" (36)]. Some information was withheld from the back burner via electronicallymediated channels [e.g., "Block and unblock them on social media" (406); "Leave him on read" (149)]. Participants' desire to not see nor be inconvenienced by the back burner also led to the use of these behaviors [e.g., "I only talk to him when I want" (418); "Making excuses to get out 
of seeing the other person" (329); “Avoiding a request to see the other person when it isn't convenient for me" (150)]. Jealousy induction was another reported behavior [e.g., "Sometimes I attempt to provoke jealousy reaction out of the other person" (332); "Try to make him jealous" (438)]. However, the back burner was not the only target for this deception as a number of behaviors involved others outside of the relationship. That is, some participants intended to deceive their friends [e.g., "Not telling anyone but ourselves" (300); "Avoid eye contact in public places" (225);], while others focused on their romantic partners [e.g., "Avoid seeing each other when with our other partner we are in a relationship with" (358)]. One participant described how they were deceitful with both the back burner and others outside of the relationship [e.g., "Downplaying the relationship to those around me while overplaying the intenseness of the relationship to other party involved" (239)].

\section{Study Two}

Before examining the second research question and hypothesis, a series of Pearson product-moment correlations were conducted with all of the back burner maintenance behaviors (see Table 8). Additional Pearson product-moment correlations were conducted between the maintenance behaviors and all of the other variables included in Study 2 (see Table 9).

\section{Research Question Two}

The second research question was interested in examining the extent to which attachment style, relational uncertainty, and self-expansion explained individuals' use of maintenance behaviors in their back burner relationships. With attachment styles operationalized as four continuous independent variables (i.e., secure attachment, preoccupied attachment, fearfulavoidant attachment, and dismissive attachment), relational uncertainty operationalized as four continuous independent variables (i.e., behavioral uncertainty, mutuality uncertainty, definitional 
Table 8

Correlation Matrix of Back Burner Maintenance Behaviors

\begin{tabular}{llllllllllll}
\hline Variable & 1 & 2 & 3 & 4 & 5 & 6 & 7 & 8 & 9 & 10 \\
\hline
\end{tabular}

\begin{tabular}{|c|c|c|c|c|c|c|c|c|c|c|}
\hline 1. Flirt/Humor & --- & & & & & & & & & \\
\hline 2. MinIntimacy & -.04 & --- & & & & & & & & \\
\hline 3. Open & $.49 * *$ & .05 & --- & & & & & & & \\
\hline 4. Pos/Supp & $.52 * *$ & .06 & $.67 * *$ & --- & & & & & & \\
\hline 5. RegContact & $.53 * *$ & .07 & $.49 * *$ & $.64 * *$ & --- & & & & & \\
\hline 6. RelTalk & $.20 *$ & $.17 *$ & $.26 * *$ & $.33 * *$ & $.33 * *$ & --- & & & & \\
\hline 7. SharedActv & $.31 * *$ & -.11 & $.36^{* *}$ & $.43 * *$ & $.44^{* *}$ & $.33 * *$ & --- & & & \\
\hline 8. SocNetwork & $.21^{*}$ & -.01 & $.25^{*}$ & $.23 *$ & $.26^{* *}$ & $.28 * *$ & $.50 * *$ & --- & & \\
\hline 9. SpecOc/Gift & $.36^{* *}$ & .05 & $.44 * *$ & $.53 * *$ & $.59 * *$ & $.33^{* *}$ & $.51 * *$ & $.41 * *$ & --- & \\
\hline 10. StrgDeceit & .07 & $.26^{* *}$ & .02 & .05 & -.01 & $.22 *$ & .03 & .08 & -.04 & --- \\
\hline
\end{tabular}


Table 9

\section{Correlation Matrix}

\begin{tabular}{|c|c|c|c|c|c|c|c|c|c|c|c|c|c|}
\hline Variable & 1 & 2 & 3 & 4 & 5 & 6 & 7 & 8 & 9 & 10 & 11 & 12 & 13 \\
\hline 1. Flirting \& Humor & $.17^{*}$ & .11 & .13 & .10 & $.24 *$ & $.28 * *$ & $.28 * *$ & $.23 *$ & $.36^{* *}$ & $.39 * *$ & $.46^{* *}$ & $.34 * *$ & $.35 * *$ \\
\hline 2. Minimize Intimacy & -.02 & $.35^{* *}$ & $.21 *$ & .10 & .10 & .01 & .01 & -.12 & -.03 & -.07 & -.08 & -.03 & $-.20 *$ \\
\hline 3. Openness & $.18^{*}$ & .13 & .01 & .01 & $.20^{*}$ & $.16^{*}$ & $.22 *$ & .06 & $.32 * *$ & $.23 *$ & $.35^{* *}$ & $.28 * *$ & $.19^{*}$ \\
\hline 4. Positivity \& Support & $.21 *$ & .06 & .04 & .09 & $.40 * *$ & $.32 * *$ & $.34 * *$ & $.20 *$ & $.45^{* *}$ & $.33^{* *}$ & $.43^{* *}$ & $.42 * *$ & $.37 * *$ \\
\hline 5. Regular Contact & $.20^{*}$ & .08 & .08 & .07 & $.24 *$ & $.32 * *$ & $.34 * *$ & $.19^{*}$ & $.46^{* *}$ & $.32 * *$ & $.46^{* *}$ & $.40 * *$ & $.38 * *$ \\
\hline 6. Relationship Talk & $.25^{*}$ & .05 & .01 & .12 & $.20 *$ & $.34 * *$ & $.32 * *$ & $.30 * *$ & $.19 *$ & $.16^{*}$ & $.17^{*}$ & $.26^{* *}$ & .14 \\
\hline 7. Shared Activities & $.19 *$ & -.06 & -.04 & -.03 & $.25^{*}$ & $.29 * *$ & $.37 * *$ & $.35 * *$ & $.43 * *$ & $.35^{* *}$ & $.43 * *$ & $.45 * *$ & $.40 * *$ \\
\hline 8. Social Networks. & $.22 *$ & -.02 & -.08 & -.10 & $.21 *$ & $.20 *$ & $.24^{*}$ & $.25^{*}$ & $.19 *$ & .14 & $.15^{*}$ & .12 & .10 \\
\hline 9. Special Oc. \& Gifts & $.20 *$ & .06 & .02 & -.01 & $.35 * *$ & $.35^{* *}$ & $.30 * *$ & $.21^{*}$ & $.45^{* *}$ & $.33 * *$ & $.40^{* *}$ & $.41 * *$ & $.39 * *$ \\
\hline 10. Strategic Deceit & -.02 & $.28 * *$ & $.30 * *$ & .11 & $-.19 *$ & -.13 & -.14 & -.06 & -.05 & -.05 & -.14 & $-.21 *$ & $-.24 *$ \\
\hline
\end{tabular}

Note. Special Oc. \& Gifts = Special Occasions \& Gifts. $1=$ Secure Attachment, $2=$ Preoccupied Attachment, $3=$ Fearful-Avoidant Attachment, 4 $=$ Dismissive Attachment, $5=$ Behavioral Uncertainty, $6=$ Mutuality Uncertainty, $7=$ Definitional Uncertainty, $8=$ Future Uncertainty, $9=$ Selfexpansion, $10=$ Commitment, $11=$ Liking, $12=$ Control Mutuality, $13=$ Relationship Satisfaction. ${ }^{*} p<.01 .{ }^{* *} p<.001$. 
uncertainty, and future uncertainty), self-expansion operationalized as one continuous independent variable, and one relational maintenance behavior as the dependent variable, 10 ordinary least squares (OLS) regression analyses were conducted. In order to conduct these analyses, it is required for the sample size to be able at least 20 times more than the total number of independent variables (Hair et al., 1995). With nine independent variables and 187 participants, this study's sample size was sufficient.

Using the enter method, the OLS regression analysis revealed that the theoretical factors (i.e., attachment, relationship uncertainty, and self-expansion) significantly contributed as predictors of individuals' use of the Flirting \& Humor maintenance behavior, $F(9,162)=3.19, p$ $<.01, R^{2}=.155, R_{\text {Adjusted }}=.105$. The analysis further revealed that self-expansion $(\mathrm{B}=.250$, $95 \%$ CI $[.090, .423])$ was a significant unique predictor of individuals' use of the Flirting \& Humor maintenance behavior in their back burner relationships. The unstandardized beta coefficients, standard errors, standardized coefficients, and t-values for all theoretical independent variables are reported in Table 10.

To test the assumption of collinearity, the VIF and Tolerance values were examined (Miles, 2005). Definitional Uncertainty had the largest VIF value with 4.83 and the smallest Tolerance value with .21. Given that the VIF value was not greater than 10 and the Tolerance value was not less than .1, multicollinearity was not a problem. As a test of the independence of error terms, the Durbin-Watson value was 2.06. Given that the Durbin-Watson value was between the critical values of 1.5-2.5, the residuals were normal (Field, 2009). As a test of outliers, the largest value of Cook's Distance was .11. Given that the largest value of Cook's Distance was not over 1 (Cook, 1977), outliers were not a problem.

Using the enter method, the OLS regression analysis revealed that the theoretical factors 
Table 10

OLS Regression Analysis: Flirting \& Humor

Flirting \& Humor

\begin{tabular}{cccc}
\hline B & SEB & $\beta$ & $t$ \\
.050 & .580 & .933 & .566 \\
-.037 & .088 & .050 & -.326 \\
.129 & .107 & -.035 & 1.02 \\
-.004 & .089 & -.003 & -.038 \\
.050 & .122 & .051 & .414 \\
.117 & .149 & .119 & .800 \\
.087 & .171 & .090 & .531 \\
-.061 & .121 & -.062 & -.510 \\
.250 & .084 & .256 & 3.05 \\
\hline
\end{tabular}

Note. Unstandardized beta coefficients are bolded if different from zero. 
(i.e., attachment, relationship uncertainty, and self-expansion) significantly contributed as predictors of individuals' use of the Minimize Intimacy maintenance behavior, $F(9,161)=5.22$, $p<.001, R^{2}=.236, R^{2}$ Adjusted $=.191$. The analysis further revealed that preoccupied attachment style $(\mathrm{B}=.389,95 \% \mathrm{CI}[.167, .568])$ and future uncertainty $(\mathrm{B}=-.354,95 \% \mathrm{CI}[-.584,-.128])$ were significant unique predictors of individuals' use of the Minimize Intimacy maintenance behavior in back burner relationships. The unstandardized beta coefficients, standard errors, standardized coefficients, and t-values for all theoretical independent variables are reported in Table 11.

To test the assumption of collinearity, the VIF and Tolerance values were examined (Miles, 2005). Definitional Uncertainty had the largest VIF value with 4.81 and the smallest Tolerance value with .21. Given that the VIF value was not greater than 10 and the Tolerance value was not less than .1, multicollinearity was not a problem. As a test of the independence of error terms, the Durbin-Watson value was 2.18. Given that the Durbin-Watson value was between the critical values of 1.5-2.5 (Field, 2009), the residuals were normal. As a test of outliers, the largest value of Cook's Distance was .09. Given that the largest value of Cook's Distance was not over 1 (Cook, 1977), outliers were not a problem.

Using the enter method, the OLS regression analysis revealed that the theoretical factors (i.e., attachment, relationship uncertainty, and self-expansion) significantly contributed as predictors of individuals' use of the Openness maintenance behavior, $F(9,161)=3.47, p<.01$, $R^{2}=.170, R^{2}$ Adjusted $=.121$. The analysis further revealed that self-expansion $(\mathrm{B}=.285,95 \% \mathrm{CI}$ $[.120, .449])$ was a significant unique predictor of individuals' use of the Openness maintenance behavior in back burner relationships. The unstandardized beta coefficients, standard errors, standardized coefficients, and t-values for all theoretical independent variables are reported in 
Table 11

OLS Regression Analysis: Minimize Intimacy

Minimize Intimacy

\begin{tabular}{rrrr}
\hline B & SEB & $\beta$ & $t$ \\
-.020 & .084 & -.020 & -.240 \\
.389 & .102 & .367 & 3.62 \\
-.032 & .096 & -.026 & -.269 \\
.021 & .084 & .020 & .234 \\
.185 & .116 & .186 & 1.61 \\
.090 & .140 & .090 & .643 \\
.141 & .161 & .146 & .908 \\
-.354 & .115 & -.356 & -3.09 \\
-.111 & .084 & -.116 & -1.38
\end{tabular}

Note. Unstandardized beta coefficients are bolded if different from zero. 
Table 12.

To test the assumption of collinearity, the VIF and Tolerance values were examined (Miles, 2005). Definitional Uncertainty had the largest VIF value with 4.83 and the smallest Tolerance value with .21 . Given that the VIF value was not greater than 10 and the Tolerance value was not less than .1, multicollinearity was not a problem. As a test of the independence of error terms, the Durbin-Watson value was 2.19. Given that the Durbin-Watson value was between the critical values of 1.5-2.5 (Field, 2009), the residuals were normal. As a test of outliers, the largest value of Cook's Distance was .06. Given that the largest value of Cook's Distance was not over 1 (Cook, 1977), outliers were not a problem.

Using the enter method, the OLS regression analysis revealed that the theoretical factors (i.e., attachment, relationship uncertainty, and self-expansion) significantly contributed as predictors of individuals' use of the Positivity \& Support maintenance behavior, $F(9,162)=$ $7.94, p<.001, R^{2}=.318, R_{\text {Adjusted }}=.278$. The analysis further revealed that behavioral uncertainty $(\mathrm{B}=.380,95 \% \mathrm{CI}[.173, .618])$ and self-expansion $(\mathrm{B}=.369,95 \% \mathrm{CI}[.236, .542])$ were significant unique predictors of individuals' use of the Positivity \& Support maintenance behavior in back burner relationships. The unstandardized beta coefficients, standard errors, standardized coefficients, and t-values for all theoretical independent variables are reported in Table 13.

To test the assumption of collinearity, the VIF and Tolerance values were examined (Miles, 2005). Definitional Uncertainty had the largest VIF value with 4.83 and the smallest Tolerance value with .21. Given that the VIF value was not greater than 10 and the Tolerance value was not less than .1, multicollinearity was not a problem. As a test of the independence of error terms, the Durbin-Watson value was 1.97. Given that the Durbin-Watson value was 
Table 12

OLS Regression Analysis: Openness

\section{Openness}

\begin{tabular}{cccc}
\hline B & SEB & $\beta$ & $t$ \\
.076 & .087 & .075 & .860 \\
.156 & .106 & .146 & 1.38 \\
-.136 & .100 & -.108 & -1.08 \\
.004 & .088 & .004 & .042 \\
.102 & .121 & .103 & .850 \\
-.121 & .147 & -.121 & -.822 \\
.300 & .169 & .320 & 1.78 \\
-.231 & .119 & -.231 & -1.94 \\
.285 & .083 & .285 & 3.42 \\
\hline
\end{tabular}

Note. Unstandardized beta coefficients are bolded if different from zero. 
Table 13

OLS Regression Analysis: Positivity \& Support

Positivity \& Support

\begin{tabular}{cccc}
\hline $\mathrm{B}$ & SEB & $\beta$ & $t$ \\
.053 & .082 & .054 & .662 \\
-.105 & .099 & -.102 & -1.03 \\
.038 & .093 & .031 & .336 \\
.050 & .082 & .048 & .590 \\
.380 & .113 & .395 & 3.51 \\
-.071 & .137 & -.073 & -.535 \\
.125 & .157 & .134 & .855 \\
-.209 & .111 & -.216 & -1.94 \\
.369 & .077 & .389 & 5.02
\end{tabular}

Note. Unstandardized beta coefficients are bolded if different from zero. 
between the critical values of 1.5-2.5 (Field, 2009), the residuals were normal. As a test of outliers, the largest value of Cook's Distance was .15. Given that the largest value of Cook's Distance was not over 1 (Cook, 1977), outliers were not a problem.

Using the enter method, the OLS regression analysis revealed that the theoretical factors (i.e., attachment, relationship uncertainty, and self-expansion) significantly contributed as predictors of individuals' use of the Regular Contact maintenance behavior, $F(9,162)=5.96, p<$ $.001, R^{2}=.260, R^{2}$ Adjusted $=.216$. The analysis further revealed that future uncertainty $(\mathrm{B}=-.224$, 95\% CI [-.442, -.006]) and self-expansion $(\mathrm{B}=.385,95 \% \mathrm{CI}[.234, .537])$ were significant unique predictors of individuals' use of the Regular Contact maintenance behavior in back burner relationships. The unstandardized beta coefficients, standard errors, standardized coefficients, and t-values for all theoretical independent variables are reported in Table 14.

To test the assumption of collinearity, the VIF and Tolerance values were examined (Miles, 2005). Definitional Uncertainty had the largest VIF value with 4.83 and the smallest Tolerance value with .21. Given that the VIF value was not greater than 10 and the Tolerance value was not less than .1, multicollinearity was not a problem. As a test of the independence of error terms, the Durbin-Watson value was 1.85. Given that the Durbin-Watson value was between the critical values of 1.5-2.5 (Field, 2009), the residuals were normal. As a test of outliers, the largest value of Cook's Distance was .11. Given that the largest value of Cook's Distance was not over 1 (Cook, 1977), outliers were not a problem.

Using the enter method, the OLS regression analysis revealed that the theoretical factors (i.e., attachment, relationship uncertainty, and self-expansion) significantly contributed as predictors of individuals' use of the Relationship Talk maintenance behavior, $F(9,161)=3.01, p$ $<.01, R^{2}=.151, R^{2}$ Adjusted $=.1$. The analysis further revealed that secure attachment 
Table 14

OLS Regression Analysis: Regular Contact

\section{Regular Contact}

\begin{tabular}{cccc}
\hline B & SEB & $\beta$ & $t$ \\
.024 & .081 & .023 & .291 \\
.006 & .098 & .006 & .057 \\
.015 & .093 & .012 & .129 \\
.037 & .081 & .034 & .419 \\
-.036 & .112 & -.035 & -.318 \\
.126 & .136 & .124 & .916 \\
.290 & .156 & .295 & 1.90 \\
-.228 & .110 & -.224 & -2.03 \\
.385 & .077 & .385 & 5.03
\end{tabular}

Note. Unstandardized beta coefficients are bolded if different from zero. 
$(\mathrm{B}=.329,95 \% \mathrm{CI}[.046, .613])$ was a significant unique predictor of individuals' use of the Relationship Talk maintenance behavior in back burner relationships. The unstandardized beta coefficients, standard errors, standardized coefficients, and t-values for all theoretical independent variables are reported in Table 15.

To test the assumption of collinearity, the VIF and Tolerance values were examined (Miles, 2005). Definitional Uncertainty had the largest VIF value with 4.85 and the smallest Tolerance value with .21. Given that the VIF value was not greater than 10 and the Tolerance value was not less than .1, multicollinearity was not a problem. As a test of the independence of error terms, the Durbin-Watson value was 1.90. Given that the Durbin-Watson value was between the critical values of 1.5-2.5 (Field, 2009), the residuals were normal. As a test of outliers, the largest value of Cook's Distance was .13. Given that the largest value of Cook's Distance was not over 1 (Cook, 1977), outliers were not a problem.

Using the enter method, the OLS regression analysis revealed that the theoretical factors (i.e., attachment, relationship uncertainty, and self-expansion) significantly contributed as predictors of individuals' use of the Shared Activities maintenance behavior, $F(9,161)=6.67, p$ $<.001, R^{2}=.283, R^{2}$ Adjusted $=.241$. The analysis further revealed that self-expansion $(\mathrm{B}=.358$, $95 \%$ CI $[.225, .548])$ was a significant unique predictor of individuals' use of the Shared Activities maintenance behavior in back burner relationships. The unstandardized beta coefficients, standard errors, standardized coefficients, and t-values for all theoretical independent variables are reported in Table 16.

To test the assumption of collinearity, the VIF and Tolerance values were examined (Miles, 2005). Definitional Uncertainty had the largest VIF value with 4.84 and the smallest Tolerance value with .21. Given that the VIF value was not greater than 10 and the Tolerance 
Table 15

OLS Regression Analysis: Relationship Talk

\section{Relationship Talk}

\begin{tabular}{llll}
\hline B & SEB & $\beta$
\end{tabular}

1. Secure Attachment

$\begin{array}{rrrr}.329 & .143 & .209 & 2.30 \\ .189 & .112 & .189 & 1.68 \\ -.045 & .107 & -.053 & -.416 \\ .018 & .097 & .018 & .188 \\ -.155 & .127 & -.147 & -1.12 \\ .307 & .157 & .291 & 1.97 \\ -.046 & .179 & -.043 & -.260 \\ .169 & .127 & .161 & 1.34 \\ .019 & .090 & .018 & .213\end{array}$

Note. Unstandardized beta coefficients are bolded if different from zero. 
Table 16

OLS Regression Analysis: Shared Activities

Shared Activities

\begin{tabular}{cccc}
\hline B & SEB & $\beta$ & $t$ \\
.074 & .086 & .078 & .906 \\
-.130 & .104 & -.129 & -1.24 \\
.110 & .099 & .093 & .941 \\
-.083 & .087 & -.082 & -.952 \\
-.068 & .119 & -.072 & -.606 \\
-.143 & .144 & -.152 & -1.05 \\
.236 & .166 & .259 & 1.57 \\
.206 & .117 & .218 & 1.85 \\
.358 & .082 & .386 & 4.73
\end{tabular}

Note. Unstandardized beta coefficients are bolded if different from zero. 
value was not less than .1, multicollinearity was not a problem. As a test of the independence of error terms, the Durbin-Watson value was 2.09. Given that the Durbin-Watson value was between the critical values of 1.5-2.5 (Field, 2009), the residuals were normal. As a test of outliers, the largest value of Cook's Distance was .06. Given that the largest value of Cook's Distance was not over 1 (Cook, 1977), outliers were not a problem.

Using the enter method, the OLS regression analysis revealed that the theoretical factors (i.e., attachment, relationship uncertainty, and self-expansion) significantly contributed as predictors of individuals' use of the Social Networks maintenance behavior, $F(9,162)=2.20, p$ $<.01, R^{2}=.114, R_{\text {Adjusted }}^{2}=.062$. The analysis further revealed that secure attachment $(\mathrm{B}=.202$, $95 \%$ CI $[.025, .433])$ was a significant unique predictor of individuals' use of the Social Networks maintenance behavior in back burner relationships. The unstandardized beta coefficients, standard errors, standardized coefficients, and t-values for all theoretical independent variables are reported in Table 17.

To test the assumption of collinearity, the VIF and Tolerance values were examined (Miles, 2005). Definitional Uncertainty had the largest VIF value with 4.83 and the smallest Tolerance value with .21. Given that the VIF value was not greater than 10 and the Tolerance value was not less than .1, multicollinearity was not a problem. As a test of the independence of error terms, the Durbin-Watson value was 2.14. Given that the Durbin-Watson value was between the critical values of 1.5-2.5 (Field, 2009), the residuals were normal. As a test of outliers, the largest value of Cook's Distance was .08. Given that the largest value of Cook's Distance was not over 1 (Cook, 1977), outliers were not a problem.

Using the enter method, the OLS regression analysis revealed that the theoretical factors (i.e., attachment, relationship uncertainty, and self-expansion) significantly contributed as 
Table 17

OLS Regression Analysis: Social Networks

Social Networks

\begin{tabular}{cccc}
\hline B & SEB & $\beta$ & $t$ \\
.202 & .103 & .229 & 2.22 \\
-.006 & .125 & -.007 & -.056 \\
.041 & .118 & .037 & .315 \\
-.174 & .104 & -.188 & -1.81 \\
.049 & .143 & .057 & .396 \\
-.050 & .173 & -.057 & -.330 \\
.016 & .199 & .018 & .093 \\
.194 & .141 & .223 & 1.58 \\
.057 & .098 & .067 & .680
\end{tabular}

Note. Unstandardized beta coefficients are bolded if different from zero. 
predictors of individuals' use of the Special Occasions \& Gifts maintenance behavior, $F(9,161)$ $=5.67, p<.001, R^{2}=.251, R_{\text {Adjusted }}^{2} .207$. The analysis further revealed that self-expansion (B $=.372,95 \%$ CI $[.226, .541])$ was a significant unique predictor of individuals' use of the Special Occasions \& Gifts maintenance behavior in back burner relationships. The unstandardized beta coefficients, standard errors, standardized coefficients, and t-values for all theoretical independent variables are reported in Table 18.

To test the assumption of collinearity, the VIF and Tolerance values were examined (Miles, 2005). Definitional Uncertainty had the largest VIF value with 4.83 and the smallest Tolerance value with .21. Given that the VIF value was not greater than 10 and the Tolerance value was not less than .1, multicollinearity was not a problem. As a test of the independence of error terms, the Durbin-Watson value was 2.04. Given that the Durbin-Watson value was between the critical values of 1.5-2.5 (Field, 2009), the residuals were normal. As a test of outliers, the largest value of Cook's Distance was .14. Given that the largest value of Cook's Distance was not over 1 (Cook, 1977), outliers were not a problem.

Using the enter method, the OLS regression analysis revealed that the theoretical factors (i.e., attachment, relationship uncertainty, and self-expansion) significantly contributed as predictors of individuals' use of the Strategic Deceit maintenance behavior, $F(9,162)=2.93, p<$ $.01, R^{2}=.147, R_{\text {Adjusted }}=.097$. The analysis further revealed that behavioral uncertainty $(\mathrm{B}=$ $-.275,95 \%$ CI $[-.521,-.032])$ was a significant unique predictor of individuals' use of the Strategic Deceit maintenance behavior in back burner relationships. The unstandardized beta coefficients, standard errors, standardized coefficients, and t-values for all theoretical independent variables are reported in Table 19.

To test the assumption of collinearity, the VIF and Tolerance values were examined 
Table 18

OLS Regression Analysis: Special Occasions \& Gifts

Special Occasions \& Gifts

\begin{tabular}{cccc}
\hline B & SEB & $\beta$ & $t$ \\
.062 & .084 & .062 & .743 \\
.062 & .101 & .058 & .575 \\
.001 & .096 & .001 & .008 \\
-.085 & .084 & -.081 & -.959 \\
.149 & .116 & .151 & 1.31 \\
.263 & .141 & .267 & 1.89 \\
-.186 & .162 & -.195 & -1.21 \\
-.021 & .115 & -.022 & -.189 \\
.372 & .080 & .384 & 4.82 \\
\hline
\end{tabular}

Note. Unstandardized beta coefficients are bolded if different from zero. 
Table 19

OLS Regression Analysis: Strategic Deceit

Strategic Deceit

\begin{tabular}{cccc}
\hline B & SEB & $\beta$ & $t$ \\
.132 & .090 & .133 & 1.49 \\
.186 & .108 & .177 & 1.63 \\
.223 & .103 & .180 & 1.75 \\
-.065 & .090 & -.062 & -.684 \\
-.271 & .124 & -.276 & -2.23 \\
.025 & .150 & .025 & .168 \\
-.003 & .173 & -.003 & -.015 \\
.120 & .122 & .122 & .995 \\
-.072 & .085 & -.074 & -.871
\end{tabular}

Note. Unstandardized beta coefficients are bolded if different from zero. 
(Miles, 2005). Definitional Uncertainty had the largest VIF value with 4.83 and the smallest

Tolerance value with .21. Given that the VIF value was not greater than 10 and the Tolerance value was not less than .1, multicollinearity was not a problem. As a test of the independence of error terms, the Durbin-Watson value was 2.17. Given that the Durbin-Watson value was between the critical values of 1.5-2.5 (Field, 2009), the residuals were normal. As a test of outliers, the largest value of Cook's Distance was .14. Given that the largest value of Cook's Distance was not over 1 (Cook, 1977), outliers were not a problem.

\section{Hypothesis Testing}

The hypothesis predicted that individuals' use of relational maintenance behaviors would be positively associated with various relational characteristics, including commitment, liking, control mutuality, and relationship satisfaction in back burner relationships. To test this hypothesis, a series of Pearson product-moment correlations were conducted (refer back to Table 9). The hypothesis was partially supported. With the exception of Minimize Intimacy, Relationship Talk, Social Networks, and Strategic Deceit, individuals' use of relational maintenance behaviors (i.e., Flirting \& Humor, Openness, Positivity \& Support, Regular Contact, Shared Activities, and Special Occasions \& Gifts) were positively associated with commitment, liking, control mutuality, and relationship satisfaction in their back burner relationships.

Minimize intimacy was negatively related to relationship satisfaction $(r=-.20, p=.008)$. However, Minimize Intimacy was not significantly related to commitment $(r=-.07, p=.354)$, liking $(r=-.08, p=.257)$, nor control mutuality $(r=-.03, p=.707)$. Relationship Talk was positively related to commitment $(r=.16, p=.032)$, liking $(r=.17, p=.024)$ and control mutuality $(r=.26, p=.000)$. However, Relationship Talk was not significantly related to 
relationship satisfaction $(r=.14, p=.06)$. Social Networks was positively related to liking $(r=$ $.15, p=.036)$. However, Social Networks was not significantly related to commitment $(r=.14, p$ $=.054)$, control mutuality $(r=.12, p=.107)$, nor relationship satisfaction $(r=.10, p=.185)$. Strategic Deceit was negatively related to control mutuality $(r=-.21, p=.005)$ and relationship satisfaction $(r=-.24, p=.001)$. However, Strategic Deceit was not significantly related to commitment $(r=-.05, p=.524)$ nor liking $(r=-.14, p=.058)$.

\section{Summary}

The results of RQ1 indicated that individuals engage in a variety of positive and negative behaviors in order to maintain their back burner relationships. The inductive investigations revealed 10 different categories of relational maintenance behaviors; resulting in the development of the Back Burner Maintenance Behaviors Typology. The results of RQ2 suggested that self-expansion was the strongest theoretical predictor of individuals' use of particular maintenance behaviors, followed closely by relationship uncertainty, and then attachment was the weakest predictor. The hypothesis was partially supported. That is, more than half of the maintenance behaviors (i.e., Flirting \& Humor, Openness, Positivity \& Support, Regular Contact, Shared Activities, and Special Occasions \& Gifts) were each positively associated with all four relational characteristics (i.e., commitment, liking, control mutuality, and relationship satisfaction). However, Minimize Intimacy was negatively associated with relationship satisfaction. Relationship Talk was positively associated with commitment, liking, and control mutuality; no significant relationship emerged for relationship satisfaction. Social Networks was only positively associated with liking. Strategic Deceit was negatively associated with both relationship satisfaction and control mutuality. 


\section{Chapter IV}

\section{Discussion}

In 1983, Ayers claimed that people engage in a variety of strategies to "keep their relationships stable and that those strategies are employed differently depending on whether one's relationship partner desires to have the relationship deteriorate, develop, or stay stable" (pp. 65-66). Scholars have since extended Ayers' work by cultivating over three decades of research on the communicative behaviors, predictive theoretical frameworks, and relational characteristics involved in the relational maintenance process (Canary \& Yum, 2016). These empirical investigations, however, have primarily directed their attention towards the maintenance of romantic relationships, followed by friendships (Dainton et al., 2003; Ogolsky \& Bowers, 2012; Stafford, 2003). However, maintenance scholars have investigated several types of alternative interpersonal relationships, including friends-with-benefits (Goodboy \& Myers, 2008), on-again/off-again relationships (Dailey et al., 2010), and cross-sex friendships with varying levels of romantic intent (Guerrero \& Chavez, 2005). It is necessary to further expand our understanding of the ways in which people maintain alternative types of interpersonal relationships, especially those that contain elements of both romantic relationship and friendships (Guerrero \& Chavez, 2005; Weger \& Emmet, 2009). Therefore, this study decided to focus on the alternative relationship type referred to as back burner relationships.

It is important for the purposes of this study to note Ayers' (1983) assertion that individuals' desired relational state does in fact influence their use of different maintenance behaviors. Recall that Dindia and Canary (1993) defined relational maintenance as the behaviors that partners enact in order to keep the relationship (a) in existence, (b) in a satisfactory condition, (c) in a desired state or condition, or (d) in repair. They urged researchers to clearly 
identify a distinct definition whenever examining the relational maintenance process as it should, in turn, guide the empirical investigation. Given that all close relationships require at least some degree of maintenance (Canary \& Stafford, 1994), it is necessary to collectively explore the motivations, enacted behaviors, and outcomes associated with the maintenance of relationships (Dindia, 2003; Stafford, 2003). For instance, some individuals have reported using openness to escalate the development of relationships (Ayres, 1983), while other individuals have reported using the same maintenance behavior because of approach-motivated relationship goals (i.e., concerned with facilitating positive relational experiences; Weigel et al., 2017).

For that reason, this study employed the third definition, which depicts relational maintenance as the process of "sustaining the present level of certain dimensions or qualities thought to be important in relationship development" (Dindia \& Canary, 1993, p. 164). Since maintenance behaviors are considered to be contextually-dependent (Ragsdale \& BrandauBrown, 2004), the use of this definition enables this contextually-dependent investigation of relational maintenance. Thus, the purpose of Study 1 was to inductively determine the maintenance behaviors utilized by people involved in back burner relationships. To further expand on the plethora of maintenance research, the purpose of Study 2 was to investigate the ways in which back burner maintenance behaviors were associated with commonly investigated theoretical factors (i.e., attachment, relationship uncertainty, and self-expansion) and perceived relational characteristics (i.e., commitment, liking, control mutuality, and relationship satisfaction). This chapter will review the major findings, speculate on theoretical and relational connections, offer general implications for research on relational maintenance and back burners, and, lastly, discuss the limitations and directions for future research. 


\section{Research Question One}

To answer the first research question, individuals were asked to provide up to five examples of behaviors (positive, negative, or a combination of both) that they used to maintain their back burner relationships. As a result of the qualitative analyses, 10 relational maintenance behaviors emerged: Flirting \& Humor, Minimize Intimacy, Openness, Positivity \& Support, Regular Contact, Relationship Talk, Shared Activities, Social Networks, Special Occasions \& Gifts, and Strategic Deceit. These findings led to the development of the Back Burner Maintenance Behaviors Typology (see Table 7). This first half of the RQ1 discussion will review the back burner maintenance behaviors that emerged and compare them to previously identified maintenance behaviors.

\section{Back Burner Maintenance Behaviors Typology}

The 10 categories capture the context-specific behaviors used by people attempting to maintain their back burner relationships. The two behaviors that had been previously identified in Stafford and Canary's (1991) original typology, along with a handful of other maintenance typologies, were openness (Canary et al., 1993; Dainton \& Stafford, 1993; Messman et al., 2000; Stafford et al., 2000) and social networks (Canary et al., 1993; Dainton \& Stafford, 1993; Guerrero \& Chavez, 2005; Stafford, 2011; Stafford et al., 2000). Additionally, Ledbetter's (2013) typology included a similar behavior referred to as shared networks. Although not in Stafford and Canary's typology, Relationship Talk has been identified as maintenance behavior used by partners in romantic relationships (Stafford, 2011), cross-sex friendships with various levels of romantic intent (Guerrero \& Chavez, 2008), and same-sex romantic relationships (Haas \& Stafford, 2005). Ayres' (1983) directness strategy also includes components of Relationship Talk. 
Several other behaviors identified here resemble maintenance behaviors found in previous research. For example, Positivity \& Support emerged as one category within back burner relationships. Positivity, on its own, has been identified in numerous typologies (Canary et al., 1993; Dainton \& Stafford, 1993; Messman et al., 2000; Stafford, 2011; Stafford \& Canary, 1991; Stafford et al., 2000). Positivity is also one of the most frequently used relational maintenance behaviors (Ogolsky \& Bowers, 2012). Support, on its own, has only been identified as a platonic opposite-sex friendship maintenance behavior (Messman et al., 2000). Specific distinctions have been made regarding different types of support as well, as demonstrated by Guerrero and Chavez (2005) who reported instrumental support on its own and combined emotional support with positivity; creating two distinct maintenance behaviors. Stafford et al. (2000) reported advice giving as a maintenance behavior and that type of action could fall under the Positivity \& Support category as well. Considering that back burner relationships are a combination of romantic and friendship characteristics, it is not surprising that the back burner maintenance behaviors reflect aspects of both relationships as well. Flirting \& Humor is another category where the two back burner maintenance behaviors have been identified separately in past. That is, Guerrero and Chavez (2005) identified flirtation as one maintenance behavior, while combining humor with gossip to form another category of behaviors. Humor can be found in several typologies as its own distinct maintenance behavior (Canary et al., 1993; Ledbetter 2013).

Another set of similarities that stem from Guerrero and Chavez's (2005) typology is their routine contact and activity category, which reflects the Regular Contact and Shared Activities identified in this study. Regular Contact also shares similarities with the talk (i.e., engaging regular small talk) and mediated communication (i.e., communicating through channels other 
than face-to-face) maintenance behaviors identified by Dainton and Stafford (1993). Shared Activities is similar to the time together, shared media (Ledbetter, 2013), share activity (Messman et al., 2000), and joint activities (Canary et al., 1993; Dainton \& Stafford, 1993; Haas \& Stafford, 2005) maintenance behaviors. Special Occasions \& Gifts emerged as its own category in this study, but certain aspects have appeared in Dainton and Stafford's (1993) typology. That is, non-ritual activities (e.g., special occasions) were included in the joint activities category, while favors/gifts were included in the positivity category.

This study uncovered two unique maintenance behaviors: Minimize Intimacy and Strategic Deceit. Minimize Intimacy refers to the active avoidance of intimacy-inducing conversations, behaviors, and situations. Avoidance has been previously reported in past typologies (Canary et al., 1993; Dainton \& Stafford, 1993) and labeled as a negative relational maintenance behavior by Dainton and Gross (2008). However, Minimize Intimacy should not automatically be regarded as a negative maintenance behavior considering that high levels of intimacy are not necessarily indicators of high-quality relationships (Duck et al., 1991). Minimize Intimacy also combines aspects of two maintenance behaviors utilized by platonic cross-sex friendships: avoidance and no flirting (Messman et al., 2000). Overall, back burners seem to be using Minimize Intimacy to assuage intimacy from exceeding one's desired level.

Strategic Deceit includes dishonest communication and withholding particular information from the back burner, as well as from those outside of the back burner relationship (e.g., friends, family). Although lying has been labeled as a negative maintenance behavior (Dainton \& Gross, 2008), Strategic Deceit involves more than just lies. Indeed, participants reported engaging in lies of commission (e.g., telling the back burner they stayed home on a Friday night when in fact they went out with their friends) and lies of omission (e.g., not sharing 
with their back burner that they hung out with a former significant other). People also used this strategy as a way to avoid potential conflict triggers, which is similar to Guerrero and Chavez's (2005) avoidance of negativity and talk about outside romance behaviors. It is important to note that Strategic Deceit is not just directed at the back burner. Individuals reported purposefully deceiving friends, family members, and even extradyadic romantic partners in order to maintain their back burner relationships. The range of motivations and actions behind individuals' use of Strategic Deceit primarily distinguishes this maintenance behavior from others similar to it.

This first half of the RQ1 discussion reviewed the back burner maintenance behaviors that emerged and compared them to previously identified maintenance behaviors. Overall, this inductively-developed Back Burner Maintenance Behaviors Typology, in part, includes several maintenance behaviors that have been deemed cross-contextually important (e.g., Openness and Social Networks; Ogolsky \& Bowers, 2012). This typology also offers two new behaviors specifically used in back burner relationships (i.e., Strategic Deceit and Minimize Intimacy). As a result, more accurately capturing the unique relational experiences between back burners. The second half of the RQ1 discussion will go into the implications of these findings. Specifically, the use of these context-specific behaviors suggests that people use these maintenance behaviors to sustain their desired casual, yet connected back burner relationship.

To keep the back burner relationship casual, individuals reported that they keep their communication informal. The use of Regular Contact is one way to achieve this relational maintenance goal. Individuals reported regularly engaging in surface-level communication with their back burners, often asking how they are doing, how their day is going, what their plans are, and what they are doing in between classes. The casual frequent communication also seems to be low-pressure and light-hearted in nature, which is not surprising given that casual relationships 
are typically not highly demanding (Dubé et al., 2017; Wentland \& Reissing, 2011). Social Networks are used as a way for back burners to hang out in casual settings, especially when they share mutual friends. That is, Social Networks can function as a facilitator for the back burners by creating situations in which the two can spend time together, as mentioned by a participant who stated that "Having a lot of mutual friends helps our paths to cross more often" (371). The use of these two behaviors seems to be less-strategically maintaining the casual state of the relationship in comparison to the more tactical maintenance behaviors, such as Strategic Deceit and Minimize Intimacy.

Canary and Stafford (1994) stated that maintenance behaviors are considered strategic when people use these behaviors at a higher level of consciousness for the purpose of achieving a certain relational goal. It appears that Strategic Deceit is enacted as a way to keep things casual between back burners. For example, one might lie about hosting a birthday party because they do not want to introduce their back burner to their friends or family yet because it could be interpreted as a relational turning point (Baxter \& Bullis, 1986). People also use maintenance behaviors to communicate the relational state to those outside of the relationship (Duck, 1994). Others engaged in Strategic Deceit in order to keep things casual with their back burner [e.g., "He has no idea how I feel about him and my future intentions" (261)], while some used it to maintain the casual public perceptions of those outside of the back burner relationship [e.g., "Keeping it a secret" (71)]. Those who are simultaneously involved in a back burner relationship with one person and an extradyadic romantic relationship with another person also use Strategic Deceit, but for different reasons [e.g., "Avoid seeing each other when with our other partner we are in a relationship with" (358)].

In addition to Strategic Deceit, Minimize Intimacy also contains components of strategic 
maintenance. Many participants indicated that they purposefully avoid intimacy-inducing communication, behaviors, and situations with their back burners. For example, individuals resisted showing affection, avoided using pet names, and circumvented discussions regarding their relational status in order to maintain the current level of intimacy. People also avoid potentially-intimate situations with their back burners, such as being alone, and some even said they avoid going to each other's homes as to not provide opportunities for relational intensification (Tolhuzien, 1989). It is important to note that the meanings and desires for intimacy differ across relationship types (Monsour, 1992) and stages of relationship development (Knobloch, 2007; Knobloch et al., 2006). Relationship stability can occur at different levels of intimacy, but changes in intimacy still occur even in stable relationships (Frost, 2012). Thus, Minimize Intimacy should not necessarily be considered a de-escalation or escalation maintenance strategy, per say, as it is primarily concerned with stabilizing a desired balance of intimacy.

In addition to their desires to keep the relationship casual, back burners also use these behaviors to stay considerably connected to each other in a variety of ways. Social Networks, for example, can bring about situations that allow back burners to spend time together, while also maintaining both interpersonal and public perceptions of the casual nature of their relationship. This seems to be especially true when back burners share mutual friends ["Having a lot of mutual friends helps our paths to cross more often" (371)]. Through Special Occasions and Gifts, back burners connect on birthdays, holidays, and major life events (e.g., graduation). Back burners also connect when they engage in Shared Activities, such as grabbing lunch in-between classes, working out together, and going to concerts. Similar to friendships and both geographically-close and long-distance romantic relationships (Dainton \& Aylor, 2001; 
Ledbetter, 2017; Ledbetter \& Kuznekoff, 2012), back burners connect through shared online activities as well (e.g., gaming, watching television). It has been argued that spending time together and staying connected are both critical to maintaining romantic relationships and friendships (Dainton et al., 2003; Girme et al., 2016; Ledbetter, 2013). The same seems to be true for back burner relationships. Thus, the emergence of these maintenance behaviors extends support for the collective importance of connection and communication to maintenance within the back burner relationship context.

Recall that communication has been deemed central to the maintenance process, as relationships cannot be sustained unless partners communicate (Canary \& Stafford, 1994; Dindia, 2003). Communication is also fundamental to back burners relationships, which cannot exist without sustained communication between both partners whether it occurs face-to-face or through communication technologies (Dibble \& Drouin, 2014; Dibble et al., 2015; Dibble et al., 2018). While this study further highlights the crucial role of communication, it also draws attention to the less frequently discussed maintenance that occurs through mundane, everyday talk (Duck et al., 1991). It has been argued that maintenance scholars should indeed investigate partners' day-to-day communication and consider the boring stabilities that emerge (Duck, 1994). That is, the incorporation of everyday trivial talk is essential to the creation, cocreation, and maintenance of relationships (Candel \& Turliuc, 2019; Duck et al., 1991). Yet, just because it might be considered mundane or insignificant, it does not mean that significant things are not occurring through everyday talk (Duck et al., 1991; Rodriguez, 2014).

The importance of everyday talk is represented here in the Regular Contact maintenance behavior. In this study, the majority of people frequently communicated with their back burners, especially given that majority of participants communicated with their back burners on a daily or 
weekly basis. This is not unique to this study as it reflects the reported average frequency of daily (28.8\%) and weekly (50.9\%) communication with a back burner from previous studies (Borzea \& Dillow, 2017; Dibble et al., 2015). The frequent communication between back burners is often mundane, such as asking "Hey are you doing?" Even though some may just consider everyday talk to be trivial and unimportant, a simple text message asking a back burner how their day is going can be comforting given that the use of maintenance behaviors between friends were negatively associated to feelings of loneliness (O'Brien, 2014). Moreover, Regular Contact is contrary to aspects of the relationship enhancement monogamy maintenance behavior (e.g., "Deleted their phone number", p. 216), which is intended to decrease one's attraction to an alternative partner (Lee \& O’Sullivan, 2018). These findings are consistent with Duck's (1994) claim that "a multitude of everyday communicative interactive behaviors define and redefine the relationship" (pg. 52).

Along with the high frequency of communication, it is important to discuss the popularity of particular channels used by back burners. Indeed, the emergence of social media and computer-mediated communication has led scholars to consider the functional role of media use in the relational maintenance process (Ledbetter, 2017; McEwan \& Horn, 2016). It is not surprising that both romantic partners and friends reported incorporating media and technology into their maintenance behaviors (Houser et al., 2012; Ledbetter, 2017; McEwan et al., 2014; McEwan \& Horn, 2016). Communication technologies provide additional channels through which partners can communicate faster and more easily, which, in turn, helps promote healthy relational functioning (Miller-Ott et al., 2012; Ramirez et al., 2007). In accordance with previous back burner research (Dibble \& Drouin, 2014; Dibble et al., 2015; Dibble et al., 2018), this study provides additional evidence to suggest that contemporary communication technologies are the 
primary channels used by back burners. Moreover, researchers have demonstrated that variations of content-specific and medium-specific aspects of enacted maintenance behaviors impact relationships in different ways (Ledbetter, 2010; McEwan et al., 2014). Texting and social media emerged here as the top two most frequently used channels for back burner communication, occurring on a daily or weekly basis. This, however, is not unique to the current study. Prior studies have also reported texting as the most common way that back burners communicate, followed by social media (Dibble \& Drouin, 2015; Dibble et al., 2018).

The regular communication between back burners seems to be both direct and indirect. For instance, individuals reported directly connecting with back burners online by liking posts, commenting on photos, and sending direct messages. These actions reflect maintenance behaviors enacted on Facebook (Dainton, 2015; Dainton \& Berkoski, 2013; McEwan et al., 2014). Furthermore, the content of their conversations ranges from just checking in to discussing topics that they both enjoy [e.g., "Messaging them things that would interest them and that made me think of them" (311)]. The role of Regular Contact, in part, is concerned with the frequency of back burners' communicative engagement. Many participants also reported how they try to initiate and entice conversations. For example, people post stories on social media to gain attention from certain individuals (Pennington \& Hall, 2021; Triệu \& Baym, 2020), which was reported by numerous participants in this study [e.g., "I post cute pictures that I know he will swipe up and start a conversation with me" (54)].

However, it should be noted that computer-mediated communication does not always serve a prosocial function for maintaining relationships, especially when partners are media dependent (Chory \& Banfield, 2009) or less committed to the relationship (Rabby, 2007). As one example, individuals' use of SNSs to spy on a partner has been identified as a negative 
relational maintenance behavior (Dainton \& Gross, 2008; Tokunaga, 2016). Yet, individuals here reported that one way to indirectly stay connected with their back burners is to survey their social media posts across different platforms, while also purposefully posting things to entice the back burner to initiate a conversation [e.g., "Post pictures on my Instagram story so I know when they look at it" (26)]. Another assumption that should not be made is that all social media outlets are used the same across relationship types when, in fact, they serve different functions and are motivated by different reasons (Alhabash \& Ma, 2017). As a result, Dibble and colleagues (2018) made a distinction between the different social media outlets (i.e., Facebook, Instagram, Twitter, and Snapchat) in regards to their relational maintenance utility in back burner relationships. Although Facebook still remains popular, research has revealed that Snapchat and Instagram have become much more popular among young adults (Alhabash \& Ma, 2017; Vaterlaus et al., 2016). The qualitative results here draw attention to the useful and popular role of Snapchat in back burner relationships.

Snapchat is a distinct social media application where users can communicate by sharing photos and videos that can also contain text and special effects -- known as 'snaps' -- that vanish after 24 hours (Makki et al., 2018). The prevalent use of Snapchat has grown among college students with over 75\% using it on a daily basis (Alhabash \& Ma, 2017; Makki et al., 2018). Connecting through Snapchat permits frequent, untraceable, and casual communication between back burners. You do not even have to exchange phone numbers to become friends on Snapchat. Snapchat has also been characterized as less intense and requires less effort in comparison to Facebook and Twitter (Alhabash \& Ma, 2017). Although Snapchat is commonly used to by young adults to maintain relationships, this maintenance communication also influences relational development (Makki et al., 2018). This may explain the prominent use of Snapchat 
among back burners given that they are in a constant state of potential relationship escalation (Dibble et al., 2015). In sum, individuals' varied usage of these maintenance behaviors signifies the importance of staying casual and regularly connected within back burner relationships.

\section{Research Question Two}

The second research question was interested in the connections between theoretical factors and back burners' enactment of maintenance behaviors. To date, there has been minimal theoretically-driven research on the maintenance of alternative types of interpersonal relationships (i.e., those outside the traditional boundaries of committed romantic relationships; Wentland \& Reissing, 2011). However, consistent with prior research on romantic relationships and friendships (e.g., Canary \& Zelley, 2000; Dainton, 2003, 2011; Forsythe \& Ledbetter, 2015; Ledbetter, 2013), the results of this study further support the premise that various theoretical factors do indeed function as predictors of enacted maintenance behaviors. Overall, the findings revealed individuals' attachment style, perceived relationship uncertainty, and experienced selfexpansion collectively and uniquely predict back burners' relational maintenance.

\section{Attachment}

As an extension of prior research connecting attachment styles to individuals' maintenance of romantic relationships (Dainton, 2007, 2011; Goodboy \& Bolkan, 2011; Goodboy et al., 2017; Guerrero \& Bachman, 2006; Pistole et al., 2010; Simon \& Baxter, 1993) and friendships (Bippus \& Rollin, 2003), the present findings indicated that attachment style also predicts individuals' use of several maintenance behaviors in back burner relationships. In comparison to the relationship-specific variables used this study (i.e., relationship uncertainty and self-expansion), attachment style offers a self-oriented perspective (Bartholomew \& Horowitz, 1991). Borzea and Dillow (2017) first demonstrated the associations between 
individual factors (e.g., sociosexual orientation and sensation seeking) and a person's likelihood of engaging in a back burner relationship. This investigation of attachment offers a self-oriented perspective on the influence of individuals' attachment on their use of particular maintenance behaviors.

Specifically, the findings revealed that preoccupied attachment predicted individuals' use of the Minimize Intimacy back burner maintenance behavior. Since people with a preoccupied attachment style often worry that their partner is going to leave or upset them (Bartholomew \& Horowitz, 1991), these anxieties may motivate them to avoid intimacy-inducing situations. Whereas secure individuals are not plagued with the fears of rejection or being hurt during intimate interactions (Guerrero \& Bachman, 2005), preoccupied individuals might habitually assume that the back burner does not want to escalate the relationship with them; potentially motivating them to engage in Minimize Intimacy as a defense mechanism. People with a preoccupied attachment may use this maintenance behavior to stabilize the current level of intimacy until they have more certainty about the back burners' commitment and desired levels of intimacy. Given that preoccupied people typically do desire intimacy and closeness with others (Bartholomew \& Horowitz; Collins \& Feeney, 2004), it is likely that they are attempting to minimize intimate interactions even when they do want to be intimate with their back burner. Despite that their heavy reliance on relational partners to sustain their own positive self-image, a lack of predictability regarding a partners' behaviors and intent often leads preoccupied individuals to engage in controlling behaviors to combat these feelings (Bartholomew, 1990; Guerrero, 1996). Consequently, their fears of being vulnerable and potentially rejected may further explain preoccupied individuals' use of this more strategically-enacted maintenance behavior. 
Participants in this study reported a variety of relational, situational, and extradyadic reasons as to why they engage in Minimize Intimacy. In regards to the relational reasons, people indicated that they tried to maintain their desired levels of intimacy because they are not emotionally ready for a committed relationship, unsure of the back burner's feelings about escalating intimacy or the relationship, don't want to lead their back burner on, or simply just do not want to escalate the relationship right now for no specific reason. It could also be that a person is just happy being single while also receiving the benefits from their back burner relationship (Girme et al., 2016). In regards to situational factors, people reported engaging in Minimize Intimacy because they are too geographically distant or too busy with school, work, or other responsibilities to be involved in a committed relationship at the present time [e.g., "School is super busy, idk how I'm going to have time for anything else" (004)]. In regards to extradyadic factors, people reported actively trying to minimize intimacy because they are involved in an extradyadic romantic relationship, deciding between more than one back burner, or do not want their social networks to know about the back burner status of their relationship. It is crucial to note that the use of the Minimize Intimacy maintenance behavior is not an automatic indicator that the person does not desire intimacy.

The current findings also revealed that secure attachment predicted individuals' use of the Relationship Talk back burner maintenance behavior. People with a secure attachment are typically better equipped to handle the uncomfortableness and uncertainty that often encompass this particular type of talk (Bartholomew \& Horowitz, 1991; Guerrero, 1996; Theiss \& Nagy, 2013). As a result, secure back burners may be less anxious to initiate or engage in conversations about the current and future state of the relationship. Given that relationship talk is often more influential when partners' report lower levels of intimacy (Knobloch et al., 2006), secure 
individuals might also be using Relationship Talk as a way to portray their desire and readiness to escalate the relationship. Indeed, this particular type of talk can be used to directly communicate desires for relationship escalation through future-oriented communication (Baxter \& Bullis, 1986; Knobloch et al., 2006; Thompson-Hayes \& Webb, 2004).

In addition to Relationship Talk, secure attachment also predicted individuals' use of the Social Networks back burner maintenance behavior. Similar to prior research (Dainton, 2007; Guerrero \& Bachman, 2006; Pistole et al., 2010), this finding suggests that people with a secure attachment feel more comfortable and confident integrating their back burners into their social networks and vice versa. A potential explanation may be that secure individuals are not excessively worrying when together with their back burner in social settings, which is contrary to preoccupied individuals (Collins \& Feeney, 2004; Guerrero \& Bachman, 2005). For instance, personal embarrassment is one reason as to why people conceal their friends-with-benefits from their social networks (Hughes et al., 2005). Considering secure individuals' assured sense of self (Bartholomew \& Horowitz, 1991), they are likely less concerned with the issue of personal embarrassment when incorporating their back burners into their social circles. Taken together, a secure attachment seems to help people maintain prosocial aspects of their back burner relationships.

\section{Relationship Uncertainty}

Many alternative interpersonal relationships are plagued with experiences of relationship uncertainty (Dibble et al., 2018; Guerrero \& Chavez, 2005). This study extends prior research connecting relationship uncertainty to individuals' maintenance of romantic relationships (Dainton, 2011; Theiss \& Knobloch, 2014), friendships (Forsythe \& Ledbetter, 2015), cross-sex friendships (Guerrero \& Chavez, 2005; Weger \& Emmett, 2009), and on-again/off-again 
relationships (Dailey et al., 2010). The current findings revealed that behavioral uncertainty predicted individuals' use of the Positivity \& Support back burner maintenance behavior. Interestingly, this is contrary to Weger and Emmett's (2009) claim that cross-sex friends who experience behavioral uncertainty are less likely to dedicate the time and effort needed to maintain the relationship. Given that that relational partners begin to mirror each other's use of maintenance behaviors over time (Dainton, 2003; Dainton \& Stafford, 1993), one explanation may be that individuals are trying to be pleasant and offer support with hopes of their back burner reciprocating such behaviors. Indeed, reciprocity has emerged as a significant predictor of individuals' relational maintenance (Dainton, 2011).

Of specific interest to this finding, prior studies have indicated that being positive and pleasant reflects positive perceptions of one's self and one's partner (Pistole et al., 2010). Perhaps back burners are still optimistic about the overall relationship if they're engaging in Positivity \& Support, regardless of their perceived behavioral uncertainty. Considering that perceptions of a partner's enacted maintenance behaviors have been argued to be the most consistent predictor of individuals' own use of maintenance behaviors (Dainton \& Stafford, 2000), individuals' back burners may also be enacting Positivity \& Support. Moreover, people who use emotionally supportive and positive relational maintenance behaviors are doing more than just communicating with a partner in a positive manner; they are also indicating that they are emotionally available (Guerrero \& Chavez, 2005). For example, people increase their use of positivity in cross-sex friendships containing some degree of romantic intent as a way to demonstrate their readiness to escalate the relationship (Guerrero \& Chavez, 2005). However, providing support can backfire when drawing attention to the other person's stressful issues because it can heighten the salience of these issues, as well convey that the other person is 
incapable of handling the stressors on their own (Bolger et al., 2000). Therefore, just because a person is engaging in Positivity \& Support it does not necessarily mean that they are successful attempts, potentially explaining why these individuals are still experiencing behavioral uncertainty.

In addition to Positivity \& Support, behavioral uncertainty also predicted individuals' decreased use of the Strategic Deceit back burner maintenance behavior. These findings may be attributed to relational length; people might not know their back burner well, or long, enough to be certain about behavioral expectations and norms. For example, increased romantic desires and a lack of relational length heightened cross-sex friends' perceptions of definitional uncertainty (Weger \& Emmett, 2009). As one might anticipate, early stages of courtship often contain relational uncertainty (Knobloch, 2007; Solomon \& Knobloch, 2004). Thus, if back burners are uncertain about which basic behaviors are acceptable to enact, it is likely that they do not have enough information to even attempt to engage in strategically deceptive behaviors. An alternative explanation may be that people are not as concerned with engaging in Strategic Deceit. Although relational uncertainty is often shown to be detrimental to romantic relationships, it can also promote excitement between partners (Baxter \& Montgomery, 1996; Knobloch \& Solomon, 2002, 2003). Thus, on one hand, the uncertainty itself might diminish back burners' use of Strategic Deceit. On the other hand, people might be enjoying their back burner experiences to such an extent that they are not as concerned with the impact of behavioral uncertainty.

Future uncertainty emerged as a predictor of individuals' decreased use of the Regular Contact back burner maintenance behavior. This is consistent with prior research indicating that relationship uncertainty is connected to diminishing interpersonal communication (Knobloch \& 
Carpenter-Theune, 2004). One explanation may be that people are experiencing a dialectic tension of wanting to be certain about the future of the relationship, while also not wanting to disrupt the frequent interactions with their back burners (Baxter \& Erbert, 1999). When individuals are uncertain about the future predictability of the relationship, they might react to this dialectic tension by minimizing their use of the contact behavior (e.g., looking for ways to initiate conversations and increase contact; Baxter \& Erbert, 1999). However, given the positive associations between individuals' relationship self-efficacy and use of prosocial maintenance behaviors (Weiser \& Weigel, 2016), Regular Contact may be underutilized when people have doubts about their own communicative abilities in addition to doubts about the future of the relationship.

Another potential explanation is that a person might not be frequently communicating with the other as a way to sustain, and not escalate, the current status of the back burner relationship. For instance, cross-sex friends who desire a romantic relationship actively try to interact with the friend more frequently (Weger \& Emmett, 2009). Additionally, Dibble and colleagues (2015) suggested that one way in which one-night stands can escalate to a back burner is to open the line of communication. Given the fact that not all back burners want the relationship to escalate in the present time (Dibble et al., 2015), these particular individuals may decrease their use of Regular Contact as a way to try and make the relationship more stable. After all, the use of proactive maintenance behaviors, or lack thereof, can be the source of both relationship changes and stability (Guerrero et al., 1993). Specific to back burners who are simultaneously involved in an extradyadic relationship, they might reduce their use of Regular Contact when experiencing future uncertainty to try and stabilize the back burner relationship in order to also maintain their extradyadic relationship. For example, Regular Contact appears to be 
contrary to the proactive avoidance monogamy maintenance behavior (e.g., "Avoided getting to know this person better"; Lee \& O'Sullivan, 2018, p. 216). Considering that monogamy maintenance behaviors are enacted by people in committed relationships as a way to handle attraction to extradyadic others (Lee \& O'Sullivan, 2018), these individuals might avoid regularly contacting their back burner as a way to obstruct the path to infidelity.

In addition to Regular Contact, future uncertainty also emerged as a predictor of individuals' decreased use of the Minimize Intimacy back burner maintenance behavior. As mentioned with Strategic Deceit, a potential explanation may also involve a lack of information. That is, if people are uncertain about the future status of the relationship, they may also be uncertain about their own relational goals (Knobloch \& Solomon, 2005). For example, people with romantic interests in a cross-sex friend interact more frequently when they are more certain about their friends' future romantic intentions (Weger \& Emmett, 2009). Thus, individuals who are not confident in the trajectory of the relationship might not utilize this maintenance behavior because of unclear objectives.

Pertinent to these findings, Minimize Intimacy seems to reflect a more conscious attempt to maintain desired intimacy-related aspects of the back burner relationship. As such, it is necessary to discuss the various reported reasons for engaging in Minimize Intimacy. Some participants reported that they purposefully avoided putting themselves in potentially-intimate situations because of a lack of self-control around each other. For example, the Minimize Intimacy behavior can be enacted as a way to weaken individuals' temptations to engage in more emotionally and physically intimate acts with their back burner (Lee \& O'Sullivan, 2018). Other individuals reported that they purposefully minimized intimacy in public settings to deter others' perceptions of the nature of their relationship. Specific to those involved in extradyadic 
relationships, individuals might utilize this maintenance behavior to justify that their involvement with the back burner is not considered infidelity (Lee \& O'Sullivan, 2018).

Also similar to Strategic Deceit, it may be that back burners' enjoyable and exciting relational experiences supersede their concerns regarding the uncertainty surrounding the future of the relationship, in turn, diminishing their desires to reduce intimacy. These fun and easygoing relational experiences may lower individuals' need for, or attention given to, minimizing intimacy with their back burner. Back burners might simply be enjoying the moment and, as a result, less concerned with answering questions regarding the future of the relationship, at least in the present time. Taken together, these findings suggest that relationship uncertainty may not necessarily always be a negative experience within the context of back burner relationships (Weigel et al., 2011).

\section{Self-Expansion}

Since the most common way individuals self-expand is through close relationships (Aron et al., 2013), it is not surprising that relational maintenance scholars have begun to recognize the utility of a self-expansion theoretical approach (Ledbetter, 2013; Ledbetter et al., 2010; Ledbetter et al., 2013). As an extension, this study demonstrated the pervasiveness of experienced selfexpansion in back burner relationships and how those experiences influence maintenance. Specifically, the findings indicated that self-expansion predicted individuals' use of the Flirting \& Humor, Shared Activities, Regular Contact, Openness, Special Occasions \& Gifts, and Positivity \& Support back burner maintenance behaviors. Notably, self-expansion emerged as a more consistent predictor of back burner maintenance behaviors than attachment and relationship uncertainty.

The motivation to self-expand is, in part, driven by the desire to have experiences that 
generate novelty, opportunity, competence, adventure, curiosity, or risk (Aron et al., 2013). For instance, Flirting \& Humor is one way to continue exciting aspects of the relationship through fun and playful interactions, while also highlighting similarities between back burners. This maintenance behavior can also function as a subtle, light-hearted way for back burners to flirt, even if they are trying to monitor their public display of behaviors (O’Meara, 1989). Back burners' engagement in Shared Activities can function as another way to self-expand. Selfexpanding activities are defined as "activities which are exciting and stimulating because they provide new resources or experiences" (Reissman et al., 1993, p. 245). Engagement in activities that elicit such experiences are considered self-expanding activities, as they provide spontaneous and novel opportunities to expand one's self-concept (Aron \& Aron, 1997; Aron et al., 2000; Graham, 2008; Strong \& Aron, 2006). Given that individuals tend to view both their relationship and their romantic partner more positively after engaging in joint activities (Reissman et al., 1993), individuals' engagement in Shared Activities plays a prosocial role in back burner relationships. However, the experience of self-expansion changes throughout the trajectory of a relationship (Aron et al., 2002; Sheets, 2014; Strong \& Aron, 2006; Tucker \& Aron, 1993). Individuals often begin a relationship with self-oriented motives (e.g., "I want to obtain your resources") that tend to transition into more relationship-oriented motives (e.g., "I want to maintain our resources") as the relationship progresses and partners become closer (Aron \& Aron, 1997). Similarly, self-expanding activities that often occur during the initiation of a relationship, such as frequent self-disclosures, are not typically considered self-expanding once the partners have established a close relationship (Aron et al., 2002). Thus, relationship length may also play another role here in regards to back burners' experienced self-expansion and enacted maintenance behaviors. Not all shared activities, however, enhance the quality of 
romantic relationships. For instance, shared activities can decrease relationship satisfaction if either partner experiences stress because of the activity (Girme et al., 2014). Engaging in challenging activities (e.g., learning to play a new sport with your partner) has resulted in heightened relationship satisfaction and love (Aron et al., 2000), whereas activities that exceed individuals' capabilities are not self-expanding because individuals lose confidence when perceived self-efficacy is weakened (Graham \& Harf, 2008). Moreover, just increasing the amount of time that couples spend together does not produce the relational benefits associated with shared time spent together engaging in self-expanding activities (Aron \& Aron, 1997; Reissman et al., 1993). Therefore, this highlights the notion that the self-expanding aspect of back burners' shared activities is beneficial more so than the activity itself.

Despite the fact that nonleisure activities are not typically a source of relational selfexpansion, Graham (2008) argued that mundane joint activities still have the potential to facilitate self-expanding experiences. Graham's argument is apparent here as the findings revealed that self-expansion predicted individuals' use of the Regular Contact back burner maintenance behavior. Although self-expanding activities, for the most part, have primarily been characterized as novel and optimally challenging behaviors (Aron et al., 2000; Reismann et al., 1993), trivial joint activities can still be self-expanding because of the frequent nature of this back burner maintenance behavior (Aron et al., 2002; Graham, 2008). That is, everyday interactions function as a way in which individuals form perceptions regarding a partner's potential to offer self-expansion opportunities in the future (Sprecher et al., 2015). Moreover, previous studies have indicated that maintenance behaviors are more effective, as well as more noticed by partners, when enacted regularly (Canary et al., 2002). Combined, these findings suggest that self-expanding activities and everyday talk are both salient to the maintenance of 
back burner relationships.

Self-expansion also predicted individuals' use of the Openness back burner maintenance behavior in this study. Openness is different than Regular Contact here in regards to the depth and breadth of information. In some ways, this finding may reflect rapid self-expansion between back burners. The experience of rapid self-expansion typically occurs during the initial development stages of a relationship (i.e., when individuals get to know a new partner and begin to develop closeness; Aron et al., 1995). During this time, communication between romantic partners is frequent and often contains intimate self-disclosures (Aron \& Aron, 1986). For instance, engaging in self-disclosure is an example of one way in which people create unique experiences that are only shared between partners (Aron et al., 1997). Partners also engage in new or uncharacteristic activities for them, such as trying new food or engaging in physical activities such as hiking (Aron \& Aron, 1997; Aron et al., 2001; Aron et al., 2005; Aron et al., 1997). As individuals obtain personal information and become increasingly familiar with one another, acquired aspects of a partner's self-concept are integrated rapidly into one's own selfconcept (Aron \& Aron, 1997; Aron et al., 1991; Weidler \& Clark, 2011). Thus, rapid selfexpansion may be an exhilarating and open experience for back burners that, in turn, influences their use of maintenance behaviors.

Every close relationship has the potential to offer something new or interesting, from learning a set of desired skills to gaining different perspectives on life (Aron et al., 2001). For example, novelty has been identified as one of the central characteristics of self-expanding activities because spending time doing new activities expands the self since it allows both partners to acquire new experiences and new information (Aron et al., 2001). Thus, Special Occasions \& Gifts can offer self-expanding opportunities as well. For example, back burners 
reported attending weddings and date parties. These special, and potentially novel, events can expand individuals' cultural experiences and perspectives.

This study also revealed that self-expansion predicted individuals' use of the Positivity \& Support back burner maintenance behavior. It is important to note that self-expansion theory takes a communally-oriented perspective (i.e., focuses on the greater good of relationships rather than individual benefits), which means engaging in other-oriented maintenance behaviors (Aron et al., 2013; Ledbetter, 2013). When people interact with their partners from an other-oriented approach, they are seen as less selfish and better able to focus their energy more towards actually helping and supporting their partners (Neff \& Pommier, 2012). Indeed, prior research has provided significant evidence suggesting prosocial associations between the communal strength of a relationship and the use of maintenance behaviors in both friends and romantic relationships (Ledbetter, 2013; Mattingly et al., 2012). Thus, it may be that experiences of self-expansion are the result of a person's communal approach to their back burner relationship, which then influences back burners' positive and supportive connections through the use of Positivity \& Support.

As aforementioned, Aron and Aron (1986) claimed that optimal relationships are sustained by partners who are able to diminish feelings of boredom in the relationship by discovering ways to continue self-expanding experiences. However, they argued that optimal relationships also provide additional future opportunities for self-expansion. The current findings demonstrated that many participants have already self-expanded with their back burner. As such, the use of back burner maintenance behaviors may also function as an indicator of future opportunities for self-expansion within relationships (Mattingly \& Lewandowski, 2014). For instance, people take into account the extent to which they believe a potential relationship will 
offer opportunities for self-expansion and the likelihood of actually expanding the self when contemplating whether or not to initiate a romantic relationship (Aron \& Aron, 1986; Mattingly et al., 2012). As such, people are more attracted to potential partners who offer self-expansion opportunities than potential partners who seem to lack opportunities for self-expansion (Aron \& Aron, 1986; Sprecher et al., 2015). Therefore, individuals who have experienced self-expansion may incorporate these experiences in the ways in which they maintain their back burner relationships.

Taken together, it appears that self-expansion is a salient experience for back burners. While maintaining the fun aspects, individuals are also minimizing the less desirable aspects of more serious, committed relationships. This notion is similar to the avoidance of negativity maintenance behavior, which is characterized by its purposeful avoidance of unfavorable experiences (i.e., conflict and criticism) within a relationship (Guerrero \& Chavez, 2005). It seems as if they want their conversations to be a positive part of each other's long, and likely stressful, day, as illustrated by one participant who said "We both are able to talk casually without any conflict” (417). Moreover, relationships with minimal opportunities for selfexpansion have been characterized as low-quality relationships (Aron et al., 2001; Aron et al., Lewandowski \& Ackerman, 2006; Lewandowski \& Bizzoco, 2007). Thus, individuals who do not perceive to have future opportunities for self-expansion with their back burners may not want to escalate the relationship or continue to maintain the relationship. Collectively, these findings suggest that the exciting, educational, and novel self-expanding experiences may be more important to back burners than the status of the relationship. 


\section{Hypothesis}

Canary and Stafford (1994) claimed that "all relationships require maintenance behaviors or else they deteriorate" (p. 7). Maintenance investigations have primarily focused on four relational characteristics (i.e., commitment, liking, control mutuality, and relationship satisfaction). Prior research has revealed significant connections between individuals' enacted maintenance behaviors and perceptions of these relational characteristics (Canary et al., 2002; Canary \& Stafford, 1992; Dindia, 2003; Oglosky \& Bowers, 2012). The findings in this study indicated that the hypothesis was partially supported. Specifically, individuals' use of six back burner maintenance behaviors (i.e., Flirting \& Humor, Openness, Positivity \& Support, Regular Contact, Shared Activities, and Special Occasions \& Gifts) were each positively associated with all four relational characteristics investigated in this study (i.e., commitment, liking, control mutuality, and relationship satisfaction). The findings also revealed unique associations with individuals' use of particular maintenance behaviors that will be discussed below.

In regards to the maintenance behaviors that were positively associated with all four relational characteristics, one potential explanation for these findings is that back burner relationships reflect the rewarding aspects of having romantic feelings towards an individual, but without the physical involvement or emotional labor that can characterize a serious dating relationship. For example, positivity as a maintenance behavior is common among friendships and romantic relationships (Dainton et al., 1994; Stafford \& Canary, 1991), but individuals' use of the Positivity \& Support maintenance behavior involves more than just communicating with a back burner in a positive manner; partners are also portraying that they are emotionally available (Guerrero \& Chavez, 2005). This maintenance behavior also includes giving advice, which has been positively associated with all of the relational characteristics, except commitment 
(Stafford, 2011; Stafford et al., 2000). A back burner, then, might function not only as someone to confide in during times of stress, but also as someone who is optimistic and pleasant to be around. Thus, reiterating the prosocial relational outcomes connected to these maintenance behaviors.

The use of the Flirting \& Humor maintenance behavior reflects the existence of playful banter between back burners, which has been previously associated with relational quality in romantic relationships (Hall, 2017). It is also possible that back burners like using humor as a way to innocently flirt, especially if they are involved in an extradyadic relationship (Lee \& O'Sullivan, 2018; O'Meara, 1989); as were 55.6\% of the participants in this study. The Special Occasions \& Gifts maintenance behavior was also positively associated with each relational characteristic. Given that sharing tasks did not emerge as a back burner maintenance behavior, as it has for romantic relationships (e.g., Stafford \& Canary, 1991), back burners may be more satisfied with having a back burner to call if they need a date to a wedding rather than one that can help them accomplish daily responsibilities.

The findings connecting Shared Activities with relational characteristics might be the result of back burners simply enjoying their time spent together doing different activities (Reissman et al., 1993). The more individuals interact, the more opportunities they have to selfdisclose (e.g., Openness), which can lead to back burners discovering more similarities that they share (Duck, 1994). Given that dating relationships contain more relationship excitement as compared to cohabitating relationships and marriages (Malouff et al., 2015), it may be that experienced self-expansion through particular behaviors further highlights the importance of liking and other quality indicators specific to back burner maintenance. Although Regular Contact might not be as exciting in comparison to others, the current findings highlight the 
importance of everyday talk (Duck et al., 1991), as demonstrated by the positive associations with relational quality indicators. Given that both romantic partners and friends have incorporated media and technology into their maintenance behaviors (Houser et al., 2012; Ledbetter, 2017; McEwan et al., 2014; McEwan \& Horn, 2016), it is not surprising that back burners most frequently engaged in Regular Contact via communication technologies (e.g., texting and Snapchat). These casual interactions can provide a reason for the back burners to communicate and keep each other updated with the latest events, but also be a way to avoid communication about their relationship by shifting the focus outwards to other topics.

Collectively, these aforementioned findings align with the insight that individuals attempt to maintain prosocial characteristics of back burner relationships. Just knowing that someone is there to talk to, whether it is something minor like checking in by sending a text message saying “hey, what's up?” (e.g., Regular Contact) or something more serious like being emotionally supportive during a crisis (e.g., Positivity \& Support), seems to be beneficial for those involved in back burner relationships. Additionally, the emergence and use of these particular maintenance behaviors may reflect the somewhat ambiguous future of back burner relationships given that a defining characteristic of a back burner relationship is that there is not current romantic or sexual involvement, but there is a desire for such involvement in the future; Dibble et al., 2015). For cross-sex friends that do not desire any romantic involvement, flirting is avoided in order to maintain the platonic nature of the friendship (Messman et al., 2000). For cross-sex friends that do desire romantic involvement, these individuals often maintain the relationship by engaging in routine relationship activity (e.g., phone calls and visiting each other at home), support and positivity (e.g., offering support and being positive in conversations), and flirtation (e.g., playful activity) relational maintenance behaviors (Weger \& Emmett, 2009). 
Thus, individuals' use of these back burner maintenance behaviors may not only heighten the quality of the current relationship, but also increase their future chances of committed involvement. For instance, positivity and openness can function as ways to show one's desire and readiness to escalate the relationship (Guerrero \& Chavez, 2005; Guerrero et al., 1993). The following section will review the unique findings that emerged for commitment, liking, control mutuality, and relationship satisfaction.

In regards to commitment, the findings indicated that individuals' use of the Relationship Talk maintenance behavior was positively associated with perceptions of commitment in back burner relationships. As a commonly studied relational quality indicator, commitment to the relationship is, in part, a function of relational maintenance; a claim that has been supported by the consistent positive associations between commitment and the use of maintenance behaviors (Canary et al., 2002; Dainton \& Aylor, 2002; Ogolsky, 2009; Stafford \& Canary, 1991). Commitment represents a long-term perspective about the relationship (Rusbult, 1980). As such, Aldrich and Morrison (2010) identified several reasons why casually dating partners engage in commitment-related conversations, including the status of the relationship, decreased level of commitment, and uncertainty. Thus, potentially explaining the associations between back burners' enacted Relationship Talk and perceived commitment. Additionally, people in romantic relationships and friends-with-benefits use of conflict management was associated with commitment (Goodboy \& Myers, 2008; Stafford et al., 2000). This particular type of behavior may be included in Relationship Talk if the conflicts are related to the current and future status of the relationship, which seems likely to occur in back burner relationships.

However, Tran and Simpson (2009) suggested that greater commitment promotes relational maintenance as way of protecting long-term relationships, but the same is not 
necessarily true for newer relationships. Thus, the degree to which commitment is important to back burners should be questioned. The answer to this likely depends on relational length, as well a back burners' desired relational state. For example, past research has indicated that a lack of discussion about future relational issues (e.g., future relationship plans) has the potential to negatively impact partners' commitment (Tan \& Agnew, 2016). Given that high commitment desirability has emerged as a predictor of enacted maintenance behaviors, whereas low commitment desirability did not (Tan et al., 2020), commitment might only play an influential role in back burner relationships when at least one partner desires more of it.

In regards to liking, the findings indicated that individuals' use of the Social Networks and Relationship Talk maintenance behaviors were both positively associated with perceptions of liking in back burner relationships. Contrary to romantic relationships and friends-withbenefits (Canary \& Stafford, 1992; Goodboy \& Myers, 2008), back burners’ use of Social Networks was not significantly associated with commitment. In fact, liking was the only relational characteristic associated with Social Networks in this study. Whereas some people purposefully withhold information about a potential romantic partner from their social networks for fear of judgement, others share this information to achieve a desirable relational outcome, help the potential partner in some way, or because it is a perceived expectation (Baxter \& Widenmann, 1993). This finding reveals the unique role of Social Networks for back burner relationships, but it also distinguishes it from other alternative types of relationships. One example is a one night stand, which involves a sexual encounter between two people who are either strangers or not very well acquainted who meet in some social setting (e.g., bar); this encounter typically is not planned nor does it include expectations for future interactions (Wentland \& Reissing, 2014). In addition, Mogilski and Welling (2017) argued that people stay 
friends with a former relational partner for a variety of reasons, including social relationship maintenance (i.e., "To prevent awkwardness in our friend group," p. 116). Thus, the use of this maintenance behavior may potentially be even more critical to back burners who share relational history.

The current findings also draw attention to the role of engaging in Relationship Talk as it pertains to liking one's back burner. Although assurance has been a commonly identified maintenance behavior (Canary \& Stafford, 1992; Canary et al., 1993; Dainton \& Stafford, 1993; Haas \& Stafford, 2005; Stafford \& Canary, 1992; Stafford et al., 2000), it did not emerge as one in this study. It may be that Relationship Talk also functions as a way to offer assurances and, in turn, heightens perceived liking of a back burner. Another explanation may involve costs and rewards. Duck (1994) argued the maintenance of romantic relationships, in comparison to friendships, is often more difficult to navigate and involves greater potential costs. While some people view these conversations as potentially threatening (Acitelli, 1988; Baxter \& Wilmot, 1985), back burners may be willing to risk engaging in Relationship Talk if the rewards outweigh the potential costs. Liking seems to be one of those rewards. Although obtaining relational knowledge is beneficial to understanding and defining relationships, increased relational knowledge also enhances partners' overall communication (Acitelli, 1988; Knobloch \& Solomon, 2003). In fact, Stafford and Canary (1991) argued that perceived liking is dependent on how people interpret their partners' use of prosocial maintenance behaviors.

In regards to control mutuality, the findings indicated that individuals' use of Relationship Talk was positively associated with perceptions of control mutuality in back burner relationship, but Strategic Deceit was negatively associated. Recall that control mutuality refers 
to "the degree to which partners agree about which of them should decide relational goals and behavioral routines" (Stafford \& Canary, 1991, p. 224). As such, individuals might engage in Relationship Talk as a way to negotiate control mutuality with their back burners. For instance, the ability to effectively maintain relationships has been argued to be crucial to the stability, continuation, and satisfaction of relationships, as well as individuals' well-being (Paul et al., 1998; Weisskirch, 2017). Given that back burners are not committed relationships (Dibble et al., 2015), negotiations of control mutuality through Relationship Talk likely reflects both individuals' and back burners' desired relational goals, routines, and needs connected to control mutuality. Although friends typically think and talk about the state of their relationships less often than romantic partners, relational awareness and talk progresses as relationships further develop (Acitelli, 1988; Goldsmith \& Baxter, 1996). Thus, this finding suggests that back burners are likely negotiating the decision-making roles regarding current and future relational goals through Relationship Talk.

Strategic Deceit, on the other hand, was negatively associated with control mutuality. If back burners have the ability to negotiate boundaries and norms for decision-making, they might not deem it necessary to deceive the other person. For instance, when needs and desires are not fulfilled within romantic relationships, individuals become less likely to engage in prosocial relational behaviors and more likely to experience negative emotions toward the relationship (Le \& Agnew, 2001; Patrick et al., 2007), which may demotivate individuals from engaging in constructive relational maintenance behaviors. Thus, individuals may have fewer reasons for using Strategic Deceit when their needs for control are being met.

In regards to relationship satisfaction, the findings indicated that individuals' usage of the Minimize Intimacy and Strategic Deceit maintenance behaviors were both negatively associated 
with perceptions of satisfaction in back burner relationships. Prior studies have demonstrated positive associations between partners' use of prosocial maintenance behaviors and high reports of satisfaction in relationships (Canary \& Yum, 2016; Ogolsky \& Bowers; Stafford \& Canary, 1991). Given that antisocial relational maintenance behaviors may be more effective in sustaining less functional relationships (Canary \& Stafford, 1991; Dainton \& Gross, 2008), individuals' decreased use of Minimize Intimacy and Strategic Deceit might depict a wellfunctioning relationship.

Relationship satisfaction is one of the most commonly investigated relational characteristics (Ogolsky \& Bowers, 2012). However, it is suggested that researchers not make general assumptions regarding desirable levels of relational characteristics across all types of relationships, especially in ambiguously-natured back burner relationship. Indeed, not all relational partners desire maximum levels of closeness, even partners in satisfying and committed romantic relationships have reported wanting less closeness (Mashek et al., 2011; Mashek \& Sherman, 2004). Taking this into consideration, back burner studies should consider desired levels of intimacy to more accurately determine how they distinctly relate to romantic partners' enacted maintenance behaviors (Malinen \& Tolvanen, 2012). For example, Guerrero and colleagues (1993) argued that perceptions of a partner's frequent engagement in relational maintenance can facilitate the stability or escalation of intimacy. Thus, potentially explaining that back burners' decreased use of Minimize Intimacy may reflect actions geared towards escalation the relationship. Additionally, self-expansion theory identified characteristics of partners and relationships that become increasingly monotonous (e.g., lack of new information, resources, perspectives), offering a motivational explanation for how habituation and boredom impede self-expansion and lead to the natural decline in relationship satisfaction (Aron \& Aron, 
1997). As such, the findings suggest that people involved in satisfactory and well-functioning back burner relationships might not need, nor want, to engage in the Strategic Deceit nor Minimize Intimacy back burner maintenance behaviors.

\section{Limitations and Future Directions}

There are several limitations and suggestions for future research. The data for both Study 1 and Study 2 were collected from undergraduate students involved in back burner relationships. Given that the average age of participants was 20 years old, the discussions of these findings are limited to younger adults enrolled in college courses. Emerging adults who are not college students (e.g., not attending a residential university) might differ in their use of relationship maintenance strategies in back burner relationships. Additionally, older individuals could also have unique relationship maintenance strategies in their back burner relationships. Recall the prevalent use of communication technologies (e.g., texting, social media) between back burners, both in the current study and prior back burner research (Dibble \& Drouin, 2014; Dibble et al., 2015; Dibble et al., 2018). However, people of different ages use communication technologies in different ways and for various maintenance goals (Houser et al., 2012; Pfeil et al., 2009; Sosik \& Bazarova, 2014). Thus, there may be generational differences in the types of enacted behaviors, as well as the channels in which they use to maintain back burner relationships.

The second limitation of this study focuses on the items used to measure back burners' use of maintenance behaviors. Dibble and colleagues (2018) first examined the maintenance of back burner relationships, but individuals only reported their usage of openness, assurances, and positivity; all of which were measured by items that emerged from Stafford and Canary's (1991) typology of romantic relationship maintenance. Following Ragsdale and Brandau-Brown's (2004) suggestion to not just use previously developed maintenance measures for other relational 
contexts, the maintenance behaviors in the current study were inductively derived from individuals actually involved in back burner relationships. Although this study provides a more context-specific understanding of back burners' relational maintenance, future research needs to verify the reliability and validity of the items in the Back Burner Maintenance Behaviors Typology.

The third limitation of this study is concerned with the secure attachment style measure. To obtain a reliable measure, the three recoded items were dropped from the analyses. This study utilized a categorical approach to assess attachment styles (i.e., secure, preoccupied, dismissive, and fearful avoidant; Bartholomew \& Horowitz, 1991). However, scholars have argued that empirical research should move away from a categorical approach and, instead, assess individuals' attachment styles using a dimensional approach (Fraley et al., 2015). Thus, the lack of reliability for the measure of secure attachment with the recoded items may reflect the empirical shortcomings of using distinct categories rather than using continuous measures of attachment-related anxiety and attachment-related avoidance (Fraley et al., 2015). In addition, other theoretical perspectives should also be considered in future research on the maintenance of back burner relationships, such as the theory of resilience and relational load (Afifi et al., 2016), relational turbulence theory (Solomon et al., 2016), and theory of negative relational maintenance (Tokunaga, 2016). Additionally, Mason and Carr (2021) have asserted the importance of developing a theory on relational maintenance specifically enacted through computer-mediated communication.

Future research should consider the degree and type of future intent held by both individuals involved in back burner relationships. Recall that a fundamental feature of this relationship type is that at least one person desires a future relationship with the back burner, but 
it does not necessarily mean that both partners feel this way (Dibble et al., 2015). The current results demonstrated that people vary in regards to their desired intentions with a back burner (i.e., romantic, sexual, or both romantic and sexual future relationship), as well as whether or not their back burner is aware of their interest. Thus, emphasizing that relational maintenance varies depending on the type of relationship, as well as the level of romantic intent associated with the relationship (Canary \& Stafford, 1994; Dainton \& Stafford, 1993; Guerrero \& Chavez, 2005; Weger \& Emmett, 2009). As aforementioned, several back burner maintenance behaviors seem to reflect relationship initiation and escalation strategies often reported in cross-sex friendships (e.g., self-presentation of positive characteristics, providing rewards, affection, and spending time together; Dindia, 1994); yet, the escalation of the back burner relationship also depends on the current status of the relationship. To gain a more complete picture of how relational maintenance behaviors operate in a back burner relationship, it is necessary to examine both individuals' perceptions, intent, and awareness.

Another avenue that future research should consider is the role of relational history between back burners. For instance, partners currently involved in a back burner relationship could also be involved in a cyclical on-again/off-again relationship, particularly because these cyclical partners maintain post-dissolution contact as they often believe the relationship is not entirely over (Dailey et al., 2010; Dailey et al., 2009). Given the common occurrence of shared relational history between back burners, both in the current study and prior studies (Dibble \& Drouin, 2014; Dibble et al., 2015; Dibble et al., 2018), the existence of a back burner relationship between former romantic partners may reflect the "off" period for people involved in onagain/off-again relationships. However, partners' use of positive relational maintenance behaviors was less frequently reported in on-again/off-again relationships in comparison to 
noncyclical relationships (Dailey et al., 2010), which is contrary to our findings on back burners' use of relational maintenance behaviors. It may also be that individuals need to self-expand outside of the relationship before being able to return and become an optimal relational partner, as cyclical romantic partners have reported that renewal transitions can lead partners to obtaining a clearer understanding of the relationship (Dailey et al., 2010; Dailey et al., 2011).

Some of the frequently identified benefits of on-again/off-again relationships include obtaining relationship knowledge for the future, gaining new perspectives about the relationship or partner, and learning how to improve the relationship (Dailey et al., 2011); all of which can occur through the use of back burner maintenance behaviors. This highlights the multiphasic view of the relational maintenance process (i.e., specific maintenance behaviors can serve different functions over the length of a relationship; Dindia, 1994). Relationships containing at least one renewal transition should be of importance to communication relational maintenance scholars because breakups and renewals likely alter the linear perceptions of relationship length, potentially resulting in unique relational maintenance experiences. Thus, future research should continue to investigate the distinctions between back burner relationships and on-again/off-again relationships.

Another factor that future back burner research should examine is the existence of extradyadic relationships. In addition to the current study, past research has also demonstrated that numerous people are simultaneously involved in a back burner relationship with one person and a committed romantic relationship with another person (Dibble \& Drouin, 2014; Dibble et al., 2015; Dibble et al., 2018). Despite the fact that a fundamental characteristic of back burner relationships is that both people are not currently romantically or sexually involved (Dibble et al., 2015), the existence of this relationship outside of a committed relationship may be 
considered a relational transgression (Luo et al., 2010; Thompson \& O'Sullivan, 2015). For example, the Minimize Intimacy back burner maintenance behavior reflects aspects of the proactive avoidance maintenance behavior intended to maintain monogamy in romantic relationships (e.g., "distanced myself from this person", p. 221), whereas the Shared Activities and Regular Contact back burner maintenance behaviors reflect the opposite of that monogamy maintenance behavior (Lee \& O'Sullivan, 2018). Given that individuals' enacted maintenance behaviors differ depending on relationship type and current stage of relationship development (Dindia, 1994; Dindia \& Baxter, 1987; Dainton \& Stafford, 1993; Guerrero et al., 1993), it is likely that the type or stage of back burner relationships, as well as the existence of extradyadic relationships, will be reflected in individuals' use of back burner maintenance behaviors.

Throughout this discussion, connections have been made between the present findings and other types of relationships that share characteristics with the back burner relationship, including cross-sex friendships with varying levels of romantic intent, back burners with relational history, and those who have extradyadic relationships in addition to the back burner. In terms of general implications for future back burner research, the influence of these various relational factors suggests possibly reconsidering the conceptualization of back burner relationships. For instance, one suggestion is a possible shift from using a contextual approach (i.e., back burner relationship) to a situational approach (i.e., back burner communication across relationship types). That is, future research should consider focusing on back burners' motivations and communicative interactions rather than attempting to generalize communicative behaviors across all back burner relationships. The potential utility of focusing on back burner communication would allow for a better understanding of the ways in which back burners' 
motivations manifest through communication across cross-sex friendships, former relational partners, on-again/off-again partners, and individuals with extradyadic relationships.

\section{Summary}

This dissertation resulted in the inductively-derived Back Burner Maintenance Behaviors Typology. The findings obtained in this study suggest that individuals in back burner relationships engage in 10 relational maintenance behaviors to sustain a casual (e.g., Minimize Intimacy), connected (e.g., Shared Activities), and rewarding (e.g., Positivity \& Support) back burner relationship. The findings also revealed that numerous theoretical factors, including individuals' attachment style, perceptions of relationship uncertainty, and experienced selfexpansion, predicted their use of maintenance behaviors. Furthermore, the use of different back burner maintenance behaviors resulted in unique perceptions of relational characteristics (i.e., commitment, liking, control mutuality, and relationship satisfaction). However, it is suggested that relational factors (e.g., relational history) likely influence back burners' relationship-specific perceptions and enacted maintenance behaviors, which should be further investigated in future research. Because communication is central to back burner relational maintenance, interpersonal communication researchers need to continue investigations on distinguishing contextual and situational characteristics of back burner relationships, along with associated predictors and outcomes. 


\section{References}

Acitelli, L. K. (1988). When spouses talk to each other about their relationship. Journal of Social and Personal Relationships, 5(2), 185-199. https://doi.org/10.1177/026540758800500204

Afifi, T. D., Merrill, A., \& Davis, S. M. (2016). The theory of resilience and relational load. Personal Relationships, 23(4), 663-683. https://doi.org/10.1111/pere.12159

Agnew, C. R., Van Lange, P. A. M., Rusbult, C. E., \& Langston, C. A. (1998). Cognitive interdependence: Commitment and the mental representation of close relationships. Journal of Personality and Social Psychology, 74(4), 939-954. https://doi.org/10.1037/0022-3514.74.4.939

Ainsworth, M. S. (1989). Attachments beyond infancy. American Psychologist, 44(2), 709-716. https://doi.org/10.1037/0003-066x.44.4.709

Aldrich, R. S., \& Morrison, K. (2010). Exploring why college students discuss commitment in dating relationships. Florida Communication Journal, 28(4), 113-122.

Alhabash, S., \& Ma, M. (2017). A tale of four platforms: Motivations and uses of Facebook, Twitter, Instagram, and Snapchat among college students? Social Media + Society, 3(1). https://doi.org/10.1177/2056305117691544

Aron, A., \& Aron, E. N. (1986). Love and the expansion of the self: Understanding attraction and satisfaction. Hemisphere Publishing. https://doi.org/10.2307/2070652

Aron, A., \& Aron, E. N. (1997). Self-expansion motivation and including other in the self. In S. Duck (Ed.), Handbook of personal relationships: Theory, research, and interventions (2nd ed., pp. 251-270). John Wiley \& Sons.

Aron, A., Aron, E. N., \& Norman, C. (2001). Self-expansion model of motivation and cognition in close relationships and beyond. In M. Clark \& G. Fletcher (Eds.), Blackwell handbook 
of social psychology: Vol. 2: Interpersonal processes (pp. 478-501). Blackwell.

Aron, A., Aron, E. N., Tudor, M., \& Nelson, G. (1991). Close relationships as including other in the self. Journal of Personality and Social Psychology, 60(2), 241-253. https://doi.org/10.1037/0022-3514.60.2.241

Aron, A., Fisher, H., Mashek, D. J., Strong, G., Li, H., \& Brown, L. L. (2005). Reward, motivation, and emotion systems associated with early-stage intense romantic love. Journal of Neurophysiology, 94(1), 327-337. https://doi.org/10.1152/jn.00838.2004

Aron, A., Lewandowski, G. W., Mashek, D., \& Aron, E. N. (2013). The self-expansion model of motivation and cognition in close relationships. In J. A. Simpson \& L. Campbell (Eds.), The Oxford handbook of close relationships (pp. 90-115). Oxford University Press.

Aron, A., Melinat, E., Aron, E. N., Vallone, R. D., \& Bator, R. J. (1997). The experimental generation of interpersonal closeness: A procedure and some preliminary findings. Personality and Social Psychology Bulletin, 23(4), 363-377. https://doi.org/10.1177/0146167297234003

Aron, A., Norman, C. C., \& Aron, E. N. (1998). The self-expansion model and motivation. Representative Research in Social Psychology, 22(2), 1-13.

Aron, A., Norman, C. C., Aron, E. N., \& Lewandowski, G. W., Jr. (2002). Shared participation in self-expanding activities: Positive effects on experienced marital quality. In P. Noller \& J. Feeney (Eds.), Understanding marriage: Developments in the study of couple interaction (pp. 177-196). Cambridge University Press.

Aron, A., Norman, C. C., Aron, E. N., McKenna, C., \& Heyman, R. E. (2000). Couples' shared participation in novel and arousing activities and experienced relationship quality. Journal of Personality and Social Psychology, 78(2), 273-284. 
https://doi.org/10.1037/0022-3514.78.2.273

Aron, A., Paris, M., \& Aron, E. N. (1995). Falling in love: Prospective studies of self-concept change. Journal of Personality and Social Psychology, 69(6), 1102-1112. https://doi.org/10.1037/0022-3514.69.6.1102

Aylor, B., \& Dainton, M. (2004). Biological sex and psychological gender as predictors of routine and strategic relational maintenance. Sex Roles, 50(9), 689-697. https://doi.org/10.1023/b:sers.0000027570.80468.a0

Ayres, J. (1983). Strategies to maintain relationships: Their identification and perceived usage. Communication Quarterly, 31(1), 62-67. https://doi.org/10.1080/01463378309369487

Baker, L. R., \& McNulty, J. K. (2011). Self-compassion and relationship maintenance: The moderating roles of conscientiousness and gender. Journal of Personality and Social Psychology, 100(5), 853-873. https://doi.org/10.1037/e634112013-256

Bartholomew, K. (1990). Avoidance of intimacy: An attachment perspective. Journal of Social and Personal Relationships, 7(2), 147-178. https://doi.org/10.1177/0265407590072001

Bartholomew, K., \& Horowitz, L. M. (1991). Attachment styles among young adults: A test of a four-category model. Journal of Personality and Social Psychology, 61(2), 226-244. https://doi.org/10.1037/0022-3514.61.2.226

Baxter, L. E., \& Bullis, C. (1986). Turning points in developing romantic relationships. Human Communication Research, 12(4), 469-493. https://doi.org/10.1111/j.1468-2958.1986.tb00088.x

Baxter, L. A., \& Erbert, L. A. (1999). Perceptions of dialectical contradictions in turning points of development in heterosexual romantic relationships. Journal of Social and Personal Relationships, 16(5), 547-569. https://doi.org/10.1177/0265407599165001 
Baxter, L. A., \& Montgomery, B. M. (1996). Relating: Dialogues \& dialectics. Guilford.

Baxter, L. A., \& Widenmann, S. (1993). Revealing and not revealing the status of romantic relationships to social networks. Journal of Social and Personal Relationships, 10(3), 321-337. https://doi.org/10.1177/0265407593103002

Baxter, L. A., \& Wilmot, W. W. (1985). Taboo topics in close relationships. Journal of Social and Personal Relationships, 2(3), 253-269. https://doi.org/10.1177/0265407585023002

Billedo, C. J., Kerkhof, P., \& Finkenauer, C. (2015). The use of social networking sites for relationship maintenance in long-distance and geographically close romantic relationships. Cyberpsychology, Behavior, and Social Networking, 18(3), 152-157. https://doi.org/10.1089/cyber.2014.0469

Bippus, A. M., \& Rollin, E. (2003). Attachment style differences in relational maintenance and conflict behaviors: Friends' perceptions. Communication Reports, 16(2), 113-123. https://doi.org/10.1080/08934210309384494

Bolger, N., Zuckerman, A., \& Kessler, R. C. (2000). Invisible support and adjustment to stress. Journal of Personality and Social Psychology, 79(6), 953-961. https://doi.org/10.1037/0022-3514.79.6.953

Borzea, D., \& Dillow, M. R. (2017). Dispositional characteristics of individuals involved in back burner relationships. Communication Research Reports, 34(4), 316-325. https://doi.org/10.1080/08824096.2017.1350572

Bowlby, J. (1969). Attachment and loss: Vol. 1. Attachment. Basic Books.

Brandau-Brown, F. E., Bello, R. S., \& Ragsdale, J. D. (2010). Attachment style and tolerance for ambiguity effects on relational repair message interpretation among remarried. Marriage \& Family Review, 46(6), 389-399. https://doi.org/10.1080/01494929.2010.528311 
Bryant, E. M., \& Marmo, J. (2009). Relational maintenance strategies on Facebook. The Kentucky Journal of Communication, 28(2), 129-150.

Burke, T. J., Ruppel, E. K., \& Dinsmore, D. R. (2016). Moving away and reaching out: Young adults' relational maintenance and psychological well-being during the transition to college. Journal of Family Communication, 16(2), 180-187.

https://doi.org/10.1080/15267431.2016.1146724

Canary, D. J. (2011). On babies, bathwater, and absolute claims: Reply to Stafford. Journal of Social and Personal Relationships, 28(2), 304-311. https://doi.org/10.1177/0265407510397523

Canary, D. J., \& Stafford, L. (1992). Relational maintenance strategies and equity in marriage. Communication Monographs, 59(3), 243-267. https://doi.org/10.1080/03637759209376268

Canary, D. J., \& Stafford, L. (1994). Maintaining relationships through strategic and routine interaction. In D. J. Canary \& L. Stafford (Eds.), Communication and relational maintenance (pp. 3-22). Academic Press.

Canary, D. J., Stafford, L., Hause, K. S., \& Wallace, L. A. (1993). An inductive analysis of relational maintenance strategies: Comparisons among lovers, relatives, friends, and others. Communication Research Reports, 10(1), 5-14. https://doi.org/10.1080/08824099309359913

Canary, D. J., Stafford, L., \& Semic, B. A. (2002). A panel study of the associations between maintenance strategies and relational characteristics. Journal of Marriage and Family, 64(2), 395-406. https://doi.org/10.1111/j.1741-3737.2002.00395.x

Canary, D. J., \& Yum, Y. (2016). Relationship maintenance strategies. In C. R. Berger and M. E. 
Roloff (Eds.), The international encyclopedia of interpersonal communication. (Vol 3., pp. 1491-1499). Blackwell Wiley.

Canary, D. J., \& Zelley, E. D. (2000). Current research programs on relational maintenance Behaviors. In M. E. Roloff (Ed.), Communication yearbook 23 (pp. 305-339). SAGE Publications.

Candel, O., \& Turliuc, M. N. (2019). Insecure attachment and relationship satisfaction: A metaanalysis of actor and partner associations. Personality and Individual Differences, 147, 190-199. https://doi.org/10.1016/j.paid.2019.04.037

Chang, P. (2015). The examination of parent-adolescent communication motives, relational maintenance and intimacy in the uses of communication technologies. Journal of Media and Communication Studies, 7(10), 171-181. https://doi.org/10.5897/jmcs2015.0457

Chory, R. M., \& Banfield, S. (2009). Media dependence and relational maintenance in interpersonal relationships. Communication Reports, 22(1), 41-53. https://doi.org/10.1080/08934210902798502

Collins, N., \& Feeney, B. (2004). An attachment theory perspective on closeness and intimacy. In D. Mashek \& A. Aron (Eds), Handbook of closeness and intimacy (pp. 163-187). Erlbaum.

Cook, D. (1977). Detection of influential observation in linear regression. Technometrics, 19(1), 15-18. https://doi.org/10.2307/1268249

Dailey, R. M., Hampel, A. D., \& Roberts, J. B. (2010). Relational maintenance in on-again/off again relationships: An assessment of how relational maintenance, uncertainty, and commitment vary by relationship type and status. Communication Monographs, 77(1), 75-101. https://doi.org/10.1080/03637750903514292 
Dailey, R. M., Jin, B., Pfiester, A., \& Beck, G. (2011). On-again/off-again dating relationships: What keeps partners coming back? The Journal of Social Psychology, 151(4), 417-440. https://doi.org/10.1080/00224545.2010.503249

Dailey, R. M., Rossetto, K. R., Pfiester, A., \& Surra, C. A. (2009). A qualitative analysis of onagain/off-again romantic relationships: "It's up and down, all around." Journal of Social and Personal Relationships, 26(4), 443-466. https://doi.org/10.1177/0265407509351035

Dainton, M. (2000). Maintenance behaviors, expectations for maintenance, and satisfaction: Linking comparison levels to relational maintenance strategies. Journal of Social and Personal Relationships, 17(6), 827-842. https://doi.org/10.1177/0265407500176007

Dainton, M. (2003). Equity and uncertainty in relational maintenance. Western Journal of Communication, 67(2), 164-186. https://doi.org/10.1080/10570310309374765

Dainton, M. (2007). Attachment and marital maintenance. Communication Quarterly, 55(2), 283-298. https://doi.org/10.1080/01463370701490083

Dainton, M. (2011). Linking theoretical explanations for the use of marital maintenance: Equity, uncertainty, attachment, and reciprocity. Psychological Research Records, 1(2), 352-374. https://doi.org/10.22201/fpsi.20074719e.2011.2.211

Dainton, M. (2015). An interdependence approach to relationship maintenance in interracial marriage. Journal of Social Issues, 71(4), 772-787. https://doi.org/10.1111/josi.12148

Dainton, M., \& Aylor, B. (2001). A relational uncertainty analysis of jealousy, trust, and the maintenance of long-distance versus geographically close relationships. Communication Quarterly, 49(2), 172-188. https://doi.org/10.1080/01463370109385624

Dainton, M., \& Aylor, B. (2002a). Routine and strategic maintenance efforts: Behavioral patterns, variations associated with relational length, and the prediction of relational 
characteristics. Communication Monographs, 69(1), 52-66.

https://doi.org/10.1080/03637750216533

Dainton, M., \& Aylor, B. (2002b). Patterns of communication channel use in the maintenance of long-distance relationships. Communication Research Reports, 19(2), 118-129. https://doi.org/10.1080/08824090209384839

Dainton, M., \& Berkoski, L. (2013). Positive and negative maintenance behaviors, jealousy, and Facebook: Impacts on college students' romantic relationships. Pennsylvania Communication Annual, 69(4), 35-50.

Dainton, M., Goodboy, A. K., Borzea, D., \& Goldman, Z. W. (2017). The dyadic effects of relationship uncertainty on negative relational maintenance behaviors. Communication Reports, 30(3), 170-181. https://doi.org/10.1080/08934215.2017.1282529

Dainton, M., \& Gross, J. (2008). The use of negative behaviors to maintenance relationships. Communication Research Reports, 25(4), 179-191. https://doi.org/10.1080/08824090802237600

Dainton, M., \& Stafford, L. (1993). Routine maintenance behaviors: A comparison of relationship type, partner similarity and sex differences. Journal of Social and Personal Relationships, 10(2), 255-271. https://doi.org/10.1177/026540759301000206

Dainton, M., \& Stafford, L. (2000). Predicting maintenance enactment from relational schemata, spousal behavior, and relational characteristics. Communication Research Reports, 17(2), 171-180. https://doi.org/10.1080/08824090009388763

Dainton, M., Stafford, L., \& Canary, D. J. (1994). Maintenance strategies and physical affection as predictors of love, liking, and satisfaction in marriage. Communication Reports, 7(2), 88-98. https://doi.org/10.1080/08934219409367591 
Dainton, M., Zelley, E., \& Langan, E. (2003). Maintaining friendships throughout the lifespan. In D. Canary \& M. Dainton (Eds.), Maintaining relationships through communication: Relational, contextual, and cultural variations (pp. 79-102). Erlbaum.

Dibble, J. L., \& Drouin, M. (2014). Using modern technology to keep in touch with back burners: An Investment Model analysis. Computers in Human Behavior, 34, 96-100. https://doi.org/10.1016/j.chb.2014.01.042

Dibble, J. L., Drouin, M., Aune, K. S., \& Boller, R. R. (2015). Simmering on the back burner: Communication with and disclosure of relationship alternatives. Communication Quarterly, 63(3), 329-344. https://doi.org/10.1080/01463373.2015.1039719

Dibble, J. L., Punyanunt-Carter, N. M., \& Drouin, M. (2018). Maintaining relationship alternatives electronically: Positive relationship maintenance in back burner relationships. Communication Research Reports, 35(3), 200-209. https://doi.org/10.1080/08824096.2018.1425985

Dindia, K. (1994). A multiphasic view of relationship maintenance strategies. In D. J. Canary \& L. Stafford (Eds.), Communication and relational maintenance (pp. 92-114). Academic Press.

Dindia, K. (2003). Definitions and perspectives on relational maintenance communication. In D. Canary \& M. Dainton (Eds.), Maintaining relationships through communication: Relational, contextual, and cultural variations (pp. 1-28). Erlbaum.

Dindia, K., \& Baxter, L. A. (1987). Strategies for maintaining and repairing marital relationships. Journal of Social and Personal Relationships, 4(2), 143-158. https://doi.org/10.1177/0265407587042003

Dindia, K., \& Canary, D. J. (1993). Definition and theoretical perspectives on maintaining 
relationships. Journal of Social and Personal Relationships, 10(2), 163-173.

https://doi.org/10.1177/026540759301000201

Dorrance Hall, E. D., \& McNallie, J. (2016). The mediating role of sibling maintenance behavior expectations and perceptions in the relationship between family communication patterns and relationship satisfaction. Journal of Family Communication, 16(4), 386-402. https://doi.org/10.1080/15267431.2016.1215316

Duck, S. (1994). Steady as (s)he goes: Relational maintenance as a shared meaning system. In D. J. Canary \& L. Stafford (Eds.), Communication and relational maintenance (pp. 45-60). Academic Press.

Duck, S., Rutt, D. J., Hoy, M., \& Strejc, H. H. (1991). Some evident truths about conversations in everyday relationships: All communications are not created equal. Human Communication Research, 18(2), 228-267. https://doi.org/10.1111/j.1468-2958.1991.tb00545.x

Dubé, S., Lavoie, F., Blais, M., \& Hébert, M. (2017). Psychological well-being as a predictor of casual sex relationships and experiences among adolescents: A short-term prospective study. Archives of Sexual Behavior, 46(6), 1807-1818. https://doi.org/10.1007/s10508-016-0914-0

Dunn, T. J., Baguley, T., \& Brunsden, V. (2013). From alpha to omega: A practical solution to the pervasive problem of internal consistency estimation. British Journal of Psychology, 105(3), 399-412. https://doi.org/10.1111/bjop.12046

Etcheverry, P. E., \& Le, B. (2005). Thinking about commitment: Accessibility of commitment and prediction of relationship persistence, accommodation, and willingness to sacrifice. Personal Relationships, 12(1), 103-123. 
https://doi.org/10.1111/j.1350-4126.2005.00104.x

Field, A. (2007). Discovering statistics using SPSS (3 $3^{\text {rd }}$ ed.). SAGE Publications.

Forsythe, K. E., \& Ledbetter, A. M. (2015). Relational uncertainty, self-other inclusion, and communication satisfaction as predictors of friendship relational maintenance, and how equity changes the story. Communication Studies, 66(3), 321-340.

https://doi.org/10.1080/10510974.2015.1018444

Fraley, R. C., Hudson, N. W., Heffernan, M. E., \& Segal, N. (2015). Are adult attachment styles categorical or dimensional? A taxometric analysis of general and relationship-specific attachment orientations. Journal of Personality and Social Psychology, 109(2), 354-368. https://doi.org/10.1037/pspp0000027

Frost, D. M. (2012). The narrative construction of intimacy and affect in relationship stories: Implications for relationship quality, stability, and mental health. Journal of Social and Personal Relationships, 30(3), 247-269. https://doi.org/10.1177/0265407512454463

Girme, Y. U., Overall, N. C., \& Faingataa, S. (2014). "Date nights" take two: The maintenance function of shared relationship activities. Personal Relationships, 21(1), 125-149. https://doi.org/10.1111/pere.12020

Girme, Y. U., Overall, N. C., Faingataa, S., \& Sibley, C. G. (2016). Happily single: The link between relationship status and well-being depends on avoidance and approach social goals. Social Psychological and Personality Science, 7(2), 122-130. https://doi.org/10.1177/1948550615599828

Goldsmith, D. J., \& Baxter, L. A. (1996). Constituting relationships in talk: A taxonomy of speech events in social and personal relationships. Human Communication Research, 23(1), 87-114. https://doi.org/10.1111/j.1468-2958.1996.tb00388.x 
Goodboy, A. K., \& Bolkan, S. (2011). Attachment and the use of negative relational maintenance behaviors in romantic relationships. Communication Research Reports, 28(4), 327-336. https://doi.org/10.1080/08824096.2011.616244

Goodboy, A. K., Bolkan, S., Knoster, K. C., \& Kromka, S. M. (2019). Instructional dissent as an expression of students' class-related achievement emotions. Communication Research Reports, 36(3), 265-274. https://doi.org/10.1080/08824096.2019.1634534

Goodboy, A. K., Dainton, M., Borzea, D., \& Goldman, Z. W. (2017). Attachment and negative relational maintenance: Dyadic comparisons using an actor-partner interdependence model. Western Journal of Communication, 81(5), 541-559.

https://doi.org/10.1080/10570314.2017.1302601

Goodboy, A. K., \& Martin, M. M. (2020). Omega over alpha for reliability estimation of unidimensional communication measures. Annals of the International Communication Association, 44(4), 422-439. https://doi.org/10.1080/23808985.2020.1846135

Goodboy, A. K., \& Myers, S. A. (2008). Relational maintenance behaviors of friends with benefits: Investigating equity and relational characteristics. Human Communication, 11(1), 71-86.

Goodboy, A. K., Myers, S. A., \& Members of Investigating Communication. (2010). Relational quality indicators and love styles as predictors of negative relational maintenance behaviors in romantic relationships. Communication Reports, 23(2), 65-78. https://doi.org/10.1080/08934215.2010.511397

Goodboy, A. K., Myers, S. A., \& Patterson, B. R. (2009). Investigating elderly sibling types, relational maintenance, and lifespan affect, cognition, and behavior. Atlantic Journal of Communication, 17(3), 140-148. https://doi.org/10.1080/15456870903024852 
Graham, J. M. (2008). Self-expansion and flow in couples' momentary experiences: An experience sampling study. Journal of Personality and Social Psychology, 95(3), 679694. https://doi.org/10.1037/0022-3514.95.3.679

Graham, J. M., \& Harf, M. R. (2008). Self-expansion and flow: The roles of challenge, skill, affect, and activation. Personal Relationships, 22(1), 45-64. https://doi.org/10.1111/pere.12062

Guerrero, L. K. (1996). Attachment-style differences in intimacy and involvement: A test of the four-category model. Communication Monographs, 63(4), 269-292. https://doi.org/10.1080/03637759609376395

Guerrero, L. K., \& Bachman, G. F. (2006). Associations among relational maintenance behaviors, attachment-style categories, and attachment dimensions. Communication Studies, 57(3), 341-361. https://doi.org/10.1080/10510970600845982

Guerrero, L. K., \& Chavez, A. M. (2005). Relational maintenance in cross sex friendships characterized by different types of romantic intent: An exploratory study. Western Journal of Communication, 69(4), 339-358. https://doi.org/10.1080/10570310500305471

Guerrero, L. K., Eloy, S. V., \& Wabnik, A. I. (1993). Linking maintenance strategies to relationship development and disengagement: A reconceptualization. Journal of Social and Personal Relationships, 10(2), 273-283. doi:10.1177/026540759301000207

Guerrero, L. K., Farinelli, L., \& McEwan, B. (2009). Attachment and relational satisfaction: The mediating effect of emotional communication. Communication Monographs, 76(4), 487514. https://doi.org/10.1177/026540759301000207

Haas, S. M., \& Stafford, L. (1998). An initial examination of maintenance behaviors in gay and lesbian relationships. Journal of Social and Personal Relationships, 15(6), 846-855. 
https://doi.org/10.1177/0265407598156008

Haas, S. M., \& Stafford, L. (2005). Maintenance behaviors in same-sex and marital relationships: A matched sample comparison. Journal of Family Communication, 5(1), 43-60. https://doi.org/10.1207/s15327698jfc0501_3

Hair, J. F., Anderson, R. E., Tatham, R. L., \& Black, W. C. (1995). Multivariate data analysis. Prentice-Hall.

Hall, J. A. (2017). Humor in romantic relationships: A meta-analysis. Personal Relationships, 24(2), 306-322. https://doi.org/10.1111/pere.12183

Hancock, G. R., \& An, J. (2020). A closed-form alternative for estimating $\omega$ reliability under unidimensionality. Measurement: Interdisciplinary Research and Perspectives, 18(1), 114. https://doi.org/10.1080/15366367.2019.1656049

Hatfield, E., Utne, M., \& Traupmann, J. (1979). Equity theory and intimate relationships. In R. L. Burgess and T. L. Huston (Eds.), Social exchange in developing relationships (pp. 99133). Academic Press.

Hayes, A. F., \& Coutts, J. J. (2020). Use omega rather than Cronbach's alpha for estimating reliability. But..., Communication Methods and Measures, 14(1), 1-24. https://doi.org/10.1080/19312458.2020.1718629

Hazan, C., \& Shaver, P. (1987). Romantic love conceptualized as an attachment process. Journal of Personality and Social Psychology, 52(3), 511-524. https://doi.org/10.4324/9781351153683-17

Hendrick, S. S. (1988). A generic measure of relationship satisfaction. Journal of Marriage and the Family, 50(1), 93-98. https://doi.org/10.2307/352430

Henry, G. T. (1990). Practical sampling. SAGE Publications. 
Hesse, C., Pauley, P. M., \& Frye-Cox, N. E. (2015). Alexithymia and marital quality: The mediating role of relationship maintenance behaviors. Western Journal of Communication, 79(1), 45-72. https://doi.org/10.1080/10570314.2014.943418

Houser, M. L., Fleuriet, C., \& Estrada, D. (2012). The cyber factor: An analysis of relational maintenance through the use of computer-mediated communication. Communication Research Reports, 29(1), 34-43. https://doi.org/10.1080/08824096.2011.639911

Hughes, M., Morrison, K., \& Asada, K. J. K. (2005). What's love got to do with it? Exploring the impact of maintenance rules, love attitudes, and network support on friends with benefits relationships. Western Journal of Communication, 69(1), 49-66. https://doi.org/10.1080/10570310500034154

Johnson, A. J. (2001). Examining the maintenance of friendships: Are there differences between geographically close and long-distance friends? Communication Quarterly, 49(4), 424435. https://doi.org/10.1080/01463370109385639

Kennedy-Lightsey, C. D. (2018). Cognitive jealousy and constructive communication: The role of perceived partner maintenance and uncertainty. Communication Reports, 31(2), 115129. https://doi.org/10.1080/08934215.2017.1423094

Knobloch, L. K. (2007). Perceptions of turmoil within courtship: Associations with intimacy, relational uncertainty, and interference from partners. Journal of Social and Personal Relationships, 24(3), 363-384. https://doi.org/10.1177/0265407507077227

Knobloch, L. K., \& Carpenter-Theune, K. E. (2004). Topic avoidance in developing romantic relationships. Communication Research, 31(2), 173-205. https://doi.org/10.1177/0093650203261516

Knobloch, L. K., \& Solomon, D. H. (1999). Measuring the sources and content of relational 
uncertainty. Communication Studies, 50(4), 261-278.

https://doi.org/10.1080/10510979909388499

Knobloch, L. K., \& Solomon, D. H. (2002). Information seeking beyond initial interaction: Negotiating relational uncertainty within close relationships. Human Communication Research, 28(2), 243-257. https://doi.org/10.1093/hcr/28.2.243

Knobloch, L. K., \& Solomon, D. H. (2003). Responses to changes in relational uncertainty within dating relationships: Emotions and communication strategies. Communication Studies, 54(3), 282-305. https://doi.org/10.1080/10510970309363287

Knobloch, L. K., \& Solomon, D. H. (2005). Relational uncertainty and relational information processing: Questions without answers? Communication Research, 32(3), 349-388. https://doi.org/10.1177/0093650205275384

Knobloch, L. K., Solomon, D. H., \& Theiss, J. A. (2006). The role of intimacy in the production and perception of relationship talk within courtship. Communication Research, 33(4), 211-241. https://doi.org/10.1177/0093650206289148

Knobloch, L. K., \& Theiss, J. A. (2011). Relational uncertainty and relationship talk within courtship: A longitudinal actor-partner interdependence model. Communication Monographs, 78(1), 3-26. https://doi.org/10.1080/03637751.2010.542471

LaBelle, S., \& Myers, S. A. (2016). The use of relational maintenance behaviors in sustained adult friendships. Communication Research Reports, 33(4), 310-316. https://doi.org/10.1080/08824096.2016.1224164

La Valley, A. G., \& Guerrero, L. K. (2012). Perceptions of conflict behavior and relational satisfaction in adult parent-child relationships: A dyadic analysis from an attachment perspective. Communication Research, 39(1), 48-78. 
https://doi.org/10.1177/0093650210391655

Le, B., \& Agnew, C. R. (2001). Need fulfillment and emotional experience in interdependent romantic relationships. Journal of Social and Personal Relationships, 18(3), 423-440. https://doi.org/10.1177/0265407501183007

Ledbetter, A. M. (2009). Family communication patterns and relational maintenance behavior: Direct and mediated associations with friendship closeness. Human Communication Research, 35(1), 130-147. https://doi.org/10.1111/j.1468-2958.2008.01341.x

Ledbetter, A. M. (2010). Content- and medium-specific decomposition of friendship relational maintenance: Integrating equity and media multiplexity approaches. Journal of Social and Personal Relationships, 27(7), 938-955. https://doi.org/10.1177/0265407510376254

Ledbetter, A. M. (2013). Relational maintenance and inclusion of the other in the self: Measure development and dyadic test of a self-expansion theory approach. Southern Communication Journal, 78(4), 289-310. https://doi.org/10.1080/1041794x.2013.815265

Ledbetter, A. M. (2017). Relational maintenance behavior and shared tv viewing as mediators of the association between romanticism and romantic relationship quality. Communication Studies, 68(1), 95-114. https://doi.org/10.1080/10510974.2016.1263804

Ledbetter, A. M., \& Beck, S. J. (2014). A theoretical comparison of relational maintenance and closeness as mediators of family communication patterns in parent-child relationships. Journal of Family Communication, 14(3), 230-252. https://doi.org/10.1080/15267431.2014.908196

Ledbetter, A. M., \& Kuznekoff, J. H. (2012). More than a game: Friendship relational maintenance and attitudes toward Xbox LIVE communication. Communication Research, 39(2), 269-290. https://doi.org/10.1177/0093650210397042 
Ledbetter, A. M., Stassen, H., Muhammad, A., \& Kotey, E. N. (2010). Relational maintenance as including the other in the self. Qualitative Research Reports in Communication, 11(1), 21-28. https://doi.org/10.1080/17459430903413457

Ledbetter, A. M., Stassen-Ferrara, H. M., \& Dowd, M. M. (2013). Comparing equity and self expansion theory approaches to relational maintenance. Personal Relationships, 20(1), 38-51. https://doi.org/10.1111/j.1475-6811.2012.01395.x

Lee, B. H., \& O’Sullivan, L. F. (2018). Ain't misbehavin? Monogamy maintenance strategies in heterosexual romantic relationships. Personal Relationships, 25(2), 205-232. https://doi.org/10.1111/pere.12235

Lewandowski, G. W., \& Ackerman, R. A. (2006). Something's missing: Need fulfillment and self-expansion as predictors of susceptibility to infidelity. The Journal of Social Psychology, 146(4), 389-403. https://doi.org/10.3200/socp.146.4.389-403

Lewandowski, G. W., \& Aron, A. P. (2002, February). The self-expansion scale: Construction and validation [Paper presentation]. Third Annual Meeting of the Society of Personality and Social Psychology, Savannah, GA, United States.

Lewandowski, G. W., \& Bizzoco, N. M. (2007). Addition through subtraction: Growth following the dissolution of a low quality relationship. The Journal of Positive Psychology, 2(1), 40-54. https://doi.org/10.1080/17439760601069234

Luo, S., Cartun, M. A., \& Snider, A. G. (2010). Assessing extradyadic behavior: A review, a new measure, and two models. Personality and Individual Differences, 49(3), 155-163. https://doi.org/10.1016/j.paid.2010.03.033

Maguire, K. C., Heinemann-LaFave, D., \& Sahlstein, E. (2013). “To be so connected, yet not at all": Relational presence, absence, and maintenance in the context of a wartime 
deployment. Western Journal of Communication, 77(3), 249-271.

https://doi.org/10.1080/10570314.2012.757797

Makki, T. W., DeCook, J. R., Kadylak, T., \& Lee O. J. (2018). The social value of snapchat: An exploration of affiliation motivation, the technology acceptance model, and relational maintenance in snapchat use. International Journal of Human-Computer Interaction, 34(5), 410-420. https://doi.org/10.1080/10447318.2017.1357903

Malinen, K., \& Tolvanen, A. (2012). Accentuating the positive, eliminating the negative? Relationship maintenance as a predictor of two-dimensional relationship quality. Family Relations, 61(5), 784-797. https://doi.org/10.1111/j.1741-3729.2012.00738.x

Malouff, J. M., Mundy, S. A., Galea, T. R., \& Bothma, V. N. (2015). Preliminary findings supporting a new model of how couples maintain excitement in romantic relationships. The American Journal of Family Therapy, 43(3), 227-237. https://doi.org/10.1080/01926187.2015.1034634

Mansson, D. H. (2014). Trust as a mediator between affection and relational maintenance in the grandparent-grandchild relationship. Southern Communication Journal, 79(3), 180-200. https://doi.org/10.1080/1041794x.2014.894555

Mansson, D. H. (2016). American grandchildren's use of relational maintenance behaviors with their grandparents. Journal of Intergenerational Relationships, 14(4), 338-352. https://doi.org/10.1080/15350770.2016.1229553

Mansson, D. H., Myers, S. A., \& Turner, L. H. (2010). Relational maintenance behaviors in the grandchild-grandparent relationship. Communication Research Reports, 27(1), 68-79. https://doi.org/10.1080/08824090903526521

Mashek, D., Le, B., Israel, K., \& Aron, A. (2011). Wanting less closeness in romantic 
relationships. Basic and Applied Social Psychology, 33(4), 333-345.

https://doi.org/10.1080/01973533.2011.614164

Mashek, D. J., \& Sherman, M. (2004). Desiring less closeness with intimate others. In D. J. Mashek \& A. Aron (Eds.), Handbook of closeness and intimacy (pp. 343-356). Erlbaum.

Mason, A. J., \& Carr, C. T. (2021). Toward a theoretical framework of relational maintenance in computer-mediated communication. Communication Theory. Advance online publication. https://doi.org/10.1093/ct/qtaa035

Mattingly, B. A., \& Lewandowski, G. W. (2014). Broadening horizons: Self-expansion in relational and non-relational contexts. Social and Personality Psychology Compass, 8(1), 30-40. https://doi.org/10.1111/spc3.12080

Mattingly, B. A., McIntyre, K. P., \& Lewandowski, G. W. (2012). Approach motivation and the expansion of self in close relationships. Personal Relationships, 19(1), 113-127. https://doi.org/10.1111/j.1475-6811.2010.01343.x

McEwan, B. (2013). Sharing, caring, and surveilling: An actor-partner interdependence model examination of Facebook relational maintenance strategies. Cyberpsychology, Behavior, and Social Networking, 16(12), 863-869. https://doi.org/10.1089/cyber.2012.0717

McEwan, B., Fletcher, J., Eden, J., \& Sumner, E. (2014). Development and validation of a Facebook relational maintenance measure. Communication Methods and Measures, 8(4), 244-263. https://doi.org/10.1080/19312458.2014.967844

McEwan, B., \& Guerrero, L. (2012). Maintenance behavior and relationship quality as predictors of perceived availability of resources in newly formed college friendship networks. Communication Studies, 63(4), 421-440. https://doi.org/10.1080/10510974.2011.639433

McEwan, B., \& Horn, D. (2016). ILY \& can u pick up some milk: Effects of relational 
maintenance via text messaging on relational satisfaction and closeness in dating partners. Southern Communication Journal, 81(3), 168-181.

https://doi.org/10.1080/1041794x.2016.1165728

McEwan, B., Sumner, E., Eden, J., \& Fletcher, J. (2018). The effects of Facebook relational maintenance on friendship quality: An investigation of the Facebook relational maintenance measure. Communication Research Reports, 35(1), 1-11. https://doi.org/10.1080/08824096.2017.1361393

McNallie, J., \& Dorrance Hall, E. (2015). The role of perceptions of sibling maintenance behavior in ratings of relationship satisfaction. Communication Research Reports, 32(2), 149-158. https://doi.org/10.1080/08824096.2015.1016147

Merolla, A. J. (2010). Relational maintenance during military deployment: Perspectives of wives of deployed US soldiers. Journal of Applied Communication Research, 38(1), 4-26. https://doi.org/10.1080/00909880903483557

Mertler, C. A., \& Vannatta, R. A. (2013). Advanced and multivariate statistical methods (5 ${ }^{\text {th }}$ ed.). Pyrczak Publishing.

Messman, S. J., Canary, D. J., \& Hause, K. S. (2000). Motives to remain platonic, equity, and the use of maintenance strategies in opposite-sex friendships. Journal of Social and Personal Relationships, 17(1), 67-94. https://doi.org/10.1177/0265407500171004

Metts, S. (1989). An exploratory investigation of deception in close relationships. Journal of Social and Personal Relationships, 6(2), 159-179. https://doi.org/10.1177/026540758900600202

Mikkelson, A. C., Hesse, C., \& Pauley, P. M. (2016). The attributes of relational maximizers. Communication Studies, 67(5), 567-587. https://doi.org/10.1080/10510974.2016.1239644 
Mikkelson, A. C., Myers, S. A., \& Hannawa, A. F. (2011). The differential use of relational maintenance behaviors in adult sibling relationships. Communication Studies, 62(3), 258271. https://doi.org/10.1080/10510974.2011.555490

Miles, J. (2005). Tolerance and variance inflation factor. In B. S. Everitt \& D. C. Howell (ed.), Encyclopedia of Statistics in Behavioral Science (pp. 2055-2056). John Wiley \& Sons,

Miller-Ott, A. E., Kelly, L., \& Duran, R. L. (2012). The effects of cell phone usage rules on satisfaction in romantic relationships. Communication Quarterly, 60(1), 17-34. https://doi.org/10.1080/01463373.2012.642263

Mogilski, J. K., \& Welling, L. L. M. (2017). Staying friends with an ex: Sex and dark personality traits predict motivations for post-relationship friendship. Personality and Individual Differences, 115, 114-119. https://doi.org/10.1016/j.paid.2016.04.016

Monsour, M. (1992). Meanings of intimacy in cross- and same-sex friendships. Journal of Social and Personal Relationships, 9(2), 277-295. https://doi.org/10.1177/0265407592092007

Morr Serewicz, M. C. M., Dickson, F. C., Morrison, J. H. T. A., \& Poole, L. L. (2007). Family privacy orientation, relational maintenance, and family satisfaction in young adults' family relationships. Journal of Family Communication, 7(2), 123-142. https://doi.org/10.1080/15267430701221578

Myers, S. A., Brann, M., \& Rittenour, C. E. (2008). Interpersonal communication motives as a predictor of early and middle adulthood siblings' use of relational maintenance behaviors. Communication Research Reports, 25(2), 155-167. https://doi.org/10.1080/08824090802022028

Myers. S. A., Byrnes, K. A., Frisby, B. N., \& Mansson, D. H. (2011). Adult siblings' use of affectionate communication as a strategic and routine relational maintenance behavior. 
Communication Research Reports, 28(2), 151-158.

https://doi.org/10.1080/08824096.2011.565276

Myers, S. A., \& Glover, N. P. (2007). Emerging adults' use of relational maintenance behaviors with their parents. Communication Research Reports, 24(3), 257-264. https://doi.org/10.1080/08824090701446633

Myers, S. A., \& Goodboy, A. K. (2010). Relational maintenance behaviors and communication channel use among adult siblings. North American Journal of Psychology, 12(2), 103116.

Myers, S. A., Goodboy, A. K., \& Members of COMM 201. (2013). Using equity theory to explore adult sibling use of relational maintenance behaviors and relational characteristics. Communication Research Reports, 30(4), 275-281. https://doi.org/10.1080/08824096.2013.836627

Myers, S. A., \& Members of COM 200. (2001). Relational maintenance behaviors in the sibling relationship. Communication Quarterly, 49(1), 19-34. https://doi.org/10.1080/01463370109385612

Myers, S. A., \& Odenweller, K. G. (2015). The use of relational maintenance behaviors and relational characteristics among sibling types. Communication Studies, 66(2), 238-255. https://doi.org/10.1080/10510974.2014.930918

Myers, S. A., \& Weber, K. D. (2004). Preliminary development of a measure of sibling relational maintenance behaviors: Scale development and initial findings. Communication Quarterly, 52(4), 334-346. https://doi.org/10.1080/01463370409370204

Neff, K. D., \& Pommier, E. (2012). The relationship between self-compassion and other-focused concern among college undergraduates, community adults, and practicing meditators. Self 
and Identity, 12(2), 160-176. https://doi.org/10.1080/15298868.2011.649546

O'Brien, C. R. (2014). Relational maintenance behaviors, conflict resolution strategies, and their relation to loneliness (Publication No. 1583) [Master's Thesis, University of North Dakota]. Theses and Dissertations.

O’Meara, D. (1989). Cross-sex friendship: Four basic challenges of an ignored relationship. Sex Roles, 21(7), 525-543. https://doi.org/10.1007/bf00289102

Ogolsky, B. G. (2009). Deconstructing the association between relationship maintenance and commitment: Testing two competing models. Personal Relationships, 16(1), 99-115. https://doi.org/10.1111/j.1475-6811.2009.01212.x

Ogolsky, B. G., \& Bowers, J. R. (2012). A meta-analytic review of relationship maintenance and its correlates. Journal of Social and Personal Relationships, 30(3), 343-367. https://doi.org/10.1177/0265407512463338

Oswald, D. L., \& Clark, E. M. (2006). How do friendship maintenance behaviors and problemsolving styles function at the individual and dyadic levels? Personal Relationships, 13(3), 333-348. https://doi.org/10.1111/j.1475-6811.2006.00121.x

Oswald, D. L., Clark, E. M., \& Kelly, C. M. (2004). Friendship maintenance: An analysis of individual and dyad behavior. Journal of Social and Clinical Psychology, 23(3), 413-441. https://doi.org/10.1521/jscp.23.3.413.35460

Padilla, M. A., \& Divers, J. (2016). A comparison of composite reliability estimators: Coefficient omega confidence intervals in the current literature. Educational and Psychological Measurement, 76(3), 436-453. https://doi.org/10.1177/0013164415593776

Patrick, H., Knee, C. R., Canevello, A., \& Lonsbary, C. (2007). The role of need fulfillment in relationship functioning and well-being: A self-determination theory perspective. Journal 
of Personality and Social Psychology, 92(3), 434-457.

https://doi.org/10.1037/0022-3514.92.3.434

Paul, E. L., Poole, A., \& Jakubowyc, N. (1998). Intimacy development and romantic status: Implications for adjustment to the college transition. Journal of College Student Development, 39(1), 75-86.

Pauley, P. M., Hesse, C., \& Mikkelson, A. C. (2014). Trait affection predicts married couples' use of relational maintenance behaviors. Journal of Family Communication, 14(2), 167187. https://doi.org/10.1080/15267431.2013.864292

Pennington, N., \& Hall, J. A. (2021). Does Facebook-enabled communication influence weak-tie relationships over time? A longitudinal investigation into mediated relationship maintenance. Communication Monographs, 88(1), 48-70.

https://doi.org/10.1080/03637751.2020.1854476

Pfeil, U., Arjan, R., \& Zaphiris, P. (2009). Age differences in online social networking: A study of user profiles and the social capital divide among teenagers and older users in Myspace. Computers in Human Behavior, 25(3), 643-654. https://doi.org/10.1016/j.chb.2008.08.015

Pistole, M. C., Roberts, A., \& Chapman, M. L. (2010). Attachment, relationship maintenance, and stress in long distance and geographically close romantic relationships. Journal of Social and Personal Relationships, 27(4), 535-552.

https://doi.org/10.1177/0265407510363427

Pytlak, M. A., Zerega, L. M., \& Houser, M. L. (2015). Jealousy evocation: Understanding commitment, satisfaction, and uncertainty as predictors of jealousy-evoking behaviors. Communication Quarterly, 63(3), 310-328. 
https://doi.org/10.1080/01463373.2015.1039716

Rabby, M. K. (2007). Relational maintenance and the influence of commitment in online and offline relationships. Communication Studies, 58(3), 315-337. https://doi.org/10.1080/10510970701518405

Ragsdale, J. (1996). Gender, satisfaction level, and the use of relational maintenance strategies in marriage. Communication Monographs, 63(4), 354-369. https://doi.org/10.1080/03637759609376399

Ragsdale, J. D., \& Brandau-Brown, F. E. (2004). Measuring relational maintenance in marriage: Theoretical and methodological issues. Southern Communication Journal, 69(2), 121135. https://doi.org/10.1080/10417940409373284

Ragsdale, J. D., \& Brandau-Brown, F. E. (2005). Individual differences in the use of relational maintenance strategies in marriage. Journal of Family Communication, 5(1), 61-75. https://doi.org/10.1207/s15327698jfc0501_4

Ragsdale, J. D., \& Brandau-Brown, F. E. (2007a). Could relational maintenance in marriage really be like grocery shopping? A reply to Stafford and Canary. Journal of Family Communication, 7(1), 47-60. https://doi.org/10.1207/s15327698jfc0701_4

Ragsdale, J. D., \& Brandau-Brown, F. E. (2007b). Asked, but not answered: A second reply to Stafford and Canary. Journal of Family Communication, 7(1), 69-73. https://doi.org/10.1080/15267430709336670

Ragsdale, J. D., Brandau-Brown, F. E., \& Bello, R. (2010). Attachment style and gender as predictors of relational repair among the remarried. Journal of Family Communication, 10(3), 158-173. https://doi.org/10.1080/15267431003682468

Ramirez, A. (2008). An examination of the tripartite approach to commitment: An actor-partner 
interdependence model analysis of the effect of relational maintenance behavior. Journal of Social and Personal Relationships, 25(6), 943-965.

https://doi.org/10.1177/0265407508100309

Ramirez, A., Zhang, S., McGrew, C., \& Lin, S. (2007). Relational communication in computer mediated interaction revisited: A comparison of participant-observer perspectives. Communication Monographs, 74(4), 492-516. https://doi.org/10.1080/03637750701716586

Reissman, C., Aron, A., \& Bergen, M. R. (1993). Shared activities and marital satisfaction: Causal direction and self-expansion versus boredom. Journal of Social and Personal Relationships, 10(2), 243-254. https://doi.org/10.1177/026540759301000205

Rittenour, C. E., Myers, S. A., \& Brann, M. (2007). Commitment and emotional closeness in the sibling relationship. Southern Communication Journal, 72(2), 169-183. https://doi.org/10.1080/10417940701316682

Rodriguez, S. R. (2014). "We'll only see parts of each other's lives:" The role of mundane talk in maintaining nonresidential parent-child relationships. Journal of Social and Personal Relationships, 31(8), 1134-1152. https://doi.org/10.1177/0265407514522898

Rusbult, C. E. (1980). Commitment and satisfaction in romantic associations: A test of the investment model. Journal of Experimental Social Psychology, 16(2), 172-186. https://doi.org/10.1016/0022-1031(80)90007-4

Rusbult, C. E. (1983). A longitudinal test of the investment model. The development (and deterioration) of satisfaction and commitment in heterosexual involvements. Journal of Personality and Social Psychology, 45(1), 101-117.

https://doi.org/10.1037/0022-3514.45.1.101 
Sacher, J. A., \& Fine, M. A. (1996). Predicting relationship status and satisfaction after six months among dating couples. Journal of Marriage and Family, 58(1), 21-32. https://doi.org/10.2307/353374

Saldaña, J. (2016). The coding manual for qualitative researchers ( $3^{\text {rd }}$ ed.). SAGE Publications.

Seidman, G. (2018). The Big 5 and relationship maintenance on Facebook. Journal of Social and Personal Relationships, 36(6), 1785-1806. https://doi.org/10.1177/0265407518772089

Sheets, V. L. (2014). Passion for life: Self-expansion and passionate love across the life span. Journal of Social and Personal Relationships, 31(7), 958-974. https://doi.org/10.1177/0265407513515618

Simon, E. O., \& Baxter, L. A. (1993). Attachment-style differences in relationship maintenance strategies. Western Journal of Communication, 57(4), 416-430. https://doi.org/10.1080/10570319309374465

Simpson, J. A. (1990). Influence of attachment styles on romantic relationships. Journal of Personality and Social Psychology, 59(5), 971-980. https://doi.org/10.1037/0022-3514.59.5.971

Solomon, D. H., \& Knobloch, L. K. (2004). A model of relational turbulence: The role of intimacy, relational uncertainty, and interference from partners in appraisals of irritations. Journal of Social and Personal Relationships, 21(6), 795-816. https://doi.org/10.1177/0265407504047838

Solomon, D. H., Knobloch, L. K., Theiss, J. A., \& McLaren, R. M. (2016). Relational turbulence theory: Explaining variation in subjective experiences and communication within romantic relationships. Human Communication Research, 42(4), 507-532. https://doi.org/10.1111/hcre.12091 
Sosik, V. S., \& Bazarova, N. N. (2014). Relational maintenance on social network sites: How Facebook communication predicts relational escalation. Computers in Human Behavior, 35, 124-131. https://doi.org/10.1016/j.chb.2014.02.044

Sprecher, S., Treger, S., Fisher, A., Hilaire, N., \& Grzybowski, M. (2015). Associations between self-expansion and actual and perceived (dis)similarity and their joint effects on attraction in initial interactions. Self and Identity, 14(4), 369-389.

https://doi.org/10.1080/15298868.2014.1003592

Stafford, L. (2003). Maintaining romantic relationships: A summary and analysis of one research program. In D. Canary \& M. Dainton (Eds.), Maintaining relationships through communication: Relational, contextual, and cultural variations (pp. 51-78). Erlbaum.

Stafford, L. (2011). Measuring relationship maintenance behaviors: Critique and development of the revised Relationship Maintenance Behavior Scale. Journal of Social and Personal Relationships, 28(2), 278-303. https://doi.org/10.1177/0265407510378125

Stafford, L., \& Canary, D. J. (1991). Maintenance strategies and romantic relationship type, gender and relational characteristics. Journal of Social and Personal Relationships, 8(2), 217-242. https://doi.org/10.1177/0265407591082004

Stafford, L., \& Canary, D. J. (2006). Equity and interdependence as predictors of relational maintenance strategies. Journal of Family Communication, 6(4), 227-254. https://doi.org/10.1207/s15327698jfc0604_1

Stafford, L., Dainton, M., \& Haas, S. (2000). Measuring routine and strategic relational maintenance: Scale revision versus gender roles, and the prediction of relational characteristics. Communication Monographs, 67(3), 306-323. https://doi.org/10.1080/03637750009376512 
Stewart, M. C., Dainton, M., \& Goodboy, A. K. (2014). Maintaining relationships on Facebook: Associations with uncertainty, jealousy, and satisfaction. Communication Reports, 27(1), 13-26. https://doi.org/10.1080/08934215.2013.845675

Strong, G., \& Aron, A. (2006). The effect of shared participation in novel and challenging activities on experienced relationship quality: Is it mediated by high positive affect? In K. D. Vohs \& E. J. Finkel (Eds.), Self and relationships: Connecting intrapersonal and interpersonal processes (pp. 342-359). The Guildford Press.

Tan, K., \& Agnew, C. R. (2016). Ease of retrieval effects on relationship commitment: The role of future plans. Personality and Social Psychology Bulletin, 42(2), 161-171. https://doi.org/10.1037/e578192014-800

Tan, K., Agnew, C. R., \& Hadden, B. W. (2020). Seeking and ensuring interdependence: Desiring commitment and the strategic initiation and maintenance of close relationships. Personality and Social Psychology Bulletin, 46(1), 36-50. https://doi.org/10.1177/0146167219841633

Theiss, J. A., \& Knobloch, L. K. (2014). Relational turbulence and the post-deployment transition: Self, partner, and relationship focused turbulence. Communication Research, 41(1), 27-51. https://doi.org/10.1177/0093650211429285

Theiss, J. A., \& Nagy, M. E. (2013). A relational turbulence model of partner responsiveness and relationship talk across cultures. Western Journal of Communication, 77(2), 186-209. https://doi.org/10.1080/10570314.2012.720746

Thompson, A. E., \& O'Sullivan, L. F. (2015). Drawing the line: The development of a comprehensive assessment of infidelity judgements. The Journal of Sex Research, 53(8), 910-926. https://doi.org/10.1080/00224499.2015.1062840 
Thompson-Hayes, M., \& Webb, L. M. (2004). Theory in progress: Commitment under construction: A dyadic and communicative model of marital commitment. Journal of Family Communication, 4(3), 249-260. https://doi.org/10.1080/15267431.2004.9670134

Toale, M. C., \& McCroskey, J. C. (2001). Ethnocentrism and trait communication apprehension as predictors of interethnic communication apprehension and use of relational maintenance strategies in interethnic communication. Communication Quarterly, 49(1), 70-83. https://doi.org/10.1080/01463370109385615

Tokunaga, R. S. (2016). Interpersonal surveillance over social network sites: Applying a theory of negative relational maintenance and the investment model. Journal of Social and Personal Relationships, 33(2), 171-190. https://doi.org/10.1177/0265407514568749

Tolhuizen, J. H. (1989). Communication strategies for intensifying dating relationships: Identification, use and structure. Journal of Social and Personal Relationships, 6(4), 413434. https://doi.org/10.1177/0265407589064002

Tran, S., \& Simpson, J. A. (2009). Prorelationship maintenance behaviors: The joint roles of attachment and commitment. Journal of Personality and Social Psychology, 97(4), 685698. https://doi.org/10.1037/a0016418

Triệu, P., \& Baym, N. K. (2020, April 25). Private responses for public sharing: Understanding self presentation and relational maintenance via stories in social media [Conference session]. Proceedings of the 2020 CHI Conference on Human Factors in Computing Systems. https://doi.org/10.1145/3313831.3376549

Tucker, P., \& Aron, A. (1993). Passionate love and marital satisfaction at key transition points in the family life cycle. Journal of Social and Clinical Psychology, 12(2), 135-147. https://doi.org/10.1521/jscp.1993.12.2.135 
VanderDrift, L. E., Lewandowski, G. W., \& Agnew, C. R. (2011). Reduced self-expansion in current romance and interest in relationship alternatives. Journal of Social and Personal Relationships, 28(3), 356-373. https://doi.org/10.1177/0265407510382321

Vaterlaus, J. M., Barnett, K., Roche, C., \& Young, J. A. (2016). "Snapchat is more personal”: An exploratory study on Snapchat behaviors and young adult interpersonal relationships. Computers in Human Behavior, 62, 594-601. https://doi.org/10.1016/j.chb.2016.04.029

Weger, H., Jr., \& Emmett, M. C. (2009). Romantic intent, relationship uncertainty, and relationship maintenance in young adults' cross-sex friendships. Journal of Social and Personal Relationships, 26(6), 964-988. https://doi.org/10.1177/0265407509347937

Weidler, D. J., \& Clark, E. M. (2011). A distinct association: Inclusion of other in the self and self-disclosure. The New School Psychology Bulletin, 9(1), 36-45. https://doi.org/10.1037/e505232012-005

Weigel, D. J., \& Ballard-Reisch, D. S. (1999a). All marriages are not maintained equally: Marital type, marital quality, and the use of maintenance behaviors. Personal Relationships, 6(3), 291-303. https://doi.org/10.1111/j.1475-6811.1999.tb00193.x

Weigel, D. J., \& Ballard-Reisch, D. S. (1999b). How couples maintain marriages: A closer look at self and spouse influences upon the use of maintenance behaviors in marriages. Family Relations, 48(3), 263-269. https://doi.org/10.2307/585635

Weigel, D. J., \& Ballard-Reisch, D. S. (1999c). The influence of marital duration on the use of relationship maintenance behaviors. Communication Reports, 12(2), 59-70. https://doi.org/10.1080/08934219909367711

Weigel, D. J., \& Ballard-Reisch, D. S. (1999d). Using paired data to test models of relational 
maintenance and marital quality. Journal of Social and Personal Relationships, 16(2), 175-191. https://doi.org/10.1177/0265407599162003

Weigel, D. J., \& Ballard-Reisch, D. S. (2001). The impact of relational maintenance behaviors on marital satisfaction: A longitudinal analysis. Journal of Family Communication, 1(4), 265-279. https://doi.org/10.1207/s15327698jfc0104_03

Weigel, D. J., \& Ballard-Reisch, D. S. (2008). Relational maintenance, satisfaction, and commitment in marriages. Journal of Family Communication, 8(3), 212-229. https://doi.org/10.1080/15267430802182522

Weigel, D. J., Brown, C., \& O'Riordan, C. K. (2011). Everyday expressions of commitment and relational uncertainty as predictors of relationship quality and stability over time. Communication Reports, 24(1), 38-50. https://doi.org/10.1080/08934215.2010.511400

Weigel, D. J., Weiser, D. A., \& Lalasz, C. B. (2017). Testing a motivation model of relational maintenance: The role of approach and avoidance relationship goals. Western Journal of Communication, 81(3), 341-361. https://doi.org/10.1080/10570314.2016.1240372

Weiser, D. A., \& Weigel, D. J. (2016). Self-efficacy in romantic relationships: Direct and indirect effects on relationship maintenance and satisfaction. Personality and Individual Differences, 89, 152-156. https://doi.org/10.1016/j.paid.2015.10.013

Weisskirch, R. S. (2017). Abilities in romantic relationships and well-being among emerging adults. Marriage \& Family Review, 53(1), 36-47. https://doi.org/10.1080/01494929.2016.1195471

Wentland, J. J., \& Reissing, E. (2011). Taking casual sex not too casually: Exploring definitions of casual sexual relationships. The Canadian Journal of Human Sexuality, 20(3), 75-91.

Wentland, J. J., \& Reissing, E. (2014). Casual sexual relationships: Identifying definitions for 
one night stands, booty calls, fuck buddies, and friends with benefits. The Canadian Journal of Human Sexuality, 23(3), 167-177. https://doi.org/10.3138/cjhs.2744

Yum, Y., \& Canary, D. J. (2009). Cultural differences in equity theory predictions of relational maintenance strategies. Human Communication Research, 35(3), 384-406. https://doi.org/10.1111/j.1468-2958.2009.01356.x

Yum, Y., \& Li, H. Z. (2007). Associations among attachment style, maintenance strategies, and relational quality across cultures. Journal of Intercultural Communication Research, 36(2), 71-89. https://doi.org/10.1080/17475750701478612 
Appendix A

Study 1 Printed Bulletin Board "Mach Form” Recruitment Script

Title: Standby Lovers: A Theoretical Investigation of Maintenance Behaviors in Back Burner Relationships

Protocol Number: 1910734233

PI: Dr. Matthew M. Martin

PI E-mail: Matt.Martin@mail.wvu.edu

Co-PI: Dana Borzea

Co-PI E-mail: daborzea@mix.wvu.edu

Purpose of Study (1 sentence): The purpose of this research study is to better understand the relational maintenance behaviors used in back burner relationships.

To be eligible for participation in this study, you must meet the following inclusion criteria:

To participate in this study, you must be at least 18 years old and currently involved in a back burner relationship.

Time Commitment: 30 minutes

Data Collection Location: Online Survey

Data Collection Date \& Time: Online Qualtrics Survey Link:

https://wvu.qualtrics.com/jfe/form/SV 8nVDqkphX4f9Cwl 


\section{Appendix B}

\section{Study 1 Cover Letter}

April 29, 2021

Dear Participant:

You are being asked to participate in a research study designed to better understand the relational maintenance behaviors used in back burner relationships. This project is being conducted by Dr. Scott A. Myers, with the assistance of Dana Borzea from the Department of Communication Studies. To participate in this study, you must be at least 18 years old and currently involved with a back burner.

\section{A BACK BURNER is a person with whom you keep in contact because you are interested in someday connecting romantically and/or sexually in the future.}

- You CANNOT be currently romantically and/or sexually involved with this person.

- You CAN have a back burner even if you're already in a romantic relationship with someone else.

- A former romantic and/or sexual partner can still count as a back burner so long as you still desire a romantic and/or sexual connection with them someday in the future.

To participate in this study, you must read over this cover letter then complete the online questionnaire about a current back burner. In order to maintain privacy, your responses will not be tracked back to you and confidentiality is guaranteed from the Principal Investigator and the Co-Investigator. Please complete the questionnaire independently and be sure to read the instructions carefully and answer honestly. There is no right or wrong answer. Your participation is voluntary. You may skip certain questions if you want and you may stop completing the questionnaire at any time without fear or penalty.

The link for the online questionnaire is https://wvu.qualtrics.com/jfe/form/SV 8nVDqkphX4f9Cwl

The questionnaire will take approximately 30 minutes to complete. If you would like more information about this research project, feel free to contact Principal Investigator Dr. Scott A. Myers at scott.myers@mail.wvu.edu. This study has been acknowledged by West Virginia University's Institutional Review Board, and is on file as Protocol \#1910734233.

As a student enrolled in an entry level COMM course during the Fall 2019 semester, you are eligible to receive extra credit for participating in this study. (Your COMM course syllabus provides the amount of potential extra credit points you may receive.) Upon completion of the questionnaire, you will receive a research receipt that you then will give to your COMM course instructor so that any extra credit points you receive will be recorded. Thank you for participation.

Sincerely, 
Scott A. Myers, Ph.D.

Professor

Principal Investigator

Scott.Myers@mail.wvu.edu
Dana Borzea, M. A.

Ph.D. Candidate

Co-Investigator

daborzea@mix.wvu.edu 


\section{Appendix C}

Study 1 Questionnaire

\section{Directions: A BACK BURNER is a person with whom you keep in contact because you are interested in someday connecting romantically and/or sexually in the future.}

- You CANNOT be currently romantically and/or sexually involved with this person.

- You CAN have a back burner even if you're already in a romantic relationship with someone else.

- A former romantic and/or sexual partner can still count as a back burner so long as you still desire a romantic and/or sexual connection with them someday in the future.

\section{Please answer the following questions:}

1. Based on the above description, think of one back burner with whom you communicate. Please provide his/her initials:

2. What is the CURRENT nature of your relationship with this back burner? (select one) specify): Acquaintance ___ Casual friend __ Close friend __ Best friend __ Other (Please

3. How often do you communicate with this back burner? (select one) Less than once a year About once a year About once every 6 months About once every 2-3 months Once a month Once a week More than once a week Every day

4. How well do you think you know this back burner? (select one) I do not know him/her at all I somewhat know him/her I mostly know him/her I completely know him/her

Only answer question \#5 if you are CURRENTLY IN A ROMANTIC RELATIONSHIP. 5. To what extent is your current romantic partner aware you maintain contact with this back burner? (select one)

My romantic partner has no idea.

My romantic partner knows I keep in touch with my back burner, but to not the full extent. My romantic partner knows the full extent to which I keep in touch with my back burner. 
Directions: To maintain our relationships the way we like them, we engage in maintenance behaviors. Some of these behaviors are positive: for example, we are open and self-disclose our feelings. However, we occasionally engage in negative behaviors within our relationships, and we do these negative things for the sake of the relationship. For example, we might avoid interacting with the other person when we do not want to deal with an issue. Much of maintaining a relationship can involve mundane or routine aspects of day-to-day life. These are things you might not have thought of above because they might seem too trivial.

Please offer up to five examples of behaviors (positive, negative, or a combination of both) that you have used to maintain your back burner relationship with this person.

1.

2.

3.

4.

5. 
Directions: Please answer the following questions about yourself and your back burner.

1. How long have you known this back burner?

years months

2. Is this back burner a former romantic or sexual partner?

Yes, a former romantic partner

Yes, a former sexual partner

Yes, both a former romantic and sexual partner

No, not a former romantic or sexual partner

2. Your age:

3. Your back burner's age:

4. Your sex:

Male F__ Female Male to Female Transgender ___ Female to Male

Transgender

Nonbinary

Other (Please specify):

Prefer not to

answer

5. Your back burner's sex:

$\begin{array}{lll}\text { Male } & \text { Female } \_ \text {Male to Female Transgender __ Female to Male } \\ \text { Transgender } & \text { Other (Please specify): } & \text { Prefer not to } \\ \text { answer } & \end{array}$

8. What is your ethnicity?

Asian/Asian-American
Black/African-American
Middle Eastern
Hispanic
Native American
White/Caucasian
Other(please specify):

9. What is your back burner's ethnicity?

Asian/Asian-American

Black/African-American

Middle Eastern 
Hispanic

Native American

White/Caucasian

Other(please specify):

Thank you for participating in this study! We appreciate your time. 
Appendix D

Study 2 Printed Bulletin Board "Mach Form” Recruitment Script

Title: Standby Lovers: A Theoretical Investigation of Maintenance Behaviors in Back Burner Relationships

Protocol Number: 1910734233

PI: Dr. Matthew M. Martin

PI E-mail: Matt.Martin@mail.wvu.edu

Co-PI: Dana Borzea

Co-PI E-mail: daborzea@mix.wvu.edu

Purpose of Study (1 sentence): The purpose of this research study is to better understand the relational maintenance of back burner relationships.

To be eligible for participation in this study, you must meet the following inclusion criteria:

To participate in this study, you must be at least 18 years old and currently involved in a back burner relationship.

Time Commitment: 30 minutes

Data Collection Location: Online Survey

Data Collection Date \& Time: Online Qualtrics Survey Link:

https://wvu.qualtrics.com/jfe/form/SV_bJgUwFbU5e4Be0B 


\section{Appendix E}

\section{Study 2 Email Recruitment Script}

"Hi everyone!

My name is Dana Borzea and I am an Ph.D. candidate in the Department of Communication Studies at WVU. I am currently conducting a research study on the relational maintenance of back burner relationships.

I am here today to possibly solicit your help! I am going to give you instructions about who can participate in this study and what they need to do if they choose to voluntarily participate.

To qualify to participate in this study you must be at least 18 years of age and currently involved in a back burner relationship.

After taking the survey, you will be able to enter your identifying information (for course credit) through a separate portal such that your identity is not linked to your survey responses. Be sure to include your full name, instructor name, and course name so that you receive your proper credit.

If you do not want to participate in this study, your grade and/or standing in the class will not be influenced. There are other research studies or alternative assignments you could complete instead. WVU IRB acknowledgement of this study is on file. Please feel free to contact me, Dana Borzea, at daborzea@mix.wvu.edu if you have any questions about this study.

Thank you for your time!

Sincerely,

Dana Borzea" 


\section{Appendix F}

\section{Study 2 Cover Letter}

Dear Participant,

This letter is a request for you to take part in a research project designed to better understand the relational maintenance of back burner relationships. The project is being conducted by Dana Borzea, M.A. in the Department of Communication Studies at WVU under the supervision of Dr. Matthew M. Martin, Ph.D., a professor in the Department of Communication Studies at WVU, to fulfill requirements for a doctorate degree in research.

If you decide to participate, you will be asked to visit the link below to complete an online questionnaire about a current back burner relationship. Your participation in this project will take approximately 30 minutes to complete. You must be 18 years of age or older AND currently involved in a back burner relationship to participate.

Link for online questionnaire: https://wvu.qualtrics.com/jfe/form/SV_bJgUwFbU5e4Be0B

You will receive extra credit for participating in this study. Your COMM course syllabus provides the amount of potential extra credit points you may receive. Your involvement in this project will be kept as confidential as legally possible. All data will be reported in the aggregate. Your responses will not be connected to your identity as a participant. Your participation is completely voluntary. You may skip any question that you do not wish to answer and you may discontinue at any time. Your class standing will not be affected if you decide wither not to participate or to withdraw. WVU IRB acknowledgement of this study is on file. Your name, communication course, and communication course's instructor will be requested so you can receive extra credit. However, it will be stored separately from any data collected in the study. A counseling services referral list is attached to this cover letter.

If you have any questions about this research project, please feel free to contact me by e-mail at daborzea@mix.wvu.edu. If you have any questions about your rights as research participant, please contact the WVU Office of Human Research Protection by phone at 304-293-7073 or by email at IRB@mail.wvu.edu.

I hope that you will participate in this research project, as it could help us better understand the process of maintaining back burner relationships. Thank you for your time and consideration.

Sincerely,

Matthew M. Martin, Ph.D.

Professor

Principal Investigator

mmartin@wvu.edu
Dana Borzea, M.A.

Ph.D. Candidate

Co-Investigator

daborzea@mix.wvu.edu 


\section{Counseling Services Referral List:}

\section{Update on services}

The Carruth Center's physical office is closed until further notice. Services are available through telehealth and other online methods. You can still reach us at 304-293-4431 if you have questions or are interested in scheduling services. You can also contact us via email for general information or questions. Information about our response and care model for COVID-19 is updated frequently. Curious about what to expect? Learn more in our Orientation to Services.

\section{Current Services}

At the Carruth Center, we provide a variety of psychological, psychiatric, and counseling services for a wide range of student concerns in a distance counseling format.

\section{Individual Counseling}

Students have the opportunity to sit down with a counselor one-on-one to discuss their concerns in a private and confidential setting. Our short-term individual counseling sessions last about forty-five to fifty minutes and may be held once a week, once every other week, or less frequently. Many students find that their concerns are resolved in three to four sessions.

\section{Crisis Clinic}

The Crisis Clinic provides same day virtual (or in some cases) in-person visits for students who are experiencing a psychological emergency. A Crisis counselor will meet with you via Zoom or telephone and help determine the type of care to meet your needs.

\section{Couples Counseling}

Couples counseling is offered only on a very limited basis at CCPPS. Both partners must be an enrolled WVU student to qualify for services. Students interested in the service should contact the Carruth Center at 304-293-4431 and ask to speak to a case manager or clinical director.

\section{Group Counseling}

Group counseling offers students the opportunity to meet with other students experiencing similar concerns. All group counseling sessions are intended to facilitate a supportive and confidential therapeutic environment. A clinician helps guide and direct the students during the group session. Group counseling sessions are held weekly and often last for a few weeks for an hour to an hour and a half per session. More information can be found on our group counseling page.

\section{Drug and Alcohol Counseling}

The Student Assistance Program offers a number of different counseling options for students seeking drug or alcohol counseling. Students may participate in individual counseling, group counseling, and educational activities. The Student Assistance Program also provides information concerning community resources, such as Alcoholics Anonymous and Narcotics Anonymous. More information can be found on the Student Assistance Program page.

\section{Psychiatry}


Our psychiatry staff offer consultation as well as outpatient treatment and management for a wide range of emotional health and well-being concerns including depression, anxiety, mania, psychosis, and attention related concerns

Students can be referred to meet with one of our psychiatrists by our counseling center staff or Student Health Service. If you wish to schedule an initial triage appointment with one of our counselors to discuss possible referral for psychiatric services, contact us to make an appointment. Please arrive 20 minutes prior to your scheduled appointment in order to complete the intake forms

A \$25 fee is charged for each psychiatry appointment. An online payment portal is available for credit card payments.

We do not schedule future psychiatry appointments beyond 4 weeks from the time the appointment is requested. In the event there are no new appointment openings within a 4 week period, our counselors will encourage other mental health resources available at the Carruth Center, at WVU or in the greater Morgantown community. 


\section{Appendix G}

Study 2 Questionnaire

\section{Directions: A BACK BURNER is a person with whom you keep in contact because you are interested in someday connecting romantically and/or sexually in the future.}

- You CANNOT be currently romantically and/or sexually involved with this person.

- You CAN have a back burner even if you're already in a romantic relationship with someone else.

- A former romantic and/or sexual partner can still count as a back burner so long as you still desire a romantic and/or sexual connection with them someday in the future.

\section{Please answer the following questions:}

1. Based on the above description, think of one back burner with whom you communicate. Please provide his/her initials:

2. What is the CURRENT nature of your relationship with this back burner? (select one)

\section{specify):} Acquaintance Casual friend Close friend Best friend Other (Please

3. How often do you communicate with this back burner? (select one) Less than once a year About once a year About once every 6 months About once every 2-3 months Once a month Once a week More than once a week Every day

4. How well do you think you know this back burner? (select one) I do not know him/her at all I somewhat know him/her I mostly know him/her I completely know him/her

Only answer question \#5 if you are CURRENTLY IN A ROMANTIC RELATIONSHIP. 5. To what extent is your current romantic partner aware you maintain contact with this back burner? (select one)

My romantic partner has no idea.

My romantic partner knows I keep in touch with my back burner, but to not the full extent. My romantic partner knows the full extent to which I keep in touch with my back burner. 
Directions: The following items describe the various ways some people behave in back burner relationships. For each of the items, indicate how often you and your back burner partner engage in these behaviors.

If never, select 1

If rarely, select 2

If sometimes, select 3

If often, select 4

If always, select 5

1. We flirt and share funny anecdotes with each other (e.g., inside jokes, memes, or funny memories).

2. We avoid potentially-intimate situations (e.g., we monitor how much time we spend alone together) or conversations (e.g., we avoid conversations about our feelings for each other and the future of the relationship).

3. We openly discuss details of our lives with each other (e.g., personal information, emotions, experiences, goals).

4. We are there for each other to offer encouraging emotional support (e.g., listening to their current struggles) and behavioral support (e.g., offering help with homework).

5. We regularly talk via some form of communication (e.g., Snapchat, texting, Facetime, phone calls, direct messages).

6. We make it clear to each other what we want and do not want out of this back burner relationship, both currently and in the future.

7. We spend time doing different activities together (e.g., getting food, going out, watching movies, or traveling).

8. We spend time in the same social circles (e.g., hanging out with mutual friends, visiting family members, or following friends and family on social media).

9. We make sure to somehow recognize special occasions together (e.g., send a text on their birthday, visit during holidays, or exchange gifts).

10. We purposefully avoid and withhold information from each other (e.g., making up excuses to avoid seeing them; concealing your other sexual partners) and people outside of the back burner relationship (e.g., downplaying the relationship to friends). 
Directions: Please honestly indicate the extent to which you agree or disagree with the following statements about your general attitudes towards yourself, others, and relationships.

If you strongly disagree with the statement, select $\mathbf{1}$.

If you disagree with the statement, select 2.

If you somewhat disagree with the statement, select 3 .

If you neither agree nor disagree with the statement, select 4.

If you somewhat agree with the statement, select 5.

If you agree with the statement, select $\mathbf{6}$.

If you strongly agree with the statement, select 7 .

1. I sometimes worry that I do not really fit in with other people.

2. I sometimes worry that I do not measure up to other people.

3. I am confident that other people will like me.

4. I worry that others will reject me.

5. I am confident that others will accept me.

6. I find it relatively easy to get close to people.

7. It is easy for me to get along with others.

8. I worry that people don't like me as much as I like them.

9. Sometimes others seem reluctant to get as close to me as I would like.

10. I worry a lot about the well-being of my relationships.

11. I worry that others do not care about me as much as I care about them.

12. I wonder how I would cope without someone to love me.

13. I sometimes worry that relational partners will leave me.

14. I need to be in a close relationship to be happy.

15. I would like to trust others, but I worry that if I open up too much people might reject

me.

16. I worry about getting hurt if I allow myself to get too close to someone.

17. I would like to have closer relationships, but getting close makes me feel vulnerable.

18. I tend not to take risks in relationships for fear of getting hurt or rejected.

19. I avoid getting too close to others so that I won't get hurt.

20. I feel smothered when a relationship takes too much time away from my personal pursuits.

21. Achieving personal goals is more important to me than maintaining good relationships.

22. Being independent is more important to me than having a good relationship.

23. Pleasing myself is much more important to me than getting along with others.

24. I need relational partners to give me space to do "my own thing."

25. I frequently pull away from relational partners when I need time to pursue my personal goals. 
Directions: We would like you to rate how certain you are about the degree of involvement between you and your back burner at this time. Please note, we are not asking you to rate how much involvement there is, but rather how certain you are about whatever degree of involvement you perceive. It might help if you first consider how much of each form of involvement is present between you and your back burner, and then evaluate how certain you are about that perception.

If you are completely or almost completely uncertain, select 1.

If you are mostly uncertain, select 2.

If you are slightly more uncertain than certain, select 3 .

If you are slightly more certain than uncertain, select 4 .

If you are mostly certain, select 5 .

If you are completely or almost completely certain, select 6 .

With this back burner you identified, how certain are you about...

1. the definition of this relationship?

2. whether or not you and your back burner feel the same way about each other?

3. whether or not you and your back burner will stay together?

4. how you and your back burner would describe this relationship?

5. the future of the relationship?

6. what you can or cannot say to each other in the relationship?

7. the boundaries for appropriate and/or inappropriate behavior in this relationship?

8. whether or not this relationship will end soon?

9. how you and your back burner view this relationship?

10. the state of the relationship at this time?

11. whether or not your back burner likes you as much as you like him or her?

12. the current status of this relationship?

13. whether or not this a romantic or platonic relationship?

14. the norms of the relationship?

15. where this relationship is going?

16. how you can or cannot behave around your back burner? 
Directions: Please read each of the following items carefully, thinking about your back burner relationship. Use the following scale to indicate how much you agree or disagree with each statement.

If you strongly disagree with the statement, select $\mathbf{1}$.

If you disagree with the statement, select 2.

If you somewhat disagree with the statement, select 3 .

If you neither agree nor disagree with the statement, select 4.

If you somewhat agree with the statement, select 5.

If you agree with the statement, select 6.

If you strongly agree with the statement, select 7 .

1. Being with my back burner results in having new experiences.

2. When I am with my back burner, I feel a greater awareness of things because of him/her.

3. My back burner increases my ability to accomplish new things.

4. Being with my back burner makes me more appealing to potential future mates.

5. My back burner helps to expand my sense of the kind of person I am.

6. I see my back burners as a way to expand my own capabilities.

7. I often learn new things about my back burner.

8. My back burner provides a source of exciting experiences.

9. My back burner's strengths as a person (skills, abilities, etc.) compensate for someone

of. My own weaknesses as a person.

10. I feel that I have a larger perspective on things because of my back burner.

11. Being with my back burner has resulted in me learning new things.

12. Knowing my back burner has made me a better person.

13. Being with my back burner increases the respect other people have for me.

14. My back burner increases my knowledge. 
Directions: Please read each of the following items carefully, thinking about your back burner relationship. Use the following scale to indicate how much you agree or disagree with each statement.

If you strongly disagree with the statement, select $\mathbf{1}$.

If you disagree with the statement, select 2.

If you somewhat disagree with the statement, select 3 .

If you neither agree nor disagree with the statement, select 4.

If you somewhat agree with the statement, select 5.

If you agree with the statement, select $\mathbf{6}$.

If you strongly agree with the statement, select 7 .

1. I want this back burner relationship to last as long as possible.

2. I like my back burner very much.

3. Both of us are satisfied with the way we handle decisions.

4. My back burner meets my needs.

5. I am committed to maintaining this back burner relationship.

6. My back burner's good points far outweigh his/her bad points.

7. We agree on what we can expect from one another.

8. In general, I am satisfied with my back burner relationship.

9. I think that it is unlikely that this back burner relationship will end in the near future.

10. My back burner is one of the most likeable people I know.

11. We are attentive to each other's comments.

12. My back burner relationship is good compared to most.

13. I feel very attached to my back burner.

14. My back burner is the sort of person whom I myself would like to be.

15. We both have an equal 'say'.

16. I often wish I hadn't gotten into this back burner relationship.

17. There are no others I want to get know romantically.

18. I admire my back burner.

19. We are co-operative with each other.

20. My back burner relationship has met my original expectations.

21. I do not want another back burner.

22. I love my back burner.

23. There are many problems in this back burner relationship 
Directions: Please answer the following questions about yourself and your back burner.

1. How long have you known this back burner?

years months

2. Is this back burner a former romantic or sexual partner?

Yes, a former romantic partner

Yes, a former sexual partner

Yes, both a former romantic and sexual partner

No, not a former romantic or sexual partner

2. Your age:

3. Your back burner's age:

4. Your sex:

Male ___ Female ___ Male to Female Transgender ___ Female to Male

Transgender

Nonbinary

Other (Please specify):

Prefer not to

answer

5. Your back burner's sex:

$\begin{array}{lll}\text { Male } & \text { Female } \quad \text { Male to Female Transgender } & \text { Female to Male } \\ \text { Transgender } & \text { Other (Please specify): } & \text { Prefer not to } \\ \text { Nonbinary } & \_\end{array}$

8. What is your ethnicity?

Asian/Asian-American
Black/African-American
Middle Eastern
Hispanic
Native American
White/Caucasian
Other(please specify):

9. What is your back burner's ethnicity?

Asian/Asian-American

Black/African-American

Middle Eastern 
Hispanic

Native American

White/Caucasian

Other(please specify):

Thank you for participating in this study! We appreciate your time. 


\section{Appendix $\mathrm{H}$}

\section{Back Burner Maintenance Behavior Items}

If never, select 1.

If rarely, select 2.

If sometimes, select 3 .

If often, select 4.

If always, select 5 .

1. We flirt and share funny anecdotes with each other (e.g., inside jokes, memes, or funny memories).

2. We avoid potentially-intimate situations (e.g., we monitor how much time we spend alone together) or conversations (e.g., we avoid conversations about our feelings for each other and the future of the relationship).

3. We openly discuss details of our lives with each other (e.g., personal information, emotions, experiences, goals).

4. We are there for each other to offer encouraging emotional support (e.g., listening to their current struggles) and behavioral support (e.g., offering help with homework).

5. We regularly talk via some form of communication (e.g., Snapchat, texting, Facetime, phone calls, direct messages).

6. We make it clear to each other what we want and do not want out of this back burner relationship, both currently and in the future.

7. We spend time doing different activities together (e.g., getting food, going out, watching movies, or traveling).

8. We spend time in the same social circles (e.g., hanging out with mutual friends, visiting family members, or following friends and family on social media).

9. We make sure to somehow recognize special occasions together (e.g., send a text on their birthday, visit during holidays, or exchange gifts).

10. We purposefully avoid and withhold information from each other (e.g., making up excuses to avoid seeing them; concealing your other sexual partners) and people outside of the back burner relationship (e.g., downplaying the relationship to friends). 


\section{Appendix I}

Attachment Style Measure (Guerrero, 1996; Guerrero, Farinelli, \& McEwan, 2009)

If you strongly disagree with the statement, select $\mathbf{1}$.

If you disagree with the statement, select 2.

If you somewhat disagree with the statement, select 3 .

If you neither agree nor disagree with the statement, select 4.

If you somewhat agree with the statement, select 5.

If you agree with the statement, select 6.

If you strongly agree with the statement, select 7 .

1. I sometimes worry that I do not really fit in with other people. $\mathbf{R}$

2. I sometimes worry that I do not measure up to other people. $\mathbf{R}$

3. I am confident that other people will like me.

4. I worry that others will reject me. $\mathbf{R}$

5. I am confident that others will accept me.

6. I find it relatively easy to get close to people.

7. It is easy for me to get along with others.

8. I worry that people don't like me as much as I like them.

9. Sometimes others seem reluctant to get as close to me as I would like.

10. I worry a lot about the well-being of my relationships.

11. I worry that others do not care about me as much as I care about them.

12. I wonder how I would cope without someone to love me.

13. I sometimes worry that relational partners will leave me.

14. I need to be in a close relationship to be happy.

15. I would like to trust others, but I worry that if I open up too much people might reject me.

16. I worry about getting hurt if I allow myself to get too close to someone.

17. I would like to have closer relationships, but getting close makes me feel vulnerable.

18. I tend not to take risks in relationships for fear of getting hurt or rejected.

19. I avoid getting too close to others so that I won't get hurt.

20. I feel smothered when a relationship takes too much time away from my personal pursuits.

21. Achieving personal goals is more important to me than maintaining good relationships.

22. Being independent is more important to me than having a good relationship.

23. Pleasing myself is much more important to me than getting along with others.

24. I need relational partners to give me space to do "my own thing."

25. I frequently pull away from relational partners when I need time to pursue my personal goals.

Note. Items 1-7 measure Secure Attachment. Items 8-14 measure Preoccupied Attachment. Items 15-19 measure Fearful-Avoidant Attachment. Items 20-25 measure Dismissive Attachment. R indicates the item is reverse coded. 
Appendix J

Relationship Uncertainty Scale (Knobloch \& Solomon, 1991)

If you are completely or almost completely uncertain, select 1 .

If you are mostly uncertain, select 2.

If you are slightly more uncertain than certain, select 3 .

If you are slightly more certain than uncertain, select 4 .

If you are mostly certain, select 5 .

If you are completely or almost completely certain, select 6 .

With this back burner you identified, how certain are you about...

1. what you can or cannot say to each other in the relationship?

2. the boundaries for appropriate and/or inappropriate behavior in this relationship?

3 . the norms of the relationship?

4. how you can or cannot behave around your back burner?

5. whether or not you and your back burner feel the same way about each other?

6. how you and your back burner view this relationship?

7. whether or not your back burner likes you as much as you like him or her?

8. the current status of this relationship?

9. the definition of this relationship?

10. how you and your back burner would describe this relationship?

11. the state of the relationship at this time?

12. whether or not this a romantic or platonic relationship?

13. whether or not you and your back burner will stay together?

14. the future of the relationship?

15. whether or not this relationship will end soon?

16. where this relationship is going?

Note. Items 1-4 measure Behavioral Uncertainty. Items 5-8 measure Mutuality Uncertainty. Items 9-12 measure Definition Uncertainty. Items 13-16 measure Future Uncertainty. 


\section{Appendix K}

Self-Expansion Questionnaire (Lewandowski \& Aron, 2002)

If you strongly disagree with the statement, select 1.

If you disagree with the statement, select 2 .

If you somewhat disagree with the statement, select 3 .

If you neither agree nor disagree with the statement, select 4 .

If you somewhat agree with the statement, select 5.

If you agree with the statement, select 6.

If you strongly agree with the statement, select 7 .

1. Being with my back burner results in having new experiences.

2. When I am with my back burner, I feel a greater awareness of things because of him/her.

3. My back burner increases my ability to accomplish new things.

4. Being with my back burner makes me more appealing to potential future mates.

5. My back burner helps to expand my sense of the kind of person I am.

6. I see my back burners as a way to expand my own capabilities.

7. I often learn new things about my back burner.

8. My back burner provides a source of exciting experiences.

9. My back burner's strengths as a person (skills, abilities, etc.) compensate for someone of. My own weaknesses as a person.

10. I feel that I have a larger perspective on things because of my back burner.

11. Being with my back burner has resulted in me learning new things.

12. Knowing my back burner has made me a better person.

13. Being with my back burner increases the respect other people have for me.

14. My back burner increases my knowledge. 


\section{Appendix L}

Global Commitment Measure (Canary \& Stafford, 1991)

If you strongly disagree with the statement, select $\mathbf{1}$.

If you disagree with the statement, select 2.

If you somewhat disagree with the statement, select 3 .

If you neither agree nor disagree with the statement, select 4.

If you somewhat agree with the statement, select 5.

If you agree with the statement, select 6.

If you strongly agree with the statement, select 7 .

1. I want this back burner relationship to last as long as possible.

2. I am committed to maintaining this back burner relationship.

3. I think that it is unlikely that this back burner relationship will end in the near future.

4. I feel very attached to my back burner.

5. There are no others I want to get know romantically.

6. I do not want another back burner 


\section{Appendix M}

Liking Measure (Stafford \& Canary, 1991)

If you strongly disagree with the statement, select $\mathbf{1}$.

If you disagree with the statement, select 2 .

If you somewhat disagree with the statement, select 3 .

If you neither agree nor disagree with the statement, select 4 .

If you somewhat agree with the statement, select 5.

If you agree with the statement, select 6 .

If you strongly agree with the statement, select 7 .

1. I like my back burner very much.

2. My back burner's good points far outweigh his/her bad points.

3. My back burner is one of the most likeable people I know.

4. My back burner is the sort of person whom I myself would like to be.

5. I admire my back burner. 


\section{Appendix N}

Control Mutuality Measure (Stafford \& Canary, 1991)

If you strongly disagree with the statement, select $\mathbf{1}$.

If you disagree with the statement, select 2 .

If you somewhat disagree with the statement, select 3 .

If you neither agree nor disagree with the statement, select 4 .

If you somewhat agree with the statement, select 5.

If you agree with the statement, select 6 .

If you strongly agree with the statement, select 7 .

1. Both of us are satisfied with the way we handle decisions.

2. We agree on what we can expect from one another.

3 . We are attentive to each other's comments.

4. We both have an equal 'say'.

5. We are co-operative with each other. 


\section{Appendix $\mathrm{O}$}

Relationship Assessment Scale (RAS; Hendrick, 1989)

If you strongly disagree with the statement, select $\mathbf{1}$.

If you disagree with the statement, select 2.

If you somewhat disagree with the statement, select 3 .

If you neither agree nor disagree with the statement, select 4.

If you somewhat agree with the statement, select 5.

If you agree with the statement, select $\mathbf{6}$.

If you strongly agree with the statement, select 7 .

1. My back burner meets my needs.

2. In general, I am satisfied with my back burner relationship.

3. My back burner relationship is good compared to most.

4. I often wish I hadn't gotten into this back burner relationship. $\mathbf{R}$

5. My back burner relationship has met my original expectations.

6. I love my back burner.

7. There are many problems in this back burner relationship. $\mathbf{R}$

Note. $\mathbf{R}$ indicates the item is reverse coded. 


\section{Appendix P}

\section{Memo Notes}

1. Many participants reported strategic reasons why they engaged in certain behaviors. Keep this in mind for categories.

2. Participants are reporting particular behaviors related to the fact that they have an extradyadic significant other. They often talk about ways in which they do not want their partners to find out. However, participants are also reporting certain things they do when their back burner is the one with an extradyadic committed relationship.

3. For future research, it would be very interesting to look at married individuals who also have back burner relationships. Many of these behaviors they are reporting have to do with being young adults in college, such as grabbing food in between classes or helping each other study. I would think that married individuals would need to be even more strategic with the ways in which they maintain back burner relationships.

4. Snapchat has been distinctly reported many, many times. Keep this in mind. It might relate to the fact that the messages disappear after 24 hours. Possibly helping it keep the relationship casual. They also can send pictures of what they are doing throughout the day as a way to stay connected. Look further into the value of Snapchat and specific use with back burners.

5. I don't feel comfortable automatically labeling some of these behaviors as negative. Some behaviors might seem antisocial, but is it negative if it is maintaining back burners' desired relationship? Something to ponder further.

6. There are behaviors that reflect some of the original ones (e.g., Openness), but I am not really seeing many assurances. I'm also not seeing the traditional notion of shared tasks either. Both of these make sense since this is not a clear, committed relationship. I put some examples that might be considered shared tasks in the positivity and support category.

7. It really seems like people are maintaining the positive aspects/rewards of back burner relationships.

8. Some participants reported that they are the one who wants to escalate the relationship, while others reported that they did not want to escalate (at least for right now). This is definitely something that needs to be considered. 


\section{FOOTNOTE}

${ }^{1}$ There was a total of 75 participants who did not respond to the demographic questions. The missing demographic data may have been the result of the structure and ordering of the Qualtrics online questionnaire. That is, the link to obtain extra credit points was on the same page as the demographic questions. Participants may have skipped over the demographic questions simply to obtain the extra credit points. 